\title{
DE-AC22-91 PC91042-TPR-4
}

\section{Effects of Low-Temperature Catalytic Pretreatments on} Coal Structure and Reactivity in Liquefaction

\author{
Technical Progress Report \\ August 1992 - November 1992 \\ C. Song, L. Huang, K. Wenzel, A.K. Saini, C. Burgess, \\ P.G. Hatcher and H.H. Schobert \\ Fuel Science Program \\ Department of Materials Science and Engineering \\ The Pennsylvania State University \\ 209 Academic Projects Building, University Park, Pennsylvania, PA 16802
}

December 1992

Prepared for the U.S. Department of Energy under Contract No.

DE-AC22-91PC91042

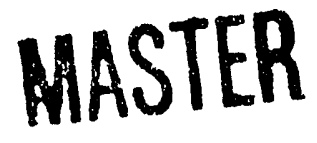

DISTRIBUTION OF THIS DOCUMENT IS UNLIMTIED

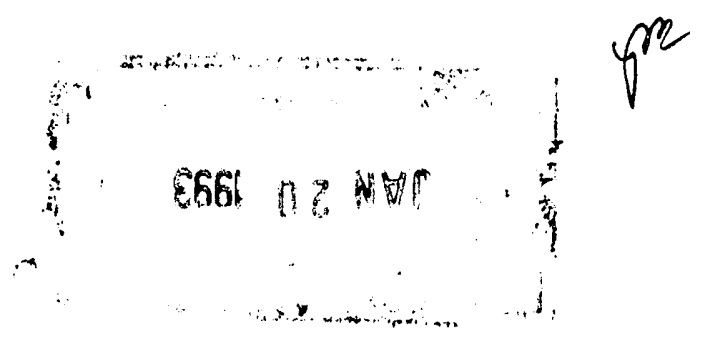




\section{DISCLAIMER}

This report was prepared as an account of work sponsored by the United States Government. Neither the United States Government nor any agency thereof, nor any of their employees, makes any warranty express or implied, or assumes any legal liability or responsibility for the accuracy, completeness, or usefulness of any information, apparatus, product, or process disclosed, or represents that its use would not infringe privately owned rights. Reference herein to any specific commercial product, process or service by trade name, mark manufacturer, or otherwise, does not necessarily constitute or imply its endorsement, recommendation, or favoring by the United States Government or any agency thereof. The views and opinions of authors expressed herein do not necessarily state or reflect those of the United States Government or any agency thereof.

\section{ACKNOWLEDGEMENTS}

This on-going project is supported by the U.S. Department of Energy, Pittsburgh Energy Technology Center, in Advanced Coal Research Program. Currently Dr. M.A. Nowak is DOE/PETC Project Manager; Dr. M. J. Baird was the project manager during the first three quarterly periods. Drs. H.H. Schobert, C. Song and F.G. Hatcher are the Co-Principal Investigators at Penn State. The authors wish to express their appreciation to Drs. M.A. Nowak, M. J. Baird, S. Lee, and E. B. Klunder of DOE/PETC for their support of this effort. The authors would also like to tiank Dr. A. Davis and Mr. D. Glick for providing coal samples and data from DOE/Penn State Coal Sample Bank, and Mr. R.M. Copenhaver for the fabrication of tubing bomb reactors. 


\section{TABLE OF CONTENTS}

EXECUTIVE SUMMARY

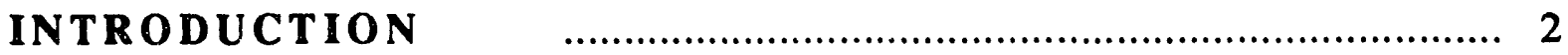

PROJECT OBJECTIVES

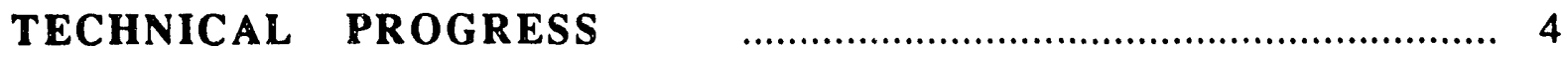

1. Characterization of Three Bituminous Coals and Their Products

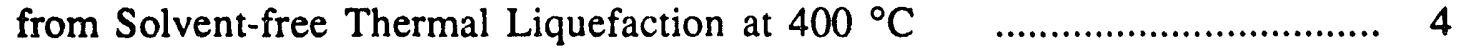

Thermal Liquefaction $\quad$..................................................... 6

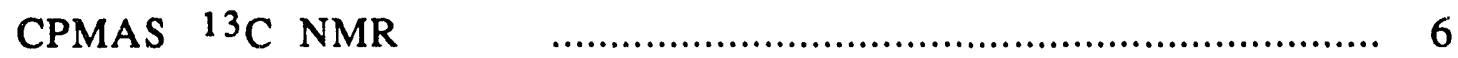

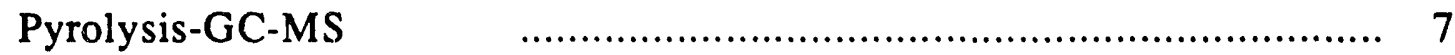

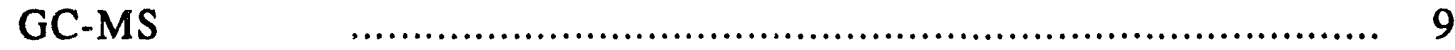

2. Structural Characterization of the Residues from the Thermal and Catalytic

Liquefactions of Dried and Oxidized Coal by FTIR and Pyrolysis-GC-MS ....... 13

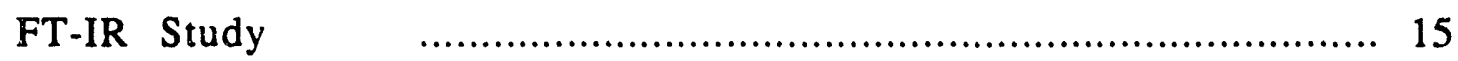

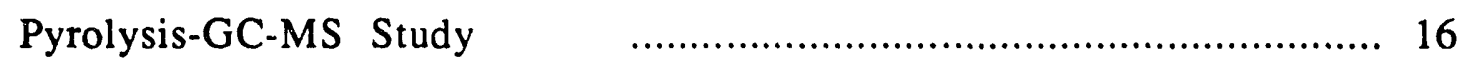

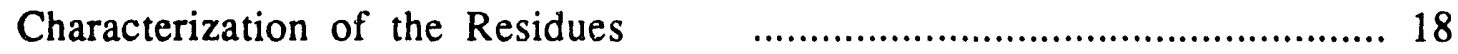

3. Effects of Reaction Conditions on Thermal and Catalytic Liquefaction

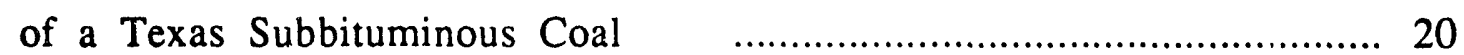

Thermal Reactivity of Three Low-Rank Coals $\quad$................................... 23

Effects of Reaction Solvents

Effects of Catalyst Impregnation Methods $\quad$..................................... 27

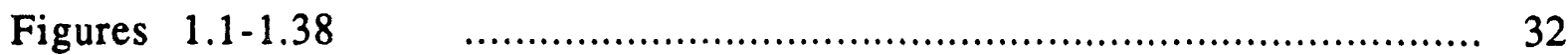

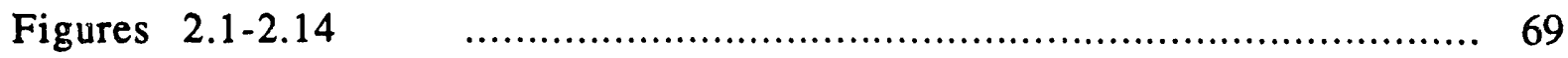




\section{EXECUTIVE SUMMARY}

During this quarterly period progress has been made in the following three subjects related to the effects of low-temperature thermal and catalytic pretreatments on coal structure and reactivity in liquefaction. First, the liquefaction behavior of three bituminous coals with a carbon content ranging from $77 \%$ to $85 \%$ was evaluated spectroscopically by $13 \mathrm{C}$ NMR and pyrolysis/gas chromatograpy/mass spectrometry to delineate the structural changes that occur in the coal during liquefaction. Complementary data includes ultimate and proximate analysis, along with optical microscopy for maceral determinations. Even though these are all bituminous coals they exhibit quite different physical and chemical characteristics. The coals vary in rank, ranging from $\mathrm{HvC} b$ to $\mathrm{HvA} \mathrm{b}$, in petrographic composition, different maceral percentages, and in chemical nature, percent of carborn and of volatiles. It is these variations that govern the products, their distribution, and conversion percentages. Some of the products formed can be traced to a specific maceral group.

Second, pyrolysis-GC-MS and FTIR techniques were used to characterize Wyodak coal before and after drying in vacuum and in air and the residues from its thermal and catalytic liquefactions. The analysis of the air-dried coal shows a decrease in the phenolic type structures in the coal network and increase in the carbonyl structures as the oxidative drying proceeds. An enhanced decrease in the carbonyl structure is observed in the liquefaction residues from the raw coal as compared to that of the vacuum dried coal. The analyses of the liquefaction residues of the air-dried coal show an increase in the ether linkages which may have a negative impact on liquefaction. The extent of the solvent adduction also increases during liquefaction with the extent of oxidation of the coal.

Finally, the effects of reaction conditions were investigated on conversion of low-rank coals using a Texas subbituminous coal. To find the optimum reaction conditions which can minimize the retrogressive reactions while enhancing hydrogenation, several reaction conditions such as single-staged liquefaction (SSL) and temperature-programmed liquefaction (TPL) were compared. The effect of reaction solvents on the liquefaction was also studied using hydrogendonor solvents (e.g. tetralin and decalin), a non-donor solvent (e.g. 1-methylnaphthalene) and a recycle solvent (Wilsonville middle distillate). Ammonium tetrathiomolybdate (ATTM) was chosen as the catalyst precursor. Three impregnation methods, including preswelling, incipient wetness and slurrying were applied to investigate the effect of impregnation methods on the activity of the catalyst for liquefaction of the Texas subbituminous coal. 


\section{INTRODUCTION}

The conventional concept for high-severity conversion of coal is that coal must be heated to high temperatures $\left(400-450^{\circ} \mathrm{C}\right)$ causing thermal cleavage of bonds in organic matrix of coal to yield free radicals, which are capped by hydrogen to form low-molecular-weight products. However, recent fundamental research in coal liquefaction and pyrolysis has revealed that coal is more reactive than had been thought previously. The thermally initiated reactions of coal can take place very rapidly and, especially for low-rank coals, can occur at lower temperatures. We have performed the temperature-programmed pyrolysis (TPP) of different coals ranging from brown to bituminous coals, and the results clearly showed that more bonds in low-rank coals are thermally broken at lower temperatures as compared to bituminous coals, and a concept of bond energy distribution has been developed from TPP (Song et al., 1991a; Song and Schobert, 1992). Considerable prior work at Penn State (Davis et al., 1986, 1989; Derbyshire et al., 1986a, 1986b, 1989; Stansberry et al., 1987; Burgess and Schobert, 1990; Burgess et al., 1991) has demonstrated that the combination of low-temperature catalytic reaction followed by the high temperature catalytic reaction using dispersed molybdenum catalysts significantly enhanced coal conversion and oil production. More recent work in this laboratory has shown that temperatureprogrammed liquefaction using programmed heat-up is more effective for converting low-rank coals (Song et al., 1991b; Song and Schobert, 1992; Huang et al., 1992). All these results point to the beneficial effects of reactions at lower temperatures as compared to conventional high-severity processes.

The above results strongly suggest that low-temperature catalytic pretreatment or preconversion is a promising approach and deserves further detailed study. This work is a fundamental study on effects of pretreatments on coal structure and reactivity in liquefaction. The main objectives of this project are to study the coal structural changes induced by low-temperature catalytic and thermal pretreatments by using spectroscopic techniques; and to clarify the pretreatment-induced changes in reactivity or convertibility of coals in the subsequent liquefaction. This report describes the recent progress of our work. 


\section{PROJECT OBJECTIVES}

This work is a fundamental study of catalytic pretreatments as a potential preconversion step to low-severity liquefaction. The ultimate goal of this work is to provide the basis for the design of an improved liquefaction process and to facilitate our understanding of those processes that occur when coals are initially dissolved. The main objectives of this project are to study the effects of low-temperature pretreatments on coal structure and their impacts on the subsequent liquefaction. The effects of pretreatment temperatures, catalyst type, coal rank and influence of solvent will be examined.

The specific objectives are to identify the basic changes in coal structure induced by catalytic and thermal pretreatments by using spectroscopic, thermochemical and chemical techniques; and to determine the reactivity of the catalytically and thermally treated coals for coal liquefaction. Combining the two lines of information will allow us to identify the pretreatment-induced desirable/undesirable basic changes in coal structure; to clarify the impacts of pretreatments on coal liquefaction; to identify the structures responsible for retrograde reactions; to evaluate the structural differences resulting from different catalytic actions in relation to the overall catalytic effects in liquefaction; and ultimately, to develop a structure-reactivity relationship for liquefaction associated with catalyst type, coal rank and solvent. Furthermore, this research will contribute greatly to the development of effective pretreatment procedures which will allow coals to be liquefied more efficiently than the current practice. Finally, much of the knowledge to be generated from this research is not only critical for developing advanced hydroliquefaction processes, but also very useful to development of coal/petroleum resid co-processing, pyrolysis and hydropyrolysis processes. 


\section{TECHNICAL PROGRESS}

\section{Characterization of Three Bituminous Coals and Their Products and Residues from Solvent-Free Thermal Liquefaction at $400^{\circ} \mathrm{C}$}

\subsection{Introduction}

The liquefaction behavior of three bituminous coals with a carbon content ranging from $77 \%$ to $85 \%$ was evaluated spectroscopically by $13 \mathrm{C}$ NMR and pyrolysis/gas chromatograpy/mass spectrometry to delineate the structural changes that occur in the coal during liquefaction. Complementary data includes ultimate and proximate analysis, along with optical microscopy for maceral determinations. Even though these are all bituminous coals they exhibit quite different physical and chemical characteristics. The coals vary in rank, ranging from $\mathrm{HvC} b$ to $\mathrm{HvA} b$, in petrographic composition, different maceral percentages, and in chemical nature, percent of carbon and of volatiles. It is these variations that govern the products, their distribution, and conversion percentages. Some of the products formed can be traced to a specific maceral group.

\subsection{Experimental}

\section{Samples}

Three bituminous coals (DECS-7, DECS-6, and DECS-12) were obtained from the DOE/Penn State Coal Sample Bank. They were thermally reacted and then analyzed by ${ }^{13} \mathrm{C} N \mathrm{NR}$ and py/GC/MS. A summary of their important properties is found in Table 1. The Adaville coal (DECS-7) has the highest vitrinite (a low hydrogen, high carbon content maceral) content and the lowest liptinite (a high hydrogen, low carbon content maceral) content. It also has the lowest carbon content by ultimate analysis of the three coals. The Blind Canyon has the lowest vitrinite content and the highest liptinite content. Pittsburgh \#8 maceral composition is intermediate between these two coals. Its carbon content is the highest, though. As it will be shown these are important parameters in determining which products are formed and in which extracted fraction they are found.

The three coals were extracted in hexane, toluene, and THF to determine the amount of mobile constituents in the samples. The results are also shown in Table 1. The THF extracted residues were pyrolyzed for comparison with the raw coals and reacted residues.

\section{Liquefaction Experiments}

Thermal reaction of four grams of raw coal was preformed on the three bituminous coals in 
duplicate in $32 \mathrm{ml}$ tubing bombs pressurized to $1000 \mathrm{psi} \mathrm{H}_{2}$. The reactors were placed in a $400^{\circ} \mathrm{C}$ sandbath and heated for 30 minutes. After cooling the reactor, the products were separated using a procedure by which the reactor was opened, the gas volume measured, then the reacted residue extracted in solvents so the oil, asphaltenes, preasphaltenes and residue could be analyzed. A detailed description of the procedure can be found in Song et al. (1992).

Table 1.1. Physical and Chemical Properties of the Selected Coals

\begin{tabular}{cccc}
\hline Coal & DECS-7 & DECS-6 & DECS-12 \\
\hline & Adaville \#1 & Blind Canyon & Pittsburgh \#8 \\
Maceral group & & & \\
dmmf, vol \% & & & \\
Vitrinite & 94.7 & 69.1 & 83 \\
Liptinite & 3.2 & 17 & 8.9 \\
Inertinite & 2.1 & 13.9 & 8.1 \\
& & & \\
\hline Rank & HvC Bit. & HvB Bit. & HvA Bit. \\
\hline & & & \\
\% C dmmf & 77.45 & 81.72 & 84.75 \\
\% volatiles & 38.11 & 42.4 & 35.16 \\
Raw coal & 12.2 & 14.2 & 8.9 \\
\% THF extracted & & & \\
dmmf & & & \\
\hline
\end{tabular}

\section{CPMAS ${ }^{13}$ C NMR Spectroscopy}

A Chemagnetics M-100 NMR spectrometer was used to collect spectra on the raw coals, Adaville \#1, Blind Canyon, and Pittsburgh \# 8, their unreacted THF-insoluble residues and their thermally reacted THF-insoluble residues. All samples used the same experimental procedures. The rotor was filled with the sample to be analyzed, inserted into the NMR probe and spun at about $3.5 \mathrm{kHz}$ with a magic angle of $54.7^{\circ}$. Acquisition of 30,000 scans was required to assure a good signal-to noise ratio. Acquisition parameters were contact time equalled $1 \mu$ s with a pulse delay of $1 \mathrm{~s}$, tau equalled $400 \mathrm{~ms}$ and line broadening equalled $29.9 \mathrm{~Hz}$. See Hatcher et al. (1989) for 
further details concerning NMR data for coals.

\section{Pyrolysis-GC-MS}

Flash Py/GC/MS procedures are the same as those explained in Song et al., 1992.

Analyses were preformed on DECS-7, DECS-6, and DECS-12, the raw coals, the reacted residues and the THF-insoluble unreacted residues. Thermal desorption experiments were also performed on all three bituminous coals. Samples were weighed in a capillary quartz tube and then placed between the heating coils of a CDS 1000 pyroprobe. The probe was then inserted into the injection port of the Dupont GC/MS. Injection port temperature is held at $280^{\circ} \mathrm{C}$. The probe was heated to $300^{\circ} \mathrm{C}$ for 30 seconds. This temperature is insufficient to cause pyrolysis (Song et al., 1992) but is high enough to drive off any mobile volatile material that has migrated into the coal's pores or that has been generated in situ. Flash pyrolysis experiments were also performed on the THFinsoluble residues generated during the thermal liquefaction experiments.

\section{GC/MS}

After rotoevaporating the solvent from the hexane soluble fraction (oil) of the reacted residues, the oil was analyzed by injecting a sample into a Hewlett Packard 5890 gas chromatograph coupled to a Hewlett Packard 5971A mass spectrometer. Injector temperature was $250^{\circ} \mathrm{C}$ and the temperature program started at $40^{\circ} \mathrm{C}$ with a three minute delay and increased at $5^{\circ} \mathrm{C} / \mathrm{min}$ to a final temperature of $280^{\circ} \mathrm{C}$.

\subsection{Results}

\section{Thermal Liquefaction}

Heating the coals to $400^{\circ} \mathrm{C}$ under $1000 \mathrm{psi}_{2}$ caused a significant redistribution in material. DECS-7 lost $30 \%$ of its mass while both DECS-6 and DECS- 12 lost almost $40 \%$ of their mass on a dry mineral matter free basis. DECS-12 had the highest overall conversion with $39.9 \%$ but also had the highest amounts asphaltene and preasphaltene. DECS- 6 had the greatest oil yield with $22.5 \%$ with almost as good total conversion. See Table 2 for conversion data.

\section{CPMAS ${ }^{13} \mathrm{C}$ NMR}

CPM ${ }^{13} \mathrm{C}$ NMR data can be used to identify the structural changes induced by thermal pretreatment of the three bituminous coals under study. The spectra for the raw coals are shown in Figure 1.1. For all the coals and residues the spectra can be divided into three regions. The first region (0-60 ppm) represents the aliphatic carbons, the second region $(80-170 \mathrm{ppm})$ represents the aromatic carbons, and the third region (170-225 ppm) represents the carboxyl and carbonyl 
carbons. The differences seen in the spectra can be related to the differences in rank between the three coals. The NMR data shows as the rank of the coals increases the aliphatic content decreases, the aromaticity increases, and the oxygen content decreases. Oxygen loss is accomplished through the loss of carboxyl (180 ppm) and carbonyl (200 ppm) functional groups. Another important mechanism for oxygen removal is the dehydration of the hydroxyl group from phenols (153 ppm).

Table 1.2. Thermal Liquefaction Data of Raw Bituminous Coals

\begin{tabular}{lccc}
\hline Coal & DECS-7 & DECS-6 & DECS-12 \\
\hline products & & & \\
dmmf wt $\%$ & & & \\
Gas + Oil & 13.8 & 22.5 & 16.5 \\
Asphaltene & 8.9 & 7.3 & 9.1 \\
Preasphaltene & 7.7 & 9.2 & 12.8 \\
Total Conversion & 30.4 & 39 & 39.9 \\
THF insol. & 69.6 & 61 & 60.1 \\
\hline
\end{tabular}

Figures 1.2 (DECS 7), 1.3 (DECS 6), and 1.4 (DECS 12) show the spectra for the raw coal versus the THF-insoluble residue of the thermally reacted coal. All three coals show the same trends. There is a major loss of ailphatics with a corresponding increase in aromaticity. Carboxyl and carbonyl functional groups are completely removed. Most catechols are lost and the phenols are diminished. The THF-insoluble residues from the reacted coals show strikingly similar spectra (Figure 5) even though the starting coals are so different, both chemically and physically.

\section{Pyrolysis GC/MS}

Pyrolysis of the coals and their reacted residue yields a complex mixture of aliphatic, phenolic, naphthalene compounds. As stated in a previous report (Song et al, 1992) the exact composition is directly related to the rank, maceral content of the particular coal analyzed. Table 1.3 lists the major peaks identified by number for all the pyrograms. Figure 1.6 is the chromatogram of DECS-7. Comparing this chromatogram with the chromatogram of an unreacted THF extracted sample (Figure 1.7 ) of DECS-7 shows a few interesting differences. There is a drastic reduction in prist-1-ene. The high molecular weight $n$-alkanes (greater than $\mathrm{C}_{22}$ ) are 
preferentially reduced over the low molecular weight alkanes. More importantly though, there is a reduction in phenol and both isomers of cresol. These are the backbone components that compose the macromolecular structure of vitrinite, the dominant maceral in all three of these bituminous coals. A reduction of these components in the pyrolyzate indicates that THF may be altering the macromolecular structure of the Adaville coal. A pyrogram (Figure 1.8) of a thermally desorbed sample of the Adaville coal does not show this similar result.

Figure 1.9 shows the py-gc-ms profile of the residue from the thermally treated Adaville. Identification numbers correspond to those shown in Table 3 . It should be noted that only a small percent $(10 \%)$ of the residue pyrolyzed indicating that much of the structure condensed into nonvolatile components during liquefaction. The pyrolyzate is dominated by benzene, $p$-xylene, phenol, and p-cresol. Toluene is a remnant of the solvent used to extract the asphaltene fraction from the residue. The percentage of naphthalene and phenanthrene/anthracene in the residue increased relative to the amount found in the raw coal, also indicating condensation reactions taking place. Thermal prereatment removed most but not completely all the alkanes. It also significantly reduced the amount of alkyl substituted benzenes, phenols, and naphthalenes. Not found in the original coal but identified in the residue was biphenyl, fluorene, and dihydroinden-1-one.

Figure 1.10 shows the pyrogram of DECS-6. Figure 1.11 is the pyrogram of the THF extracted sample of the Blind Canyon. Here again significant changes occurred. Again as with DECS-7 the high molecular weight n-alkanes were reduced. The resinite components were also extracted. Missing are cadalene and the tetrahydronaphthalenes that originate from resinite. Prist1-ene was reduced but not as drastically as in the Adaville. The amount of $C_{1}, C_{2}$, and $C_{3}$ naphthalenes decreased. Unlike DECS-7 the phenol components seem to be uneffected. Again the thermally desorbed pyrogram (Figure 1.12) of DECS-6 does not show these changes. What effect THF has on the structure of these coals needs to be investigated further.

The chromatogram of the residue form the thermally treated Blind Canyon coal is shown in Figure 1.13. Again only a small percentage pyrolyzed. The same trends that were seen happening in the Adaville are occuring with the Blind Canyon. The benzene and phenol group of compounds dominate, naphthalene and phenanthrene/anthracene increased along with the addition of fluorene, dihydroinden-1-one, but not biphenyl. Fluoranthene was also identified as a new product.

Comparing the raw coal pyrogram of DECS-12, Figure 1.14, with the pyrograms of the THF extracted DECS-12, Figure 1.15, and the thermally desorbed pyrogram, Figure 1.16, structural changes do not seem to occur. Both reactions show similar features. The straight chain hydrocarbons are lost along with a reduction of alkylated naphthalenes. 2, 4-Dimethyl phenol does seem to be enhanced, though.

Figure 1.17 is the chromatogram of the reacted THF-insoluble residue for DECS-12. It 
too is dominated by benzene and alkyl benzenes, phenol and cresols like the residues from the other reacted coals. Naphthalene and $\mathrm{C}_{1}$ and $\mathrm{C}_{2}$ naphthalene are also present. Biphenyl, fluorene, fluoranthene, and $C_{1}$ phenanthrene/anthracene and $C_{2}$ phenanthrene/anthracene have been formed in the reaction process.

\section{GC/MS}

Figures $1.18,1.19$, and 1.20 are the total ion chromatograms of the oil generated during liquefaction of DECS-7, DECS-6, and DECS-12, respectively. Table 1.4 lists the major peaks identified by number. All three oils contained the same groups of compounds: alkanes, benzene, alkylated benzenes, indan, alkylated indane, phenol, alkylated phenols, naphthalene, alkylated naphthalenes, phenanthrene/anthracene, and alkylated phenanthrene/anthracenes. The different coals chromatographic signatures are quite distinctive, though. The Adaville coal is dominated by phenols, cresols, and $\mathrm{C}_{2}$ phenols. These are derived from the degradation of vitrinite, the dominate maceral $(94.7 \%)$ in this coal. Figures 1.21 through 1.26 are single ion chromatograms representing the above named groups of compounds for DECS-7. Taule 1.5 lists a few of the isomers identified by number for the $C_{2}$ and $C_{3}$ phenols. These show the degree of alkylated side chains on each class of compounds. Combined these groups represent over ninety percent of the compounds in all three oils. Even though some isomers are not very abundant they do show a compete mix of species. The Blind Canyon is dominated by compounds derived from the maceral resinite. The resinite in this coal in composed of bicyclic sesquiterpenoids and diterpenoids. Upon degradation these compounds produce alkylated two ring compounds such as cadalene, propyl (C3) naphthalene, and dimethyl $\left(\mathrm{C}_{2}\right)$ naphthalene. Figures 1.27 through 1.32 are single ion chromatograms for DECS-6. Naphthalene is the major compound in the Pittsburgh \#8 coal. It has no dominant group, though. The alkanes, benzenes, phenols and naphthalenes all contribute about equally. Figures 1.33 through 1.38 are single ion chromatograms for DECS-12. 
Table 1.3. Identified Peaks in TICs from PY-GC-MS of Bituminous Coals and Residues

\begin{tabular}{|c|c|c|c|c|c|c|}
\hline $\begin{array}{l}\text { Peak } \\
\text { No. }\end{array}$ & $\overline{\mathrm{MW}}$ & Compound ${ }^{*}$ & & $\begin{array}{l}\text { Peak } \\
\text { No. }\end{array}$ & $\overline{\mathrm{MW}}$ & Compound * \\
\hline 1 & 56 & $C_{4}$ alkene & $\therefore$ & 39 & 266 & $\mathrm{C}_{19}$, prist-1-ene \\
\hline 2 & 70 & C5 alkene & & 40 & 170 & $C_{3}$ naphthalene \\
\hline 3 & 86 & $\mathrm{C}_{6}$ & & 41 & 184 & $C_{4}$ naphthalene \\
\hline 4 & 100 & $\mathrm{C}_{7}$ & & 42 & 254 & $\mathrm{C} 18$ \\
\hline 5 & 78 & benzene & & 43 & 182 & naphthol \\
\hline 6 & 114 & $\mathrm{C}_{8}$ & & 44 & 268 & $\mathrm{C}_{19}$ \\
\hline 7 & 92 & toluene & & 45 & 198 & Cadalene \\
\hline 8 & 128 & $\mathrm{C}_{9}$ & & 46 & 282 & $\mathrm{C}_{20}$ \\
\hline 9 & 106 & p-xylene & & 47 & 296 & $\mathrm{C}_{21}$ \\
\hline 10 & 142 & $\mathrm{C}_{10}$ & & 48 & 178 & phenanthrere/anthracene \\
\hline 11 & 106 & o-xylene & & 49 & 306 & quaterphenyl \\
\hline 12 & 120 & propyl benzene & & 50 & 310 & $\mathrm{C}_{22}$ \\
\hline 13 & 120 & ethyl methyl benzene & & 51 & 192 & $C_{1}$ phen/anth \\
\hline 14 & 156 & $\mathrm{C}_{11}$ & & 52 & 324 & $\mathrm{C}_{23}$ \\
\hline 15 & 120 & trimethyl benzene & & 53 & 206 & $\mathrm{C}_{2}$ phen/anth \\
\hline 16 & 134 & $\mathrm{C}_{4}$ benzene & & 54 & 338 & $\widetilde{C}_{24}$ \\
\hline 17 & 106 & benzaldehyde & & 55 & 220 & C 3 phen/anth \\
\hline 18 & 94 & phenol & & 56 & 352 & $\mathrm{C}_{25}$ \\
\hline 19 & 118 & indane & & 57 & 366 & $\mathrm{C}_{26}$ \\
\hline 20 & 170 & $\mathrm{C}_{12}$ & & 58 & 380 & $\mathrm{C}_{27}$ \\
\hline 21 & 132 & $\mathrm{C}_{1}$ indane & & 59 & 394 & $\mathrm{C}_{28}$ \\
\hline 22 & 108 & o-cresol & & 60 & 408 & $\mathrm{C}_{29}$ \\
\hline 23 & 108 & p-cresol & & 61 & 422 & $\mathrm{C}_{30}$ \\
\hline 24 & 184 & $\mathrm{C}_{13}$ & & 62 & 320 & $\mathrm{C}_{1}$ quaterphenyl \\
\hline 25 & 122 & 2-ethyl phenol & & 63 & 436 & $\mathrm{C}_{31}$ \\
\hline 26 & 122 & 2,4-dimethyl phenol & & 64 & 450 & $\mathrm{C}_{32}$ \\
\hline 27 & 122 & $\mathrm{C}_{2}$ phenol & & 65 & 464 & $\mathrm{C}_{33}$ \\
\hline 28 & 122 & 4-ethyl phenol & & 66 & 468 & $\mathrm{C}_{34}$ \\
\hline 29 & 128 & naphthalene & & 67 & 154 & biphenyl \\
\hline 30 & 122 & $\mathrm{C}_{2}$ phenol & & 68 & 68 & fluorene \\
\hline 31 & 198 & $\mathrm{C}_{14}$ & & 69 & 106 & benzaldehyde \\
\hline 32 & 136 & ethyl methyl phenol & & 70 & 256 & dimethyl benzophenanthrene \\
\hline 33 & 136 & $C_{3}$ phenol & & 71 & 188 & tetramethyl dihydronaphthalene \\
\hline 34 & 212 & $\mathrm{C}_{15}$ & & 72 & 202 & dimethyl methyl-ethyl \\
\hline & 142 & $C_{1}$ naphthalene & & 73 & 132 & $\begin{array}{l}\text { dihydronaphthalene } \\
\text { dihydroindn-1-one }\end{array}$ \\
\hline 36 & 226 & $\mathrm{C}_{16}$ & & 74 & 178 & methylene fluorene \\
\hline 37 & 156 & $\mathrm{C}_{2}$ naphthalene & & 75 & 202 & fluoranthene \\
\hline 38 & & $\mathrm{C}_{17}$ & & & & \\
\hline
\end{tabular}


Table 1.4. Identified Peaks in TICs from GC-MS of the Hexane Soluble Fraction (Oil)

\begin{tabular}{|c|c|c|c|c|c|}
\hline Peak No. & MW & Compound* & Peak No. & MW & Compound* \\
\hline 1 & 114 & $\mathrm{C}_{8}$ branched & 34 & 142 & $C_{1}$ naphthalene \\
\hline 2 & 114 & $\mathrm{C}_{8}$ branched & 35 & 188 & $\mathrm{C}_{4}$ indan-one \\
\hline 3 & 92 & toluene & 36 & 226 & $\mathrm{C}_{16}$ \\
\hline 4 & 128 & $\mathrm{C}_{9}$ & 37 & 156 & $\mathrm{C}_{2}$ naphthalene \\
\hline 5 & 106 & p-xylene & 38 & 156 & $C_{2}$ naphthalene \\
\hline 6 & 142 & $\mathrm{C}_{10}$ & 39 & 268 & $C_{19}$ branched \\
\hline 7 & 106 & o-xylene & 40 & 240 & $\mathrm{C}_{17}$ \\
\hline 8 & 120 & ethyl methyl benzene & 41 & 266 & $\mathrm{C}_{19}$ alkene \\
\hline 9 & 156 & $\mathrm{C}_{11}$ & 42 & 188 & $\mathrm{C}_{4}$ indan-one \\
\hline 10 & 120 & trimethyl benzene & 43 & 266 & $\mathrm{C}_{19}$ alkene \\
\hline 11 & 134 & $\mathrm{C}_{4}$ benzene & 44 & 170 & $C_{3}$ naphthalene \\
\hline 12 & 120 & trimethyl benzene & 45 & 254 & $\mathrm{C}_{18}$ \\
\hline 13 & 94 & phenol & 46 & 170 & C3 naphthalene \\
\hline 14 & 118 & indane & 47 & 170 & $C_{3}$ naphthalene \\
\hline 15 & 170 & $\mathrm{C}_{12}$ & 48 & 268 & $\mathrm{C}_{19}$ \\
\hline 16 & 184 & $\mathrm{C}_{13}$ branched & 49 & 184 & C4 naphthalene \\
\hline 17 & 132 & $\mathrm{C}_{1}$ indane & 50 & 198 & Cadalene \\
\hline 18 & 108 & o-cresol & 51 & 184 & C4 naphthalene \\
\hline 19 & 108 & p-cresol & 52 & 282 & $\mathrm{C}_{20}$ \\
\hline 20 & 132 & $C_{1}$ benzofuran & 53 & 184 & $\mathrm{C}_{4}$ naphthalene \\
\hline 21 & 184 & $\mathrm{C}_{13}$ & 54 & 296 & $\mathrm{C}_{21}$ \\
\hline 22 & 122 & 2-ethyl phenol & 55 & 178 & phen/anth \\
\hline 23 & 122 & 2,4-dimethyl phenol & 56 & 310 & $\mathrm{C} 22$ \\
\hline 24 & 122 & $C_{2}$ phenol & 57 & 324 & $\mathrm{C}_{23}$ \\
\hline 25 & 122 & A-ethyl phenol & 58 & 338 & $\mathrm{C}_{24}$ \\
\hline 26 & 122 & $\mathrm{C}_{2}$ phenol & 59 & 352 & $\mathrm{C}_{25}$ \\
\hline 27 & 198 & $\mathrm{C}_{14}$ & 60 & 366 & $\mathrm{C}_{26}$ \\
\hline 28 & 136 & ethyl methyl phenol & 61 & 380 & $\mathrm{C}_{27}$ \\
\hline 29 & 136 & ethyl methyl phenol & 62 & 394 & $\mathrm{C}_{28}$ \\
\hline 30 & 226 & $\mathrm{C}_{16}$ branched & 63 & 408 & $\mathrm{C}_{29}$ \\
\hline 31 & 136 & C3 phenol & 64 & 422 & C30 \\
\hline 32 & 212 & $\mathrm{C}_{15}$ & 65 & 436 & $\mathrm{C}_{31}$ \\
\hline 33 & 142 & naphthalene & & & \\
\hline
\end{tabular}


Table 1.5. List of Phenol Isomers

\begin{tabular}{cccccc}
\hline No. & MW & Compound & No. & MW & Compound \\
\hline 1 & 122 & 2-ethyl phenol & 5 & 122 & dimethyl phenol \\
2 & 122 & 2,4-dimethyl phenol & 6 & 136 & ethyl methyl phenol \\
3 & 122 & dimethyl phenol & 7 & 136 & propyl phenol \\
4 & 122 & 4-ethyl phenol & 8 & 136 & trimethyl phenol \\
\hline
\end{tabular}

\subsection{Conclusions}

Liquefaction of this suite of bituminous coals at $400^{\circ} \mathrm{C}$ provided conversions between 30 and 40 percent. The higher the liptinite content the higher the oil and gas yields. The aliphatic components of these coals are being redistributed into all the products: gas, oil, asphaltenes and preasphaltenes. Whereas, high concentrations of vitrinite yielded lower quantities of a phenolic based oil. Preasphaltene concentrations increased slightly, from seven to thirteen percent, with increasing carbon content (increasing rank). The asphaltene content was roughly the same (8\%) for three coals.

NMR data revealed a loss of aliphatic carbon with a corresponding increase in aromatic carbon, which corresponds with the product distribution; aliphatic hydrocarbons were in all product class. There is also a decrease in oxygen content, most likely through the generation of $\mathrm{CO}$, and $\mathrm{CO}_{2}$, but also through the generation of $\mathrm{H}_{2} \mathrm{O}$ through dehydration reactions Aromaticity is increasing, most likely by retrogressive reactions. Py/GC/Ms data suggest the reacted residue is a low volatile highly condensed char, low in oxygen and hydrogen functional groups. Most likely some of the hydrogen being abstracted to cap the radicals formed due to thermal cracking of the aliphatic compounds found in the liptinite macerals causes further condensation. Also some of the hydrogen is lost with the generation of water.

By combining modern spectroscopic techniques, 13C NMR and pyrolysis/gas chromatograpy/mass spectrometry with proven analytical techniques, optical microscopy and elemental data, a more detailed understanding of the relationship between the physical and chemical composition, and structure of coal can be achieved. By using these same techniques to characterize the products generated during liquefaction experiments a better understanding of the conversion processes and reaction pathways should be revealed. Work is continuing along these lines, as well as new work with single-staged liquefaction and temperature-programmed liquefaction 
experiments with and without solvents and catalysts on these three bituminous coals.

\subsection{References}

Hatcher, P.G. et al., Org. Geochem., 1989, 14, 145.

Song, C.; Saini, A.K.; Huang, L.; Wenzel, K.; Hatcher, P.G.; Schobert, H.H.; "Effects of LowTemperature Catalytic Pretreatments on Coal Structure and Reactivity in Liquefaction", Technical Progress Report for the period April - July 1992, DE-AC22-91PC91042-TPR-3, U.S. DOE/PETC, August 1992.

Song, C. et al., ACS Fuel Chem. Preprint., 1992, 37 (2), 976.

\section{Structural Characterization of the Residues from the Thermal and Catalytic Liquefactions of Dried and Oxidized Coal by FTIR and Pyrolysis-GC-MS}

Pyrolysis-GC-MS and FTIR techniques were used to characterize Wyodak coal before and after drying in vacuum and in air and the residues from its thermal and catalytic liquefactions. The analysis of the air-dried coal shows a decrease in the phenolic type structures in the coal network and increase in the carbonyl structures as the oxidative drying proceeds. An enhanced decrease in the carbonyl structure is observed in the liquefaction residues from the raw coal as compared to that of the vacuum dried coal. The analysis of the liquefaction residues of the air-dried coal shows an increase in the ether linkages which may have a negative impact on liquefaction. The extent of the solvent adduction also increases during liquefaction with the extent of oxidation of the coal.

\subsection{INTRODUCTION}

Low-rank coals have a high moisture content which makes them expensive and difficult to transport and results in low heat output on combustion. Drying of the coal, however, has its own penalties. This study was undertaken primarily to observe the effect of oxidative and nonoxidative drying of coal on liquefaction and chemical and physical changes of the treated coal. The effect of drying on the liquefaction products has been discussed in the DOE report (1); emphasis herein is directed towards the characterization of coal and coal residues after thermal and catalytic liquefactions.

Many studies (2-11) have been devoted to understand the mechanism of oxidation of coal but this still remains poorly understood. Previous studies on a variety of low-rank coals suggest a 
three-step reaction sequence. Up to $70^{\circ} \mathrm{C}$ the major feature is the formation of coal-oxygen complexes by reaction between oxygen and radical sites in the coal structure. Between $70-150^{\circ} \mathrm{C}$ these complexes decompose and around $150^{\circ} \mathrm{C}$ a new set of coal-oxygen complex form exothermically. The decomposition of the intermediate complexes can produce various oxygencontaining compounds such as acids, peracids, alcohols, ketones, aldehydes, esters and ethers.

In this study we report the results of FTIR and pyrolysis-GC-MS characterization of a subbituminous coal and the liquefaction residues of the dried coal. The analysis of the coal dried in air shows an increase in the carbonyl and ether type structures in the coal network with the extent of oxidation which may have a negative impact on liquefaction. The Py-GC-MS analysis reveals that upon oxidative drying of coal there is a decrease in the phenolic structures in the coal network which could relate to the increase in the carbonyl structures upon oxidation of phenols to quinones. The ether type of structures in the residues could be formed by the condensation of the hydroxyl groups.

\subsection{TXPERIMENTAL}

The coal used was Wyodak subbituminoius coal provided by the Penn State Sample Bank (DECS-8). The characteristics of this coal are as follows: $32.4 \%$ volatile matters, $29.3 \%$ fixed carbon, $9.9 \%$ ash and $28.4 \%$ moisture, on a as-received basis; $75.8 \% \mathrm{C}, 5.2 \% \mathrm{H}, 1.0 \% \mathrm{~N}, 0.5 \%$ $\mathrm{S}$ and $17.5 \% \mathrm{O}$, on a dmmf basis.

The coal was dried under vacuum for $2 \mathrm{~h}$ at $100^{\circ} \mathrm{C}$ and in air for 2,20 , and $100 \mathrm{~h}$ at $100^{\circ} \mathrm{C}$. At $150^{\circ} \mathrm{C}$ the coal was dried only for $20 \mathrm{~h}$. The oxidative drying of coal was done in an oven preheated at desired temperature keeping the door partially open.

The thermal and catalytic liquefaction of the raw and the dried coal was carried out at 350 ${ }^{\circ} \mathrm{C}$ with and without tetralin and 1-methylnaphthalene. The catalyst used was ammonium tetrathiomolybdate (ATTM). The detailed liquefaction procedure can be found in DOE report Jan. 1992-March 1992(12). The THF-insolubles obtained after the liquefaction were then analyzed by FTIR and pyrolysis-GC-MS. The experimental procedure for recording FTIR and py-GC-MS can also be found in the DOE report Jan. 1992-March 1992 (12)

\subsection{RESULTS AND DISCUSSION}

In the last DOE report (1) it was shown that the oxidative drying of coal increases the carbonyl type functional groups in the raw coal indicated by the increase in the 1720 and 1580 
$\mathrm{cm}^{-1}$ bands in the FTIR spectra, with the extent of oxidation(figures 39 and 40 in reference 1). These bands can be assigned to the carboxyl ( $\mathrm{COOH}$ ) and carboxylate (COO-) groups, respectively. The region between $1000-1200 \mathrm{~cm}^{-1}$, characteristic of C-O groups in ether esters and phenols, also showed an increase with the extent of oxidation.

\section{ETIR Study of the residues from the solvent-free liquefactions}

Figures 2.1 and 2.2 show the difference spectra of the residues from the solvent-free thermal and catalytic liquefactions. The difference spectra have been obtained by subtracting the FTIR spectra of the raw coal (as-received coal) from that of the residues. The subtraction factor was determined by the ratio of the amount of the dmmf coal per gram of pellet keeping the diameter of the pellet constant. There are apparent differences in the FTIR spectra of the residues from the raw coal and the dried coal. The region between $2700-3600 \mathrm{~cm}^{-1}$ is overwhelmed by the negative water band making the detailed analysis of this region very difficult; however, the negative aliphatic peaks between $2800-2950 \mathrm{~cm}^{-1}$ are apparent, indicating the decrease in the aliphatic functionalities in the residues compared to the as-received coal. The differences in the region 800$2000 \mathrm{~cm}^{-1}$ are more informative. The residue from the raw coal shows an enhanced decrease in the carbonyl functional groups shown by the negative peak at $1720 \mathrm{~cm}^{-1}$ as compared to that of the vacuum dried coal. Compared to the vacuum dried coal the air-dried coal at $100^{\circ} \mathrm{C}$ also shows an increased loss of carbonyl groups and increases with the extent of drying in air. The negative band at $1650 \mathrm{~cm}^{-1}$ is an indicative of the loss of highly conjugated carbonyls, as found in quinones, from the coal network. This band may also include a characteristic $\mathrm{O}-\mathrm{H}$ bending mode from water which appears at $1640 \mathrm{~cm}^{-1}$. Another apparent difference in the air-dried coal is in the 1000-1150 $\mathrm{cm}^{-1}$ region. This region comprises of ether type (C-O) linkages in ethers, phenols and esters. Compared to the vacuum dried coal there is an increase in such functionalities as the coal is dried in air. Up to $20 \mathrm{~h}$ of drying in air at $100^{\circ} \mathrm{C}$ there is no significant increase in the ether type functionalities but after drying for longer period of time or at $150^{\circ} \mathrm{C}$ for $20 \mathrm{~h}$ it becomes very significant. The increase in such functionalities leads to more refractory coal network and hence less liquefaction product yields.

\section{ETIR study of the Residues from the liquefaction in presence of a solvent}

Figures 2.3-2.6 show the difference spectra of the residues from the thermal and catalytic liquefactions in presence of tetralin and 1-methylnaphthalene. The difference spectra have been obtained by subtracting the FTIR spectrum of the raw coal from that of the residues keeping the criteria for subtraction factor same as that for the solvent-free runs. Similar to the solvent-free runs 
the residues from the runs in presence of solvents also show a decrease in the aliphatics indicated by the negative peaks between the region $2800-2950 \mathrm{~cm}^{-1}$. The negative band at $1720 \mathrm{~cm}^{-1}$ is due to the loss of the carbonyl groups. The interesting feature in the FTIR difference spectra of these residues is the increased intensity of bands near $1600 \mathrm{~cm}^{-1}$ due to aromatic $\mathrm{C}=\mathrm{C}$ stretching mode and the broad band near $1400 \mathrm{~cm}^{-1}$ due to methyl and methalene groups. The $1600 \mathrm{~cm}^{-1}$ band may be broadened by the $1580 \mathrm{~cm}^{-1}$ band due to COO-groups. The increase in the intensity of these bands may be due to the adduction of the solvent during liquefaction. Compared to the vacuum dried coal these bands are more intense indicating increased adduction of solvent with the extent of oxidation. The adduction of the solvent is more readily observed by the pyrolysis GCMS technique. The FTIR spectra of the residues from the thermal runs also show a slight increase in the $1100 \mathrm{~cm}^{-1}$ region due to the ether type of linkages as the extent of oxidative drying increases.

\section{Pyrolysis-GC-MS_Study}

\section{Characterization of the Raw and the Dried Coal}

Figure 2.7 compares the pyrograms for the raw coal and the coal dried under vacuum. Figure 8 shows the comparison between the coal dried in air for different extent of oxidation. The pyrolyses of the raw coal and the dried coal seem to have produced similar types of aromatic and aliphatic compounds. The major aromatic components are the alkyl benzenes and the phenolic compounds. Direct comparison of these pyrograms gives an impression of no significant effect of drying on the physical or chemical coal structure. Since the major aromatic components in the pyrogram of coal are alkyl benzenes and phenolic compounds, the areas of $\mathrm{Cl}-\mathrm{C} 3$ benzenes and phenol, C1-C2 phenol and catechol from the pyrograms were added and the ratio phenolic to alkyl benzenes were calculated (Tables 2.1 and 2.2). These ratios clearly show significant difference in the coal structure as a consequence of drying. The phenolic to alkylbenzene ratio decreases significantly from raw coal to the vacuum dried coal. This change may be attributed to the pinysical change in the coal network. As can be seen from the pyrogram of the raw coal the peaks due to alkanes and alkenes are not clearly distinguishable and are not well separated where as these peaks are more easily identifiably in the pyrogram of the vacuum dried coal. As the coal is dried under vacuum at $100^{\circ} \mathrm{C}$ the coal network becomes more open and relaxed. During the pyrolysis of the raw coal some of the compounds may have been trapped in the highly entangled network and unable to come out, but after drying in vacuum these networks open up slightly and make a free passage for the trapped molecules. The pyrogram of the dried coal is a better representation of the coal structure. 
Table 2.1. Major identified peaks in Py-GC-MS chromatograms of the raw coal and the residues.

\begin{tabular}{ll}
\hline No. & Identified Compounds \\
\hline 1 & Toluene \\
2 & p-Xylene \\
3 & o-Xylene \\
4 & C3-Benzene \\
5 & c3-Benzene \\
6 & Phenol \\
7 & o-Cresol \\
8 & m-p-Cresol \\
9 & C2-Phenol \\
10 & C2-Phenol \\
11 & C2-Phenol \\
12 & Catechol \\
13 & Naphthalene \\
14 & Methylnaphthalene \\
\hline
\end{tabular}

Table 2.2. Ratios of the amount of oxygen-containing units to the alkylbenzene units in the raw and unreacted dry coal and the liquefaction residues in the solvent-free runs.

\begin{tabular}{lllc}
\hline Drying Conditions & $\begin{array}{l}\text { Unreacted } \\
\text { Coal }\end{array}$ & $\begin{array}{l}\text { Solv.-free } \\
\text { Thermal }\end{array}$ & $\begin{array}{c}\text { Solv.-Free } \\
\text { Catalytic }\end{array}$ \\
\hline Raw & 5.2 & 1.9 & 2.8 \\
Vacuum-Dried & 3.6 & 2.3 & 2.4 \\
Air-Dried $/ 2 \mathrm{~h} / 100^{\circ} \mathrm{C}$ & 3.5 & 2.0 & 2.8 \\
Air-Dried $/ 20 \mathrm{~h} / 100^{\circ} \mathrm{C}$ & 2.5 & 2.4 & 3.5 \\
Air-Dried $/ 100 \mathrm{~h} / 100^{\circ} \mathrm{C}$ & 2.3 & 2.0 & 2.2 \\
Air-Dried $/ 20 \mathrm{~h} / 150^{\circ} \mathrm{C}$ & 1.1 & 1.2 & 1.6 \\
\hline
\end{tabular}


Upon drying in air the phenolic to alkyl benzene ratio seems to be decreasing with the extent of drying (Figure 2.8, Table 2.2). It is known that the presence of hydroxyl groups activate the aromatic ring towards oxidation and that phenols are easily oxidized to quinones, which subsequently can evolve to carboxyl through rupture of benzenic ririg (14). Furthermore, the disappearance of hydroxyl groups can also be a result of condensation reaction between hydroxyl and carboxyl or hydroxyl groups to form esters and ether bonds respectively.

\section{Characterization of the Residues}

\section{Solvent-free Liquefactions}

Figures 2.9 and 2.10 show the pyrograms of the residues from the solvent-free thermal and catalytic liquefactions. Compared to the raw coal, the major pyrolysis compounds from the residues are the same as listed in Table 2.1. The major difference is the relative intensities of the each component. The phenolic to alkyl benzene ratios calculated for the residues, given in Table 2.2, give an insight of the complex structure of the residues. There is a significant decrease in these ratios for the residues from the raw, vacuum dried and air-dried coal for $2 \mathrm{~h}$ at $100^{\circ} \mathrm{C}$ as compared to the corresponding unreacted coal. The coal dried at $100^{\circ} \mathrm{C}$ for 20 and $100 \mathrm{~h}$ and the ccal dried at $150^{\circ} \mathrm{C}$ for $20 \mathrm{~h}$ did not show any significant change in the phenolic to alkyl benzene ratios. This could be an insight for the more complexed structure formed upon extensive oxidative drying of coal.

\section{Liquefactions in the Presence of Solvents}

Figures 2.11-2.14 show the pyrograms of the residues obtained from the liquefactions of the raw and dried coal in presence of tetralin and 1-methylnaphthalene. Besides the major pyrolysis components found in the residues from the solvent-free runs there are several new compounds which are seen in the pyrograms of these residues and in a relatively high abundance. The type of compounds observed depends on the type of solvent used. For example, in the presence of tetralin the compounds observed in the order of their relative abundance are naphthalene, 1- and 2-methylnaphthalene, tetralin and dihydronaphthalene. When 1methylnaphthalene was used as a solvent the most abundant compound observed in the pyrogram of the residues is itself; besides there is an increase in the abundance of the naphthalene peak too. These new peaks in the pyrograms appear to have come from the solvent used during liquefaction. The solvent molecules may be present in the residues either physically trapped or chemically bonded to the coal network. 
The phenomenon of adduction of the solvent seems to be affected by the oxidative drying of coal. It appears from the pyrogram of the residues from the coal dried in air to various extent of oxidation, that the adduction of solvent increases with the extent of oxidation (Figures 2.12-2.14). In the catalytic runs the adduction of the solvent is relatively less as compared to that of the corresponding thermal runs, as seen before in our previous work (13).

\subsection{SUMMARY}

The above results have shown that the degradation of coal upon oxidative drying is mainly due to the formation of the ether type linkages. Upon drying coal at $100^{\circ} \mathrm{C}$ in air for up to $20 \mathrm{~h}$ the increase in the ether type functionalities was not very significant. From the previously reported liquefaction results, the total conversions of the air dried coal at $100^{\circ} \mathrm{C}$ for up to $20 \mathrm{~h}$ were similar to that of the vacuum-dried coal in the solvent-free runs. In the presence of solvents the total conversions were rather better than that of the vacuum dried coal. This suggests that to some extent the oxidative drying of coal may be beneficial for liquefaction. Py-GC-MS results show decrease in the phenolic type structures from the coal network upon oxidative drying. This could be related to the increase in the carbonyl groups due to the oxidation of phenols to quinones. PyGC-MS results have also shown an enhanced adduction of solvent during liquefaction with the extent of oxidative drying.

\subsection{REFERENCES}

1 Song, C., Saini, A.K.,Huang, L., Wenzel, K., Hatcher, P.G., Schobert, H.H., 1992, "Effects of Low-Temperature Catalytic Pretreatments on Coal Structure and Reactivity In Liquefaction", Technical progress report to U.S. DOE Pittsburgh Energy Technology Center, DE-AC22-91PC91042-TPR-1, April 1992-July 1992.

2. Cronauer, D.C., Ruberto, R.G., Jenkins, R.G., Davis, A., Painter, P.C., Hoover, D.S., Starsinic, M.E. and Schlyer, D.; Fuel, 1983,Vol.62,1124.

3. Painter, P.C., Coleman, M.M., Snyder, R.W., Mahajan, O., Komatsu, M. and Walker, P.L., Jr.; Applied Spectroscopy, 1981, Vol. 35, No. 1, 106.

4. Painter, P.C., Snyder, R.W., Pearson, D.E. and Kwong, J.; Fuel,1980, Vol. 59, 283.

5. Mahajan, O.P., Komatsu, M., and Walker,Jr.,P.L.; Fuel, 1980, Vol. 59, 3.

6. Clemens, A.H., Matheson, T.W., and Rogers, D.E.; Fuel, 1991, Vol. 70, 215.

7. Tognotti, L., Petarca, L., D'Alessio, A., and Benedetti, E.; Fuel, 1991, Vol. 70, 1059.

8. Chamberlain, E.A.C., Barrass, Barrass, G., Thirlaway, J.T; Fuel, 1976, Vol. 55, 217. 
9. Ignasiak, B.S., Clugston, D.M. and Montgomary, D.S. Fuel 1972, Vol.51, 76.

10. Ignasiak, B.S., Szladow, A.J. and Montgomary, D.S.; Fuel 1974, Vol.53, 12.

12. Song, C., Saini, A.K., Hatcher, P.G., and Schobert, H.H.; "Effects of Low-Temperature Catalytic Pretreatments On Coal Structure and Reactivity in Liquefaction", Technical Progress report, Jan. 1992-March 1992, Prepared for the U.S. Department of Energy, Pittsburgh, DE-AC22-91PC91042.

13. Saini, A.K., Song, C., Schobert, H.H., Hatcher, P.G., 1992, Am. Chem. Soc. Div. Fuel Chem. Prepr., 37 (3): 1235-1242.

14. Petit, J. C.; Fuel, 1991, 70, 1053.

\section{Effects of Reaction Conditions on Thermal and Catalytic Liquefaction of a Texas Subbituminous Coal}

For low-rank coals, such as Texas subbituminous, thermally initiated reactions can take place very rapidly at low temperatures producing free radicals. These free radicals can either take the pathway of retrogressive reactions to form heavy materials or can be hydrogenated to form the desired light products. To find the optimum reaction conditions which can minimize the retrogressive reactions while enhancing hydrogenation, several reaction conditions such as singlestaged liquefaction (SSL) and temperature-programmed liquefaction (TPL) were compared. The effect of reaction solvents on the liquefaction was also studied using hydrogen-donor solvents (e.g. tetralin and decalin), a non-donor solvent (e.g. 1-methylnaphthalene) and a recycle solvent (Wilsonville middle distillate). Ammonium tetrathiomolybdate (ATTM) was chosen as the catalyst precursor. Three impregnation methods, including preswelling, incipient wetness and slurrying impregnation, were applied to investigate the effect of impregnation methods on the activity of the catalyst for liquefaction.

\subsection{Introduction}

The characteristic of low-rank coals is that they have low carbon content and high cxygen content. The aromatic ring clusters in low-rank coals are generally small while the aliphatic crosslinks and the crosslinks containing heteroatoms, such as oxygen, are abundant [1]. This structural feature makes it easy to break coal macromolecules into fragments (radicals). Whether these radicals are stabilized by hydrogenation or by retrogressive reactions is the critical point in the liquefaction of low-rank coals. The important factors which have significant impact on the hydrogenation or retrogressive reactions are reaction conditions (temperature, $\mathrm{H}_{2}$ pressure and 
time), reaction solvents and catalysts. The reaction conditions have been studied by many workers and the procedures for single-staged liquefaction (SSL), temperature-staged liquefaction (TSL) and temperature-programmed liquefaction (TPL) have been established [2-4]. The TPL was found to be superior to SSL and TSL for catalytic liquefaction of a subbituminous coal using dispersed Mo catalyst in terms of higher conversion and oil yield [2]. Three types of reaction solvents, hydrogen donor, non-donor, and recycle solvent, are often used and their behavior in the liquefaction was investigated [3-6]. For the catalytic conversion, a very important aspect, besides the activity of the catalyst, is its dispersion. Several impregnation methods were often used. They are preswelling $[7,8]$, incipient wetness $[2,9,10]$ and slurrying.

In this work, the liquefaction of DECS-1 coal was studied comparing with DECS-9 and DECS-11 coals. Four reaction solvents were used for examining the effect of the solvent on liquefaction. The three impregnation methods mentioned above were applied to disperse the catalyst precursor, ammonium tetrathiomolybdate (ATTM), onto the coal, and their effects were studied comparatively.

\subsection{Experimental}

The coal samples were a Texas subbituminous (DECS-1), a North Dakota lignite (DECS11) and a Montana subbituminous coal (DECS-9), obtained from Penn State Coal Sample Bank. Their compositional data are summarized in Table 1 . The coal samples were dried at $95^{\circ} \mathrm{C}$ in vacuum for $5 \mathrm{~h}, 5 \mathrm{~h}$, and $3 \mathrm{~h}$ respectively before use. The reaction solvents are tetralin (Aldrich, 99\%), decalin (Aldrich 99+\%), 1-methylnaphalene (1-MN, Aldrich, 98\%) and Wilsonville Middle Listillate (WIMD). The catalyst precursor was ammonium tetrathiomolybdate (ATTM, Aldrich, 99.97\%). All the chemicals were used without further purification.

The catalyst loading was $1 \mathrm{wt} \%$ of Mo based on the dmmf coal. A THF/ $\mathrm{H}_{2} \mathrm{O}(56: 44)$ mixture was used to make the solution of the catalyst precursor, because this binary mixture was superior to $\mathrm{H}_{2} \mathrm{O}$ in terms of higher conversion and oil yield [2]. The impregnation methods were swelling, incipient wetness and slurrying. In the swelling method, the volume of the $\mathrm{THF} / \mathrm{H}_{2} \mathrm{O}$ solution was four times of the coal volume. The swelling was carried out at room temperature under $\mathrm{N}_{2}$ atmosphere for $24 \mathrm{~h}$ with continuous stirring. The swelling ratio was 1.85 for this coal. The swollen coal with the catalyst precursor on was then dried in a vacuum oven at room temperature for $48 \mathrm{~h}$ to remove the THF followed by drying at $40^{\circ} \mathrm{C}$ for $24 \mathrm{~h}$ and $95^{\circ} \mathrm{C}$ for $48 \mathrm{~h}$ to remove the remaining THF and $\mathrm{H}_{2} \mathrm{O}$. In the incipient wetness method, the precursor was dissolved in the desired volume of the $\mathrm{THF} / \mathrm{H}_{2} \mathrm{O}$ for a certain amount of the coal sample. This 
solution was added drop by drop while the coal was constantly stirred manually. After all the solution was added, the coal was dried in the vacuum oven at $95^{\circ} \mathrm{C}$ for $4 \mathrm{~h}$ to remove the THF and $\mathrm{H}_{2} \mathrm{O}$. In the slurrying method, the same amount of $\mathrm{THF} / \mathrm{H}_{2} \mathrm{O}$ mixture as that in the incipient wetness method was used to dissolve the ATTM. The solution was then added to the coal sample to make a slurry. The slurry was stirred by a magnetic stirrer for 15 minutes at room temperature under $\mathrm{N}_{2}$ atmosphere, followed by drying in the vacuum oven at room temperature for $48 \mathrm{~h}, 40^{\circ} \mathrm{C}$ for $48 \mathrm{~h}$ and $95^{\circ} \mathrm{C}$ for $6 \mathrm{~h}$ to remove the THF and $\mathrm{H}_{2} \mathrm{O}$.

Table 3.1. Proximate and ultimate analysis of the coals

\begin{tabular}{llll}
\hline \multicolumn{1}{c}{ Coal } & DECS-1 & DECS-11 & DECS-9 \\
\hline \multicolumn{1}{c}{ Proximate Analysis } & (As Rec'D) & & \\
\% moisture & 30.0 & 33.4 & 24.7 \\
\% ash & 11.1 & 6.4 & 4.8 \\
\% volatile & 33.2 & 37.4 & 33.5 \\
\% fixed carbon & 25.8 & 22.9 & 37.1 \\
& & & \\
Ultimate Analvsis & (dmmf) & & \\
& & & \\
\% carbon & 76.1 & 74.2 & 76.1 \\
\% hydrogen & 5.5 & 4.4 & 5.1 \\
\% nitrogen & 1.5 & 1.0 & 0.9 \\
\% organic sulfur & 1.1 & 0.44 & 0.3 \\
\% oxygen (diff) & 15.8 & 20.0 & 17.5 \\
\end{tabular}

Liquefaction experiments were conducted in $25 \mathrm{ml}$ tubing bombs in a preheated fluidized sandbath. For each reaction, $4 \mathrm{~g}$ of coal sample and $4 \mathrm{~g}$ of a solvent were loaded into a tubing bomb. Hydrogen was purged three times and the final pressure was $1000 \mathrm{psi}(7 \mathrm{MPa})$ at room temperature. The reactor was then plunged into the sandbath and agitated at a rate of 200 cycles per minute. For a single-staged liquefaction (SSL), the tubing bomb was rapidly heated up to $350^{\circ} \mathrm{C}$ and kept at that temperature for 30 minutes followed by rapid quench. For a temperature- 
programmed liquefaction (TPL), the tubing bomb was rapidly heated up to $200^{\circ} \mathrm{C}$, held at this temperature for 15 minutes, then slowly heated to $400^{\circ} \mathrm{C}$ at a rate of about $7{ }^{\circ} \mathrm{C} / \mathrm{min}$, and held at that temperature for 30 minute, finally the reactor was rapidly quenched.

After the reaction, the gases were vented, the liquids and the solids in the tubing bomb were washed into a tarred ceramic thimble using hexane. Then the products were separated under a nitrogen atmosphere by Soxhlet-extraction using hexane, toluene and THF sequentially. The soluble products were classified as oil, asphaltene and preasphaltene, respectively. Most of the experiments were repeated at least once. If the difference between the two runs was larger than 4 percentage units, the experiment was repeated again and the two closer ones were chosen to calculate the average value.

\subsection{Results and Discussion}

\section{Thermal Reactivity of Three Low-Rank Coals}

In order to gain some general information about the liquefaction of the DECS-1 coal, the coal is first compared with DECS-11 and DECS-9 under two different reactions. Table 2 lists the results of experiments with WIMD as the reaction solvent. The reactor heat-up profiles are illustrated in Scheme 1 for TPL at final temperature of $400^{\circ} \mathrm{C}$ and Scheme 2 for SSL at $350^{\circ} \mathrm{C}$. In single-staged liquefaction (SSL) at $350^{\circ} \mathrm{C}$, the conversions of the three coals are all in the high twenty percent range without a significant difference. The product distributions are similar with the exception of DECS-9. In temperature-programmed liquefaction (TPL) at $200^{\circ} / 400^{\circ} \mathrm{C}$, all of the three coals have dramatic increases in conversion, with the DECS-1 increasing the most (about 10 percentage units more than the other two). However, the yields of desired light materials, such as oil and asphalte' 1 , are identical for the three coals in TPL. The higher increase in the conversion of DECS-1 is due to the higher yield (10 percentage units) of preasphaltene.

It appears that the liquefaction reactivity of the DECS-1 coal at mild conditions (SSL at $350^{\circ} \mathrm{C}$ ) is nearly identical with the other two coals; while changing the reaction condition to the temperature-programmed at $200^{\circ} \mathrm{C} / 400^{\circ} \mathrm{C}$, the conversion can be significantly increased, though a fraction as high as one third (22.8/67.1) of the total product is preasphaltene. Nevertheless, DECS-1 coal can still be an interesting feedstock for liquefaction, if the preasphaltene can ie 


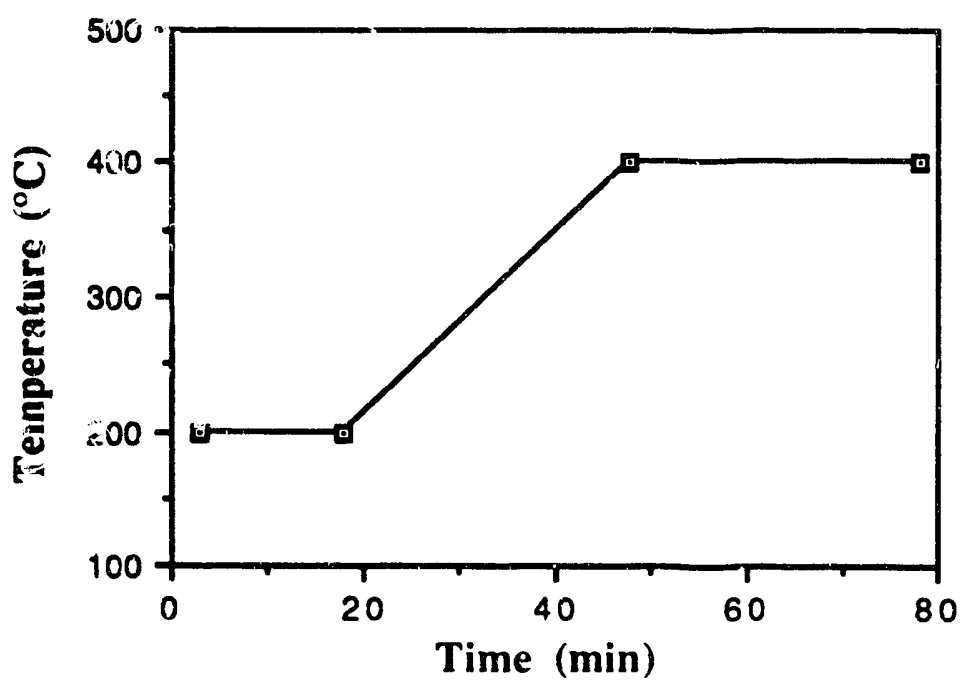

Scheme 1. Reactor temperature as a function of time for TPL

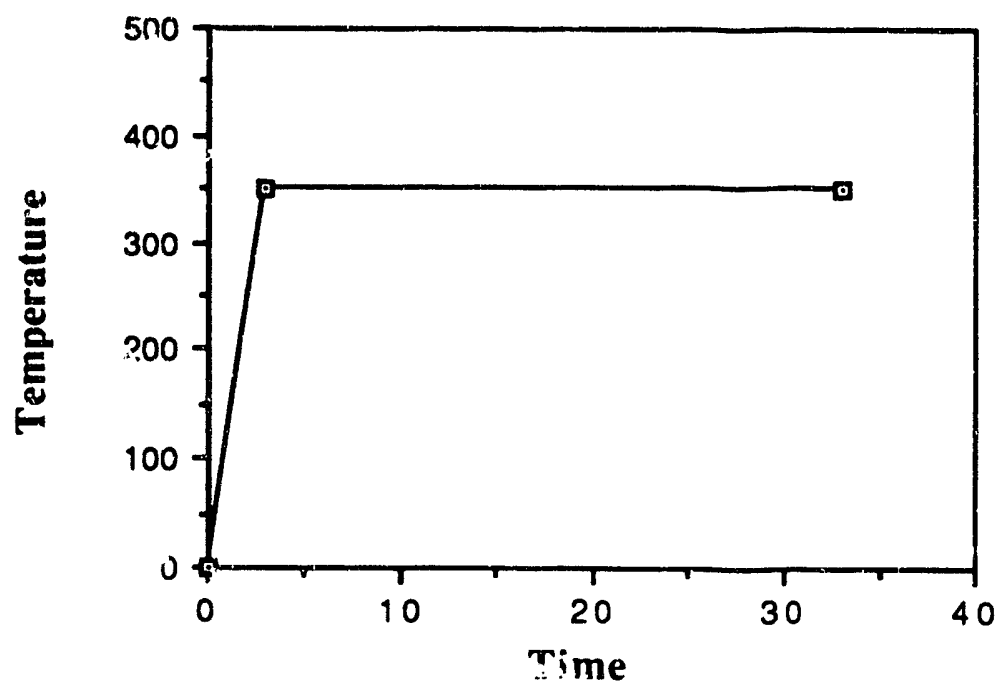

Scheme 2. Reactor temperature as a function of time for SSL

converted to oil, the desired product. The preasphaltene could be attributed to two types of reactions. One is the depolymerization of coal macromolecules into fragments. These fragments may dissolve in THF, but they may be so large that they do not dissolve in hexane or toluene, thus they appear as preasphaltene. The other is the recoinibination of small fragments. At the reaction temperature, the coal molecules may be cracked down to small fragment radicals which could be 
stabilized by hydrogen and produce oil or asphaltene, but due to the unavailability of hydrogen, those radicals may recombine with one another and produce preasphaltene. In the former case, the amount of preasphaltene can be reduced by further cracking the fragments, which produce the preasphaltene, into smaller ones. In the latter case, it is crucial to improve the hydrogenation of any radicals, especially those which may produce oil and asphaltene, and thus to prevent the recombination. Regardless of how the preasphaltene formed, reducing their contribution to the product slate means that we have to crack the coal macromolecular structure extensively (but not to the extreme that too much gas forms) as well as to enhance the hydrogen up-take by the system. Hence it is necessary to find the proper reaction conditions, to introduce catalysts into the reaction, and/or to improve the performance of the reaction solvents in liquefaction.

Table 3.2. Comparison of DECS- 1 with DECS- 9 and DECS- 11 in TPL and SSL with WIMD as solvent

\begin{tabular}{llll}
\hline Coal Samples & Tot. Conv. Oil + Gas Asph. & Preasph. \\
\hline
\end{tabular}

\section{SSL $\left(350^{\circ} \mathrm{C}\right)$}

$\begin{array}{lllll}\text { DECS-1 } & 29.9 & 16.7 & 7.2 & 6.0 \\ \text { DECS-11 } & 25.3 & 17.5 & 4.6 & 3.3 \\ \text { DECS-9 } & 28.0 & 10.1 & 10.2 & 7.8\end{array}$

TPL $\left(200^{\circ} \mathrm{C} / 400^{\circ} \mathrm{C}\right)$

$\begin{array}{lllll}\text { DECS-1 } & 67.1 & 28.5 & 15.8 & 22.8\end{array}$

$\begin{array}{lllll}\text { DECS-11 } & 57.1 & 31.9 & 15.2 & 10.0 \\ \text { DECS-9 } & 55.9 & 26.9 & 17.6 & 11.4\end{array}$

\section{Effects of Reaction Solvents}

The effects of solvents on the liquefaction of DECS-1 coal were investigated and the results are presented in Table 3.3. In SSL at $350^{\circ} \mathrm{C}$, the reaction with tetralin has slightly higher conversion than those with other three solvents. In term of product distribution, tetralin, WIMD 
and 1-MN are the same while decalin produced lower fraction of asphaltene and preasphaltene while much higher fraction of oil plus gas. In TPL at $200^{\circ} \mathrm{C} / 400^{\circ} \mathrm{C}$, the differences in conversion caused by the reaction solvents are more apparent. The reaction with tetralin produced 10 percentage units higher in conversion than the reaction with WIMD, which produced about 20 percentage units higher than those with decalin and 1-MN. In terms of product distribution under this condition, tetralin and 1-MN have very similar behavior while WIMD and decalin are on two opposite extremes. With WIMD, large fraction of preasphaltene and small fraction of oil were produced; while with decalin, small faction of preasphaltene and large fraction of oil were obtained. As for asphaltene, it has same fraction in the total conversion regardless the reaction solvents.

Table 3.3 shows that the effects of solvents on liquefaction strongly depend on the reaction conditions. At temperature as low as $350^{\circ} \mathrm{C}$, the coal macromolecules may not be broken down to fragments extensively, or the generation of radicals accessible to the H-donor solvent may not occur extensively [6]. Therefore, the effects of solvents can not be determined because the coalderived radicals, even they are generated at this temperature, may not be accessible to the H-donors in the solvents. However, tetralin is a well-known swelling (weak) solvent; it may diffuse into the coal particles, loosen the structure and make those radicals accessible. The other possible cause is the low reactivity of solvents at this temperature. Hill et al. claimed that the hydrogen transfer from the solvents to the coal is not abundant [7]. While under temperature-programmed conditions $\left(200^{\circ} \mathrm{C} / 400^{\circ} \mathrm{C}\right)$, more and more free radicals are generated as the temperature rises. On the other hand, one advantage of the TPL process is to provide the chance for the solvents to diffuse into the pores in the coal particles [4] and to obtain access to the radicals. It is observed that the order of the solvents in term of conversion is tetralin $>$ WIMD $>$ decalin $=1-\mathrm{MN}$ in $\mathrm{TPL}\left(200^{\circ} \mathrm{C} / 400^{\circ} \mathrm{C}\right)$. However, as mentioned earlier, the reaction with WIMD produced very high yield of preasphaltene while the reaction with decalin produced very low preasphaltene. Previous investigation at Penn State has shown that WIMD contains abundant pyrene and hydropyrene [12] which can serve as hydrogen shuttlers. During the liquefaction, the macromolecules are cracked down to radicals of different sizes. Generally, radicals of large size, or large aromatic clusters, are more stable, in other words less active in hydrogen abstraction, than the radicals of smaller sizes. With a good $\mathrm{H}$ donor, the radicals with all sizes are stabilized by hydrogen abstraction from the donor and appear as preasphaltene (for large-sized radicals), asphaltene or oil (for small-sized radicals). If the radicals of large size do not have chances to further crack down after their stabilization, the preasphaltene yield will be high. This could be one possible explanation why tetralin and WIMD produce high yield of preasphaltene. While with a poor $\mathrm{H}$-donor as the reaction solvent, the radicals of large size, with low activity, may lose the competition of hydrogen abstraction to the 
radicals of small size. Since these radicals are not stable, they either take the pathway of recombination to form large molecules, e. g. THF insolubles, and reduce the conversion, or they can be further cracked down to small fragment radicals which can be stabilized and produce high yield of oil and asphaltene. Therefore, donor solvents have high conversion accompanied with high preasphaltene yield while non-donor solvents have low conversion with low preasphaltene yield.

\section{Effects of Catalyst Impregnation Methods}

Table 3.4 shows the effects of the catalyst and the catalyst impregnation methods on the liquefaction. Temperature-programmed liquefaction was first conducted with WIMD as reaction solvent. It was found that there was a significant increase in the total conversion, comparing the average of all catalytic runs with the thermal run, and the product slate was drastically shifted to enhance the gas + oil yield at the expense of the asphaltene and preasphaltene, which can be seen in Table 4. As for the effects of impregnation methods in TPL, total conversions of the reactions using the swelling and the incipient wetness methods are very close and that using the slurrying method is slightly lower. These data show that at proper reaction conditions such as TPL, the impregnation method does not play a significant role in the liquefaction.

From comparison of Table 3.2 and Table 3.3, it is found that the reaction conditions have very significant impacts on the conversion. Any small differences in catalyst dispersion caused by different impregnation methods will be diminished by the strong effects of reaction conditions. Therefore, it is necessary to carry out liquefaction experiments at milder conditions in order to study the effects of the impregnation methods.

Single-staged liquefaction experiments at $350^{\circ} \mathrm{C}$ were carried out, again with WIMD as reaction solvent, and the results are listed in Table 4 . Comparing the average of all the catalytic runs with the thermal run, it is observed that the catalyst is active under this con rition, though its impact on conversion [(36.8-29.7)/29.7=24\%] is not as large as that in TPL [(91.0-67.1)=36\%]. This is evidence that the catalyst is more active in TPL $\left(200^{\circ} \mathrm{C} / 400^{\circ} \mathrm{C}\right)$ than in SSL $\left(350^{\circ} \mathrm{C}\right)$. The catalytic SSL managed to reduce the preasphaltene, relative to non-catalytic, but the main effect is to enhance asphaltenes at the expense of preasphaltene, because there is no increase in the proportion of gas + oil. In other words, at less severe conditions, the use of the catalyst promotes the conversion from preasphaltene to asphaltene, but contributes little to their conversion to oil. As for 


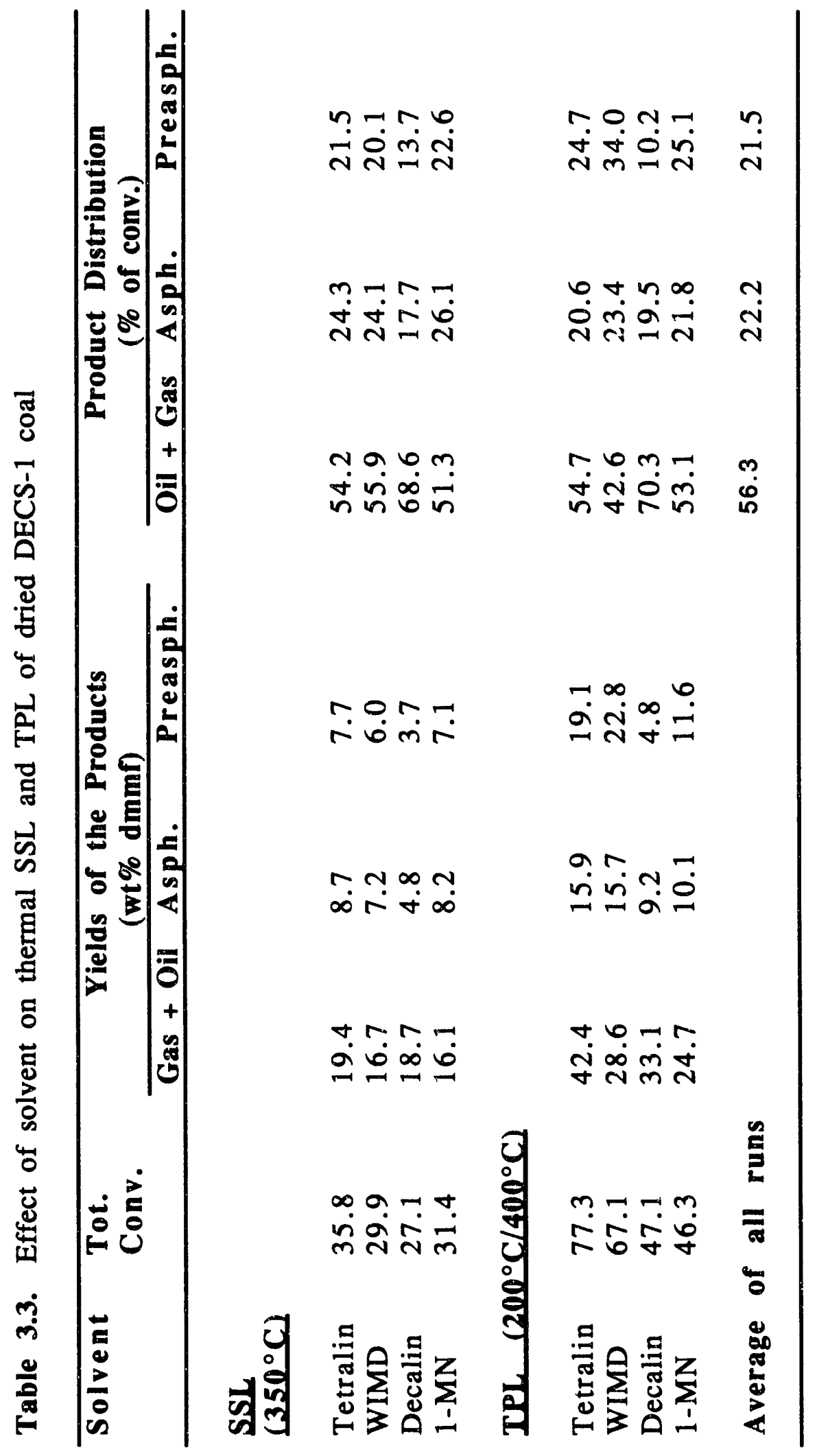




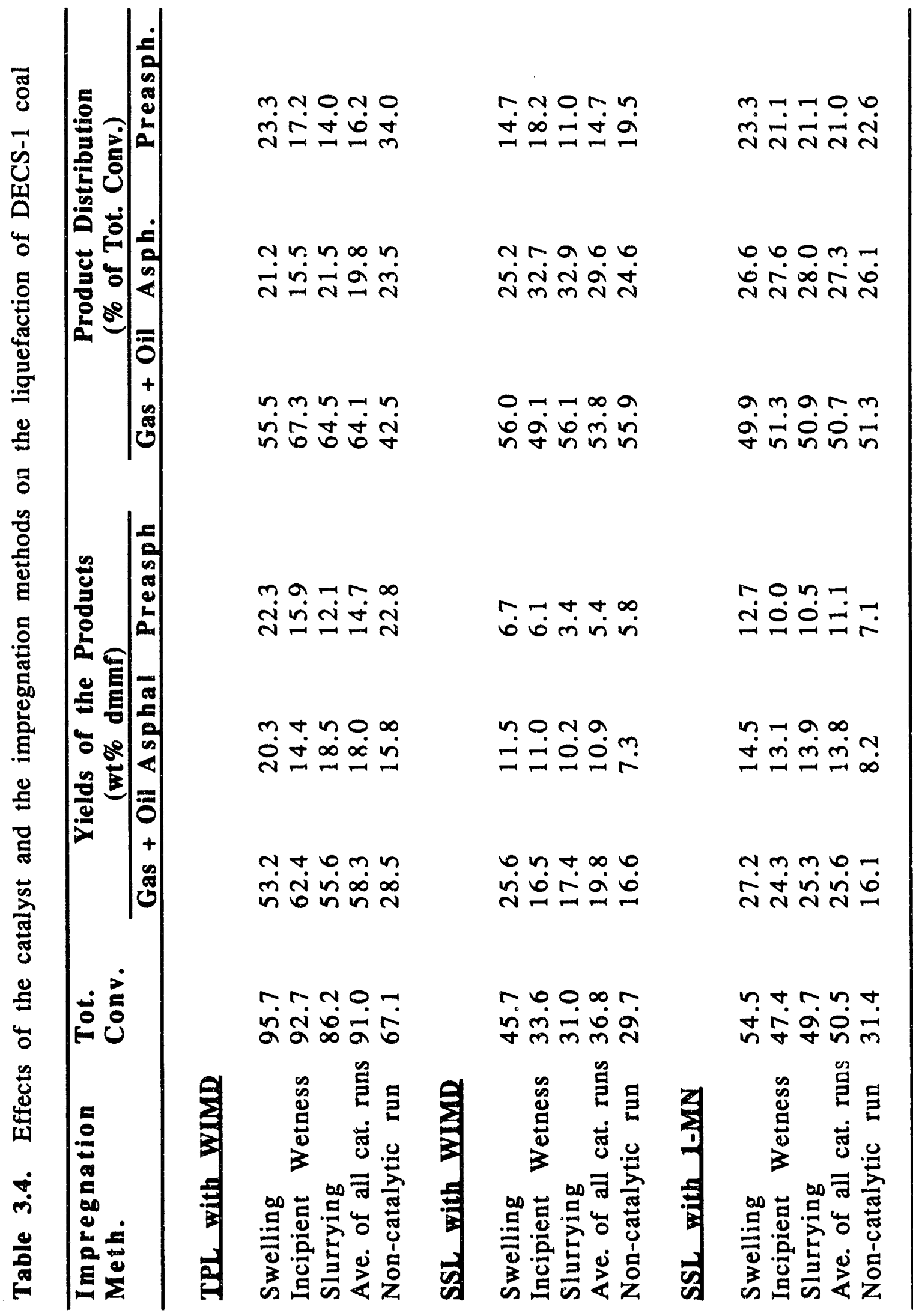


the effect of impregnation methods, the swelling method seems to be better than the other two in terms of gaining higher conversion under this mild conditions. However in terms of the product distribution, it does not show any significant advantage.

\subsection{SUMMARY}

At mild reaction conditions, e.g. single-staged at $350^{\circ} \mathrm{C}$, the DECS-1 coal behaves very similar to DECS-9 and DECS-11 coals. At higher temperature and better designed reaction procedures, e.g. temperature-programmed at $200^{\circ} \mathrm{C} / 400^{\circ} \mathrm{C}$, the coal is very interesting in the way that it has higher conversion than the other two, which is due to the higher yield of the preasphaltene. The study on the reaction solvents shows that at low temperature and single-staged condition, they do not make much differences, while at higher tempsrature in TPL, the order of them in terms of producing high conversion is tetralin $>$ WIMD $>$ decalin $=1-\mathrm{MN}$. However, in terms of oil or preasphaltene yield, the order is not the same. Some possible explanations are proposed. The applied catalyst (ATTM) is very effective in achieving high conversion, especially in shifting the product distribution to a high fraction of oil. The effect of the catalyst impregnation methods on the catalyst activity was investigated and it was found that under an optimized reaction condition, such as temperature-programmed run at $200^{\circ} \mathrm{C} / 400^{\circ} \mathrm{C}$, this effect is negligible relative to the thermal effect and catalytic effect. Under milder conditions, e.g. $350^{\circ} \mathrm{C}$, the swelling method is superior to the others in term of conversion. However, in regard to the product distribution or product selectivity, the three methods gave very similar results.

\subsection{REFERENCE}

1. Schobert, H. H. Resources, Conservation and Recycling, 1990, 3, 111-123

2. Huang, L., Song, C., Schobert, H. H., Am. Chem. Soc. Div. Fuel Chem. Prepr., 1992, 37(1), 223-227

3. Song, C., Schobert, H. H., Energy \& Fuel, 1992, 6, 326-328

4. Song, C., Schobert, H. H., Am. Chem. Soc. Div. Fuel Chem. Prepr., 1992, 37(2),976-983

5. Vlieger, J. J., Kieboom, A. P., Bekkum, H. V., Fuel, 1984, 63, 334-340

6. Schulten, H. R., Marzec, A., Fuel Proc. Tech., 1987,15, 307-318

7. Hill, G. R., Hairiri, H., Reed, R. I., and Anderson, L. L., Am. Chem. Soc., Advanced in Chem. Ser. 1966, 55, 427-447 
8. Joseph, J. T., Fuel, 1991, 70, 459-464

9. Joseph, J. T., Fuel, 1991, 70, 139-144

10. Utz, B. R., Cugini, A. V., and Frommel, E. A., Am. Chem. Soc. Div. Fuel Chem. Prepr., $1989,34(4), 1423$

11. Derbyshire, F. and Hager, T., Am. Chem. Soc. Div. Fuel Chem. Prepr., 1992, 37, 312-319

12. Lai, W., Song, C., Schobert, H. H., Am. Chem. Soc. Div. Fuel Chem. Prepr., 1992, 37(4), 1671-1680 


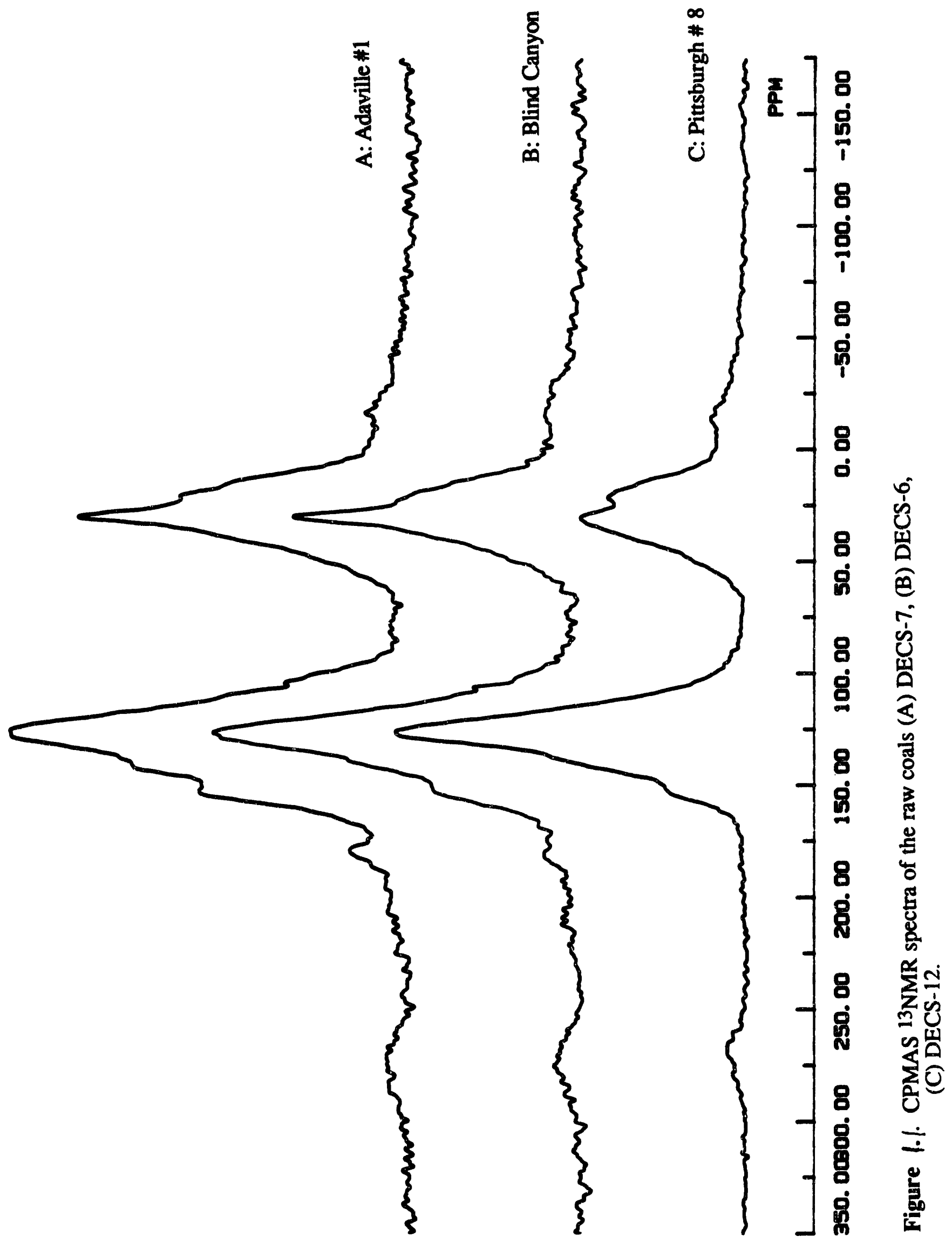




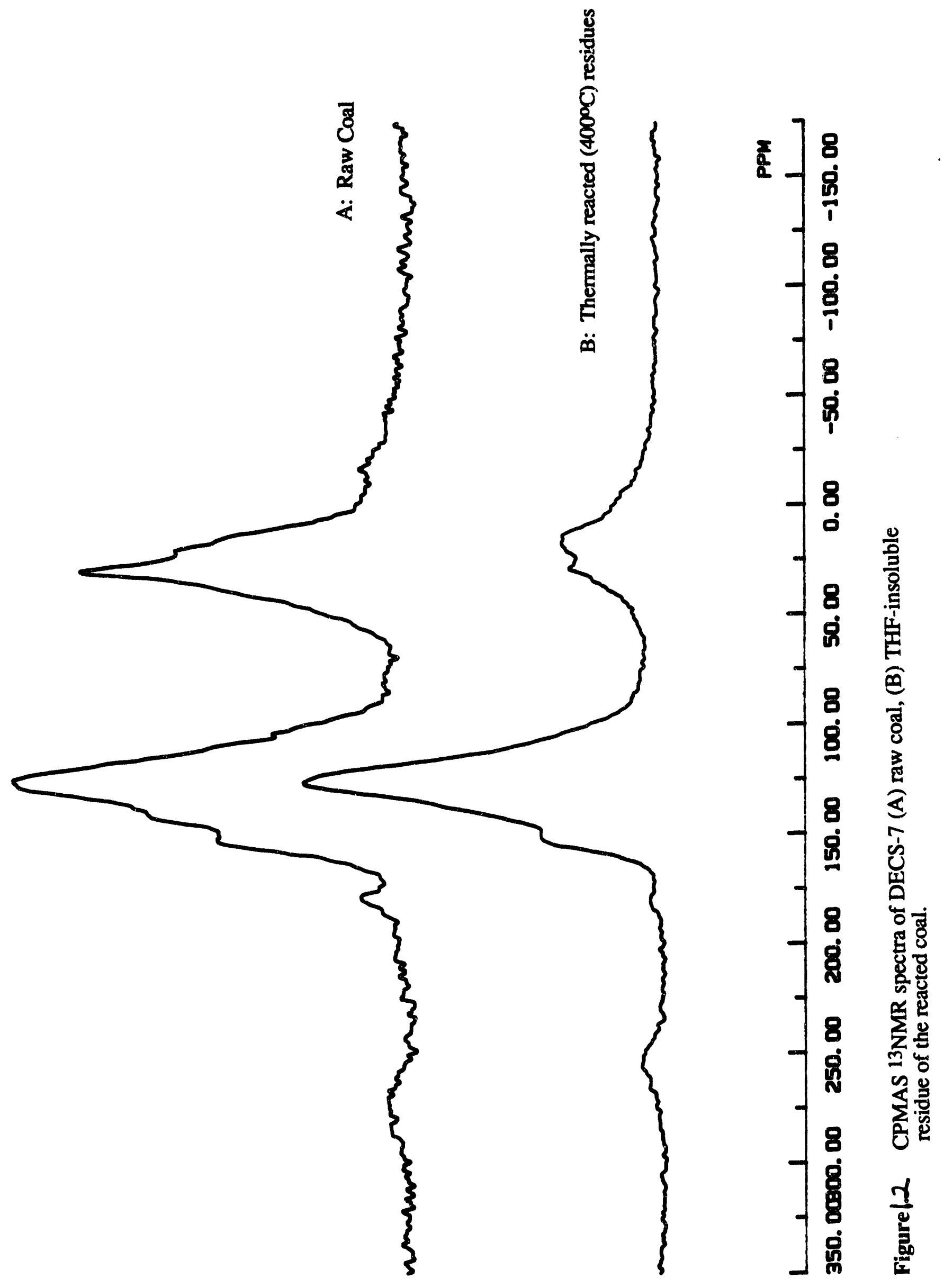




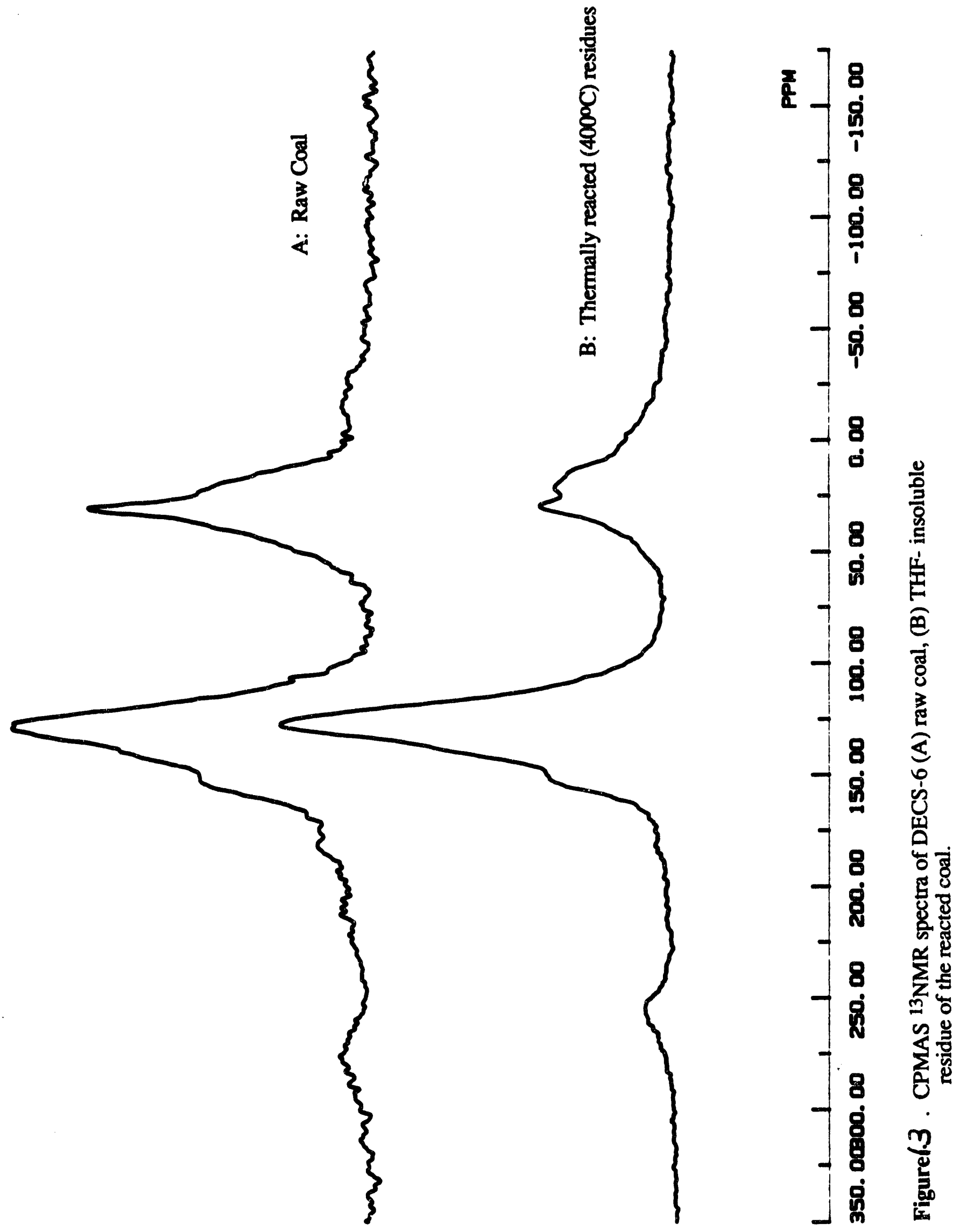




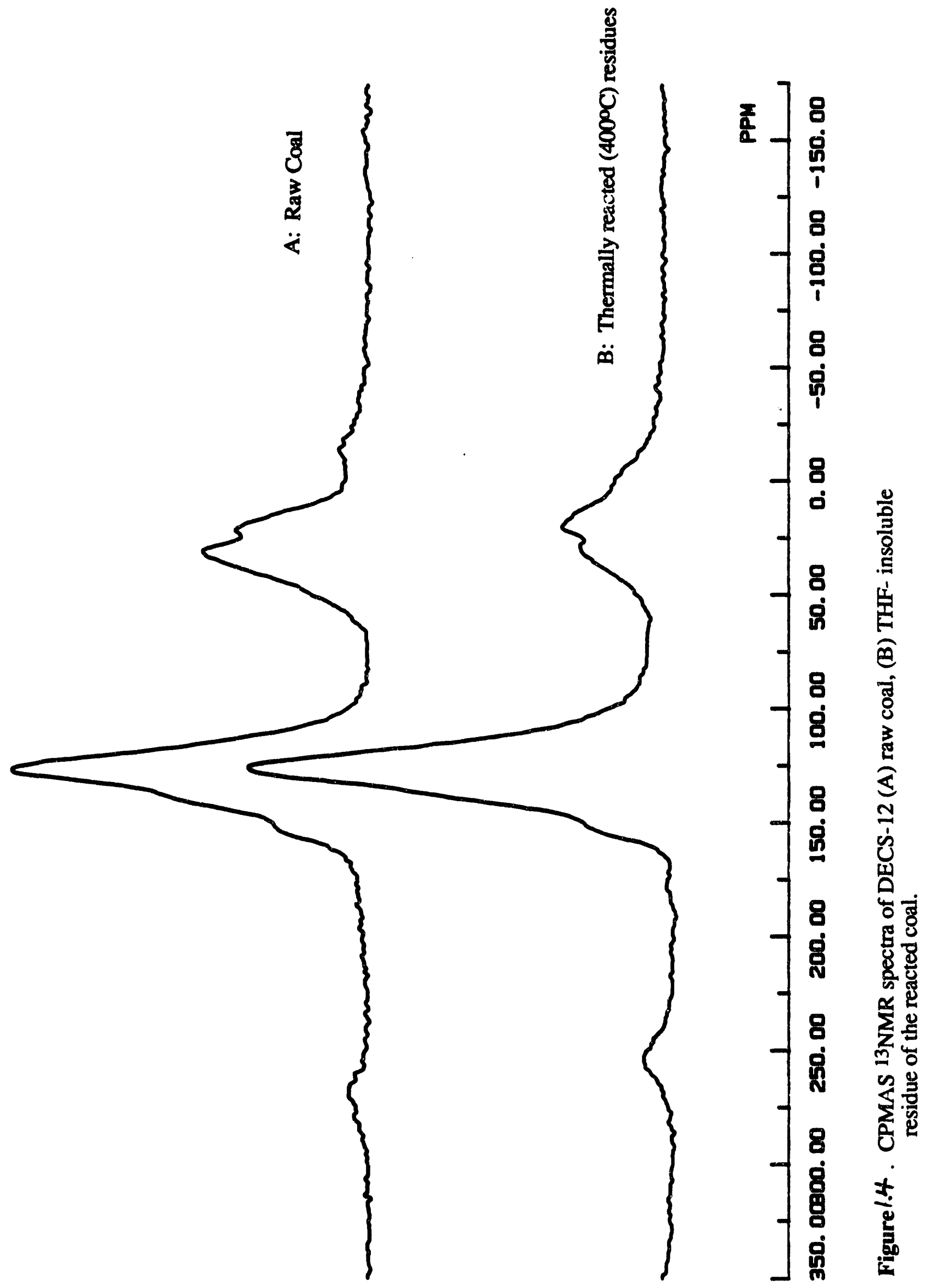




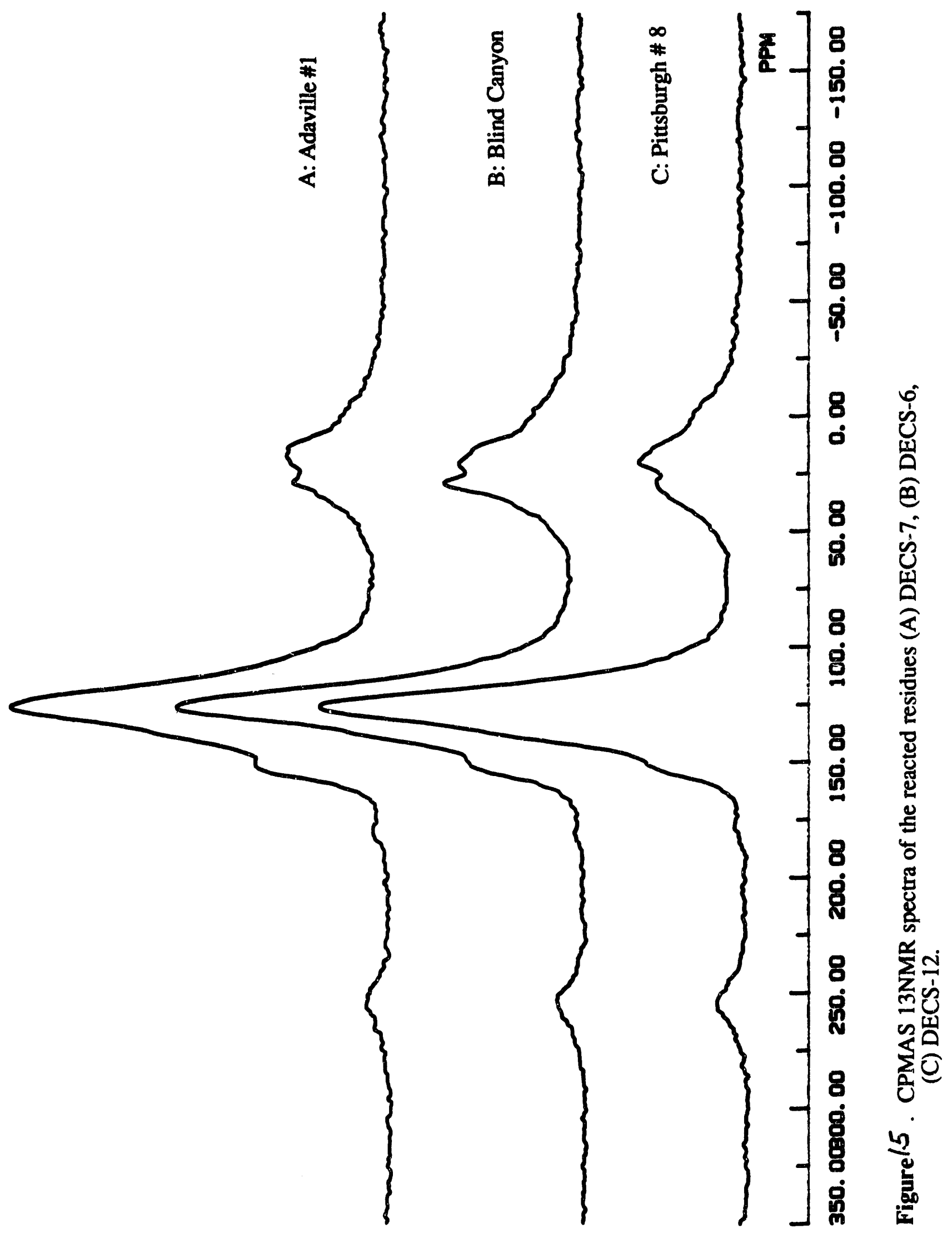




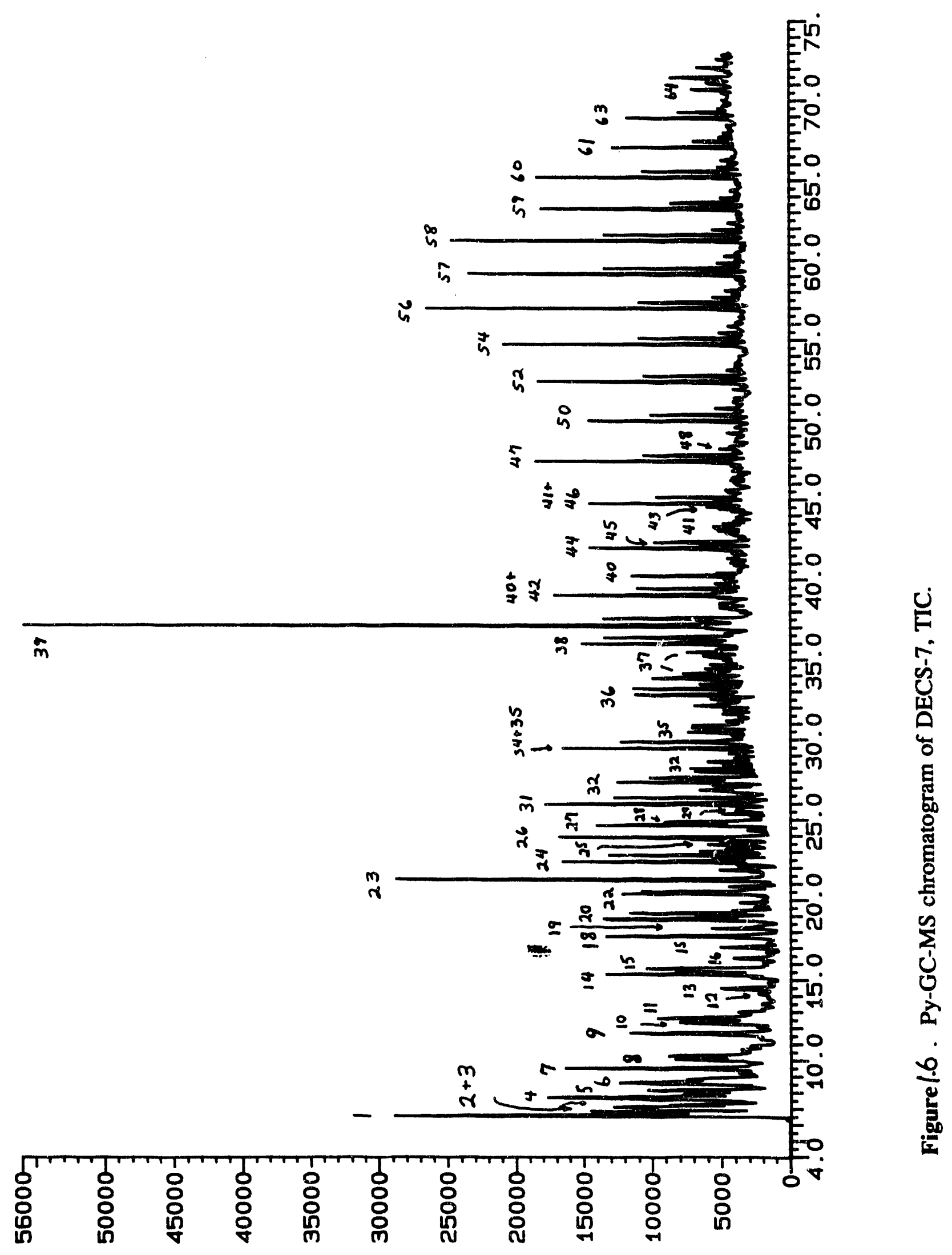




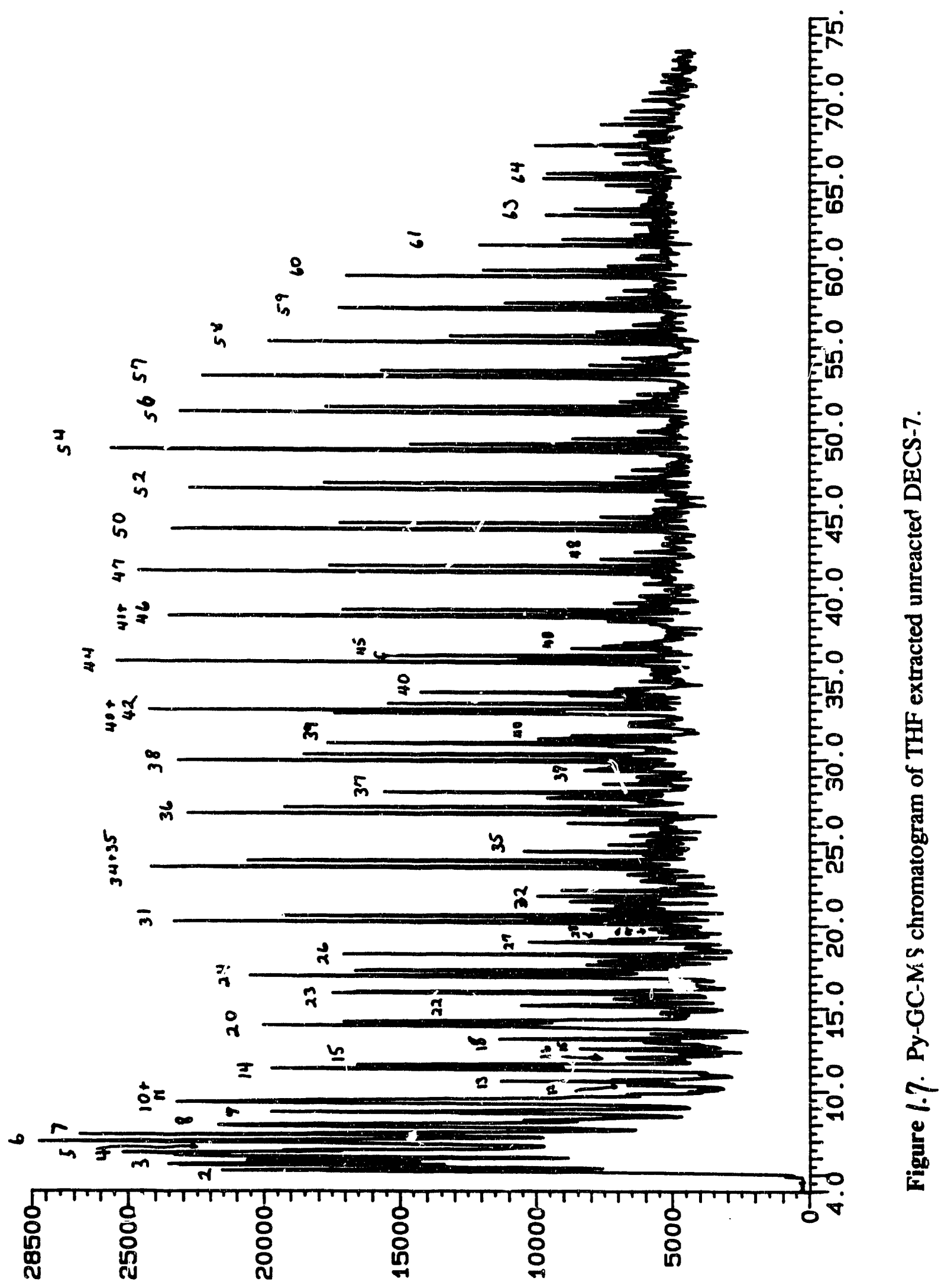




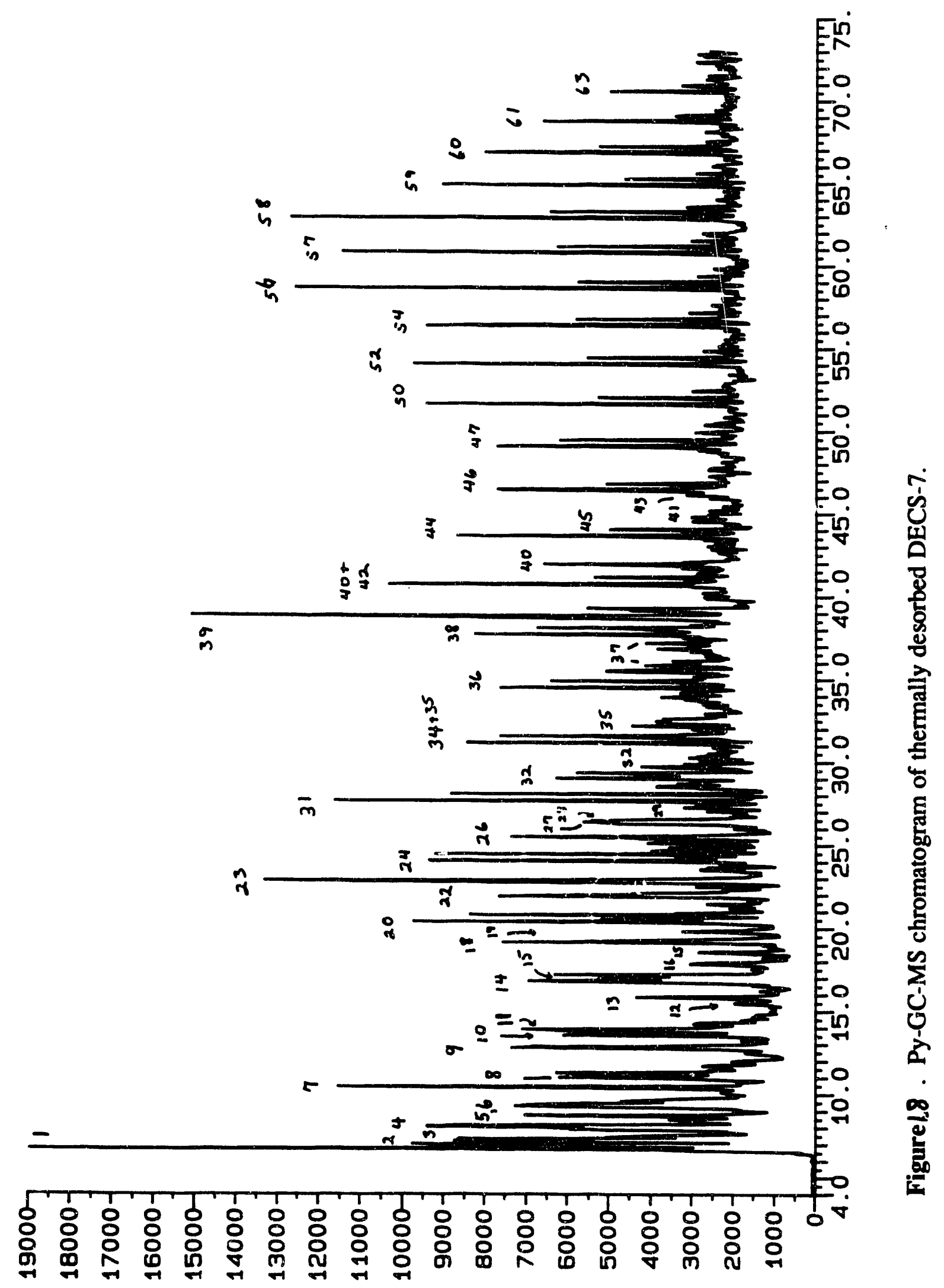




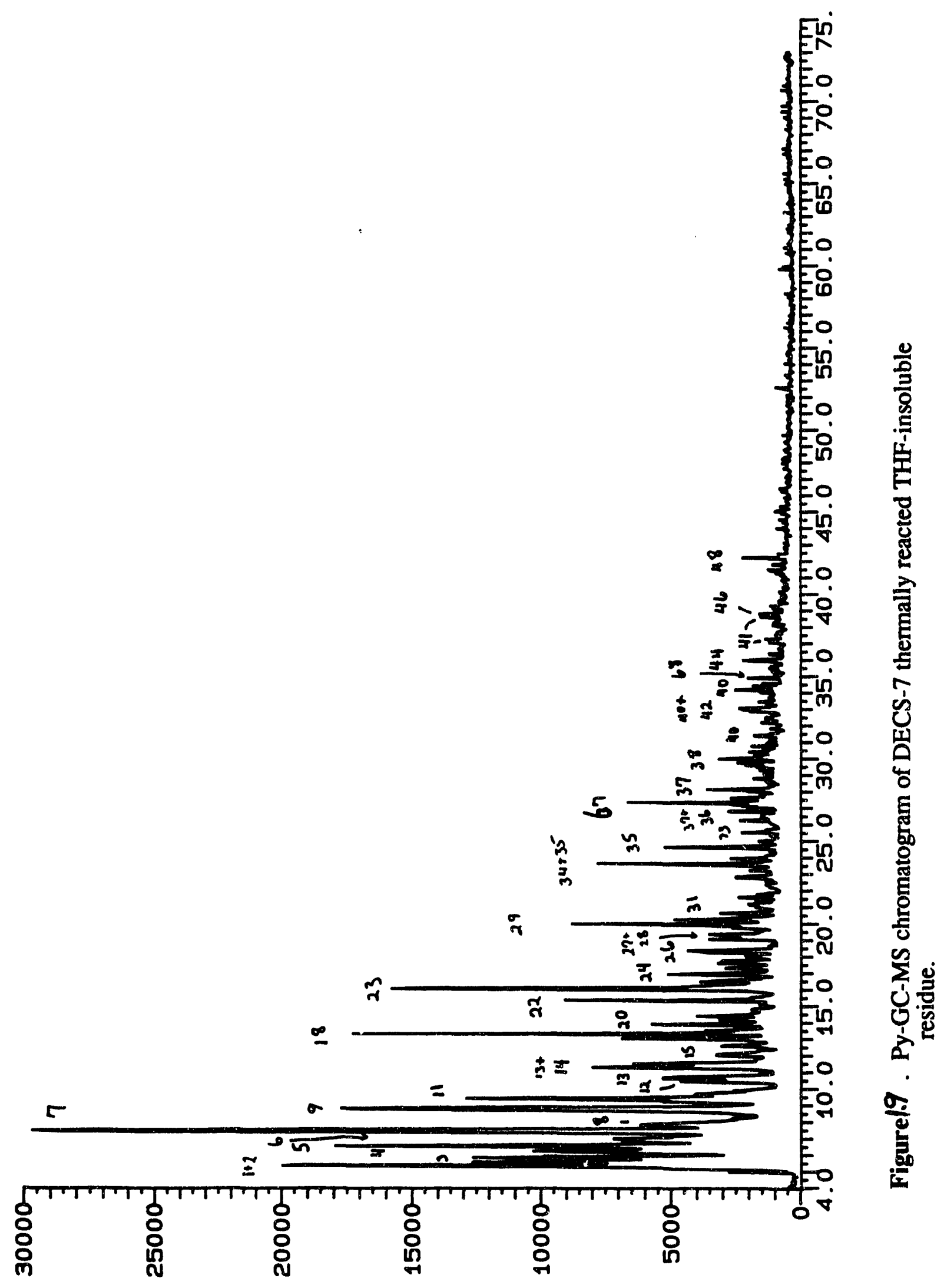




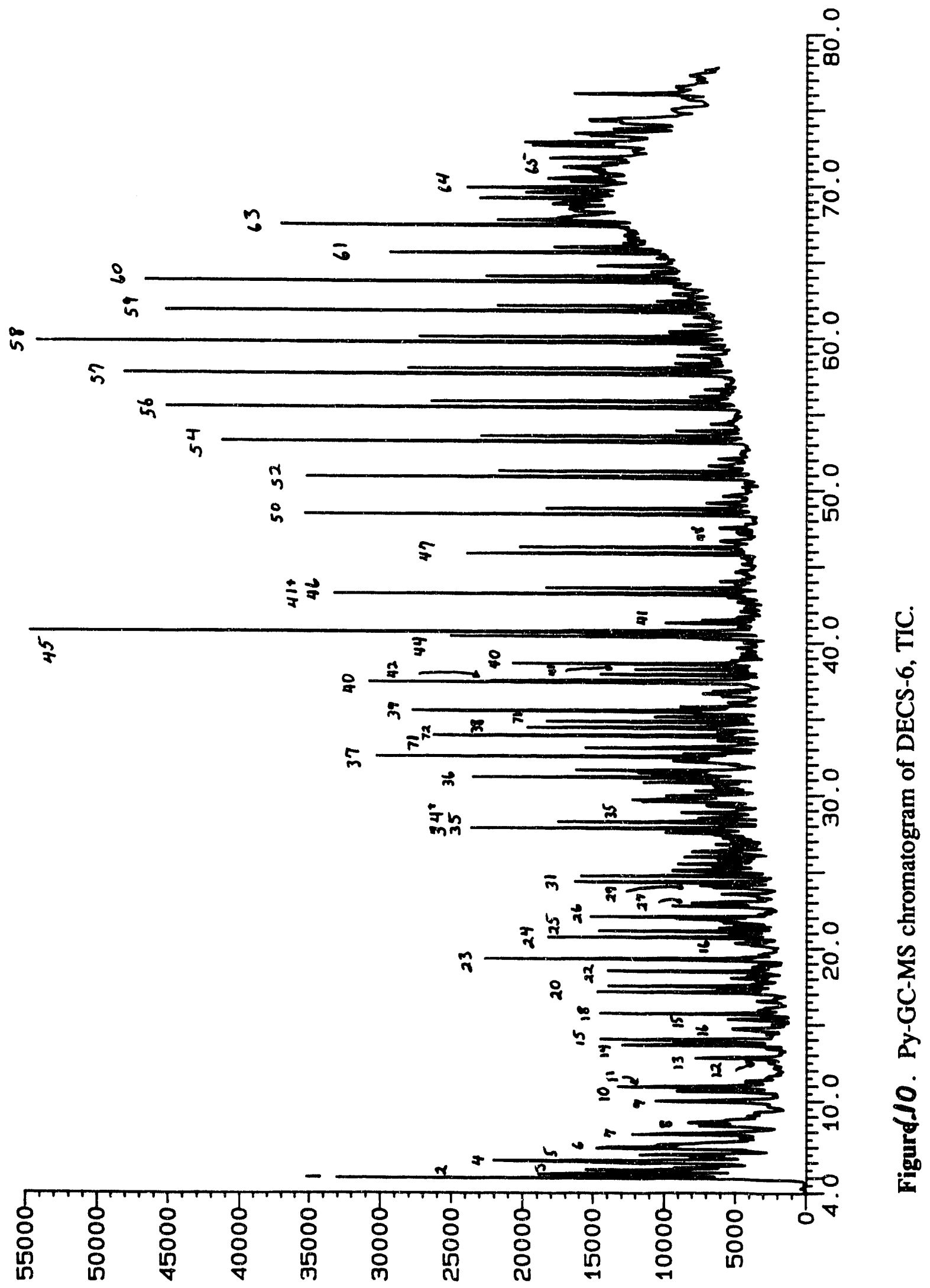




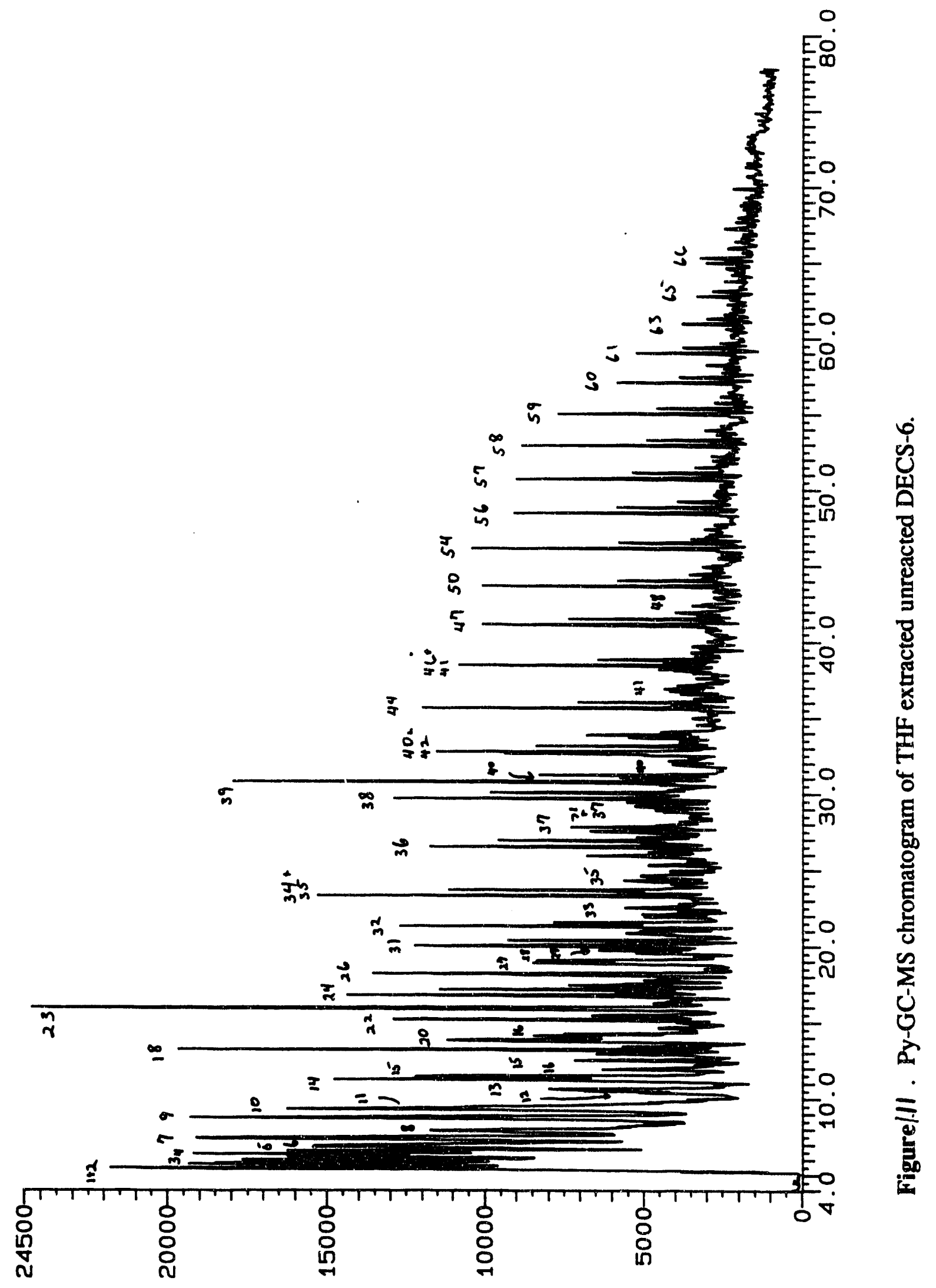




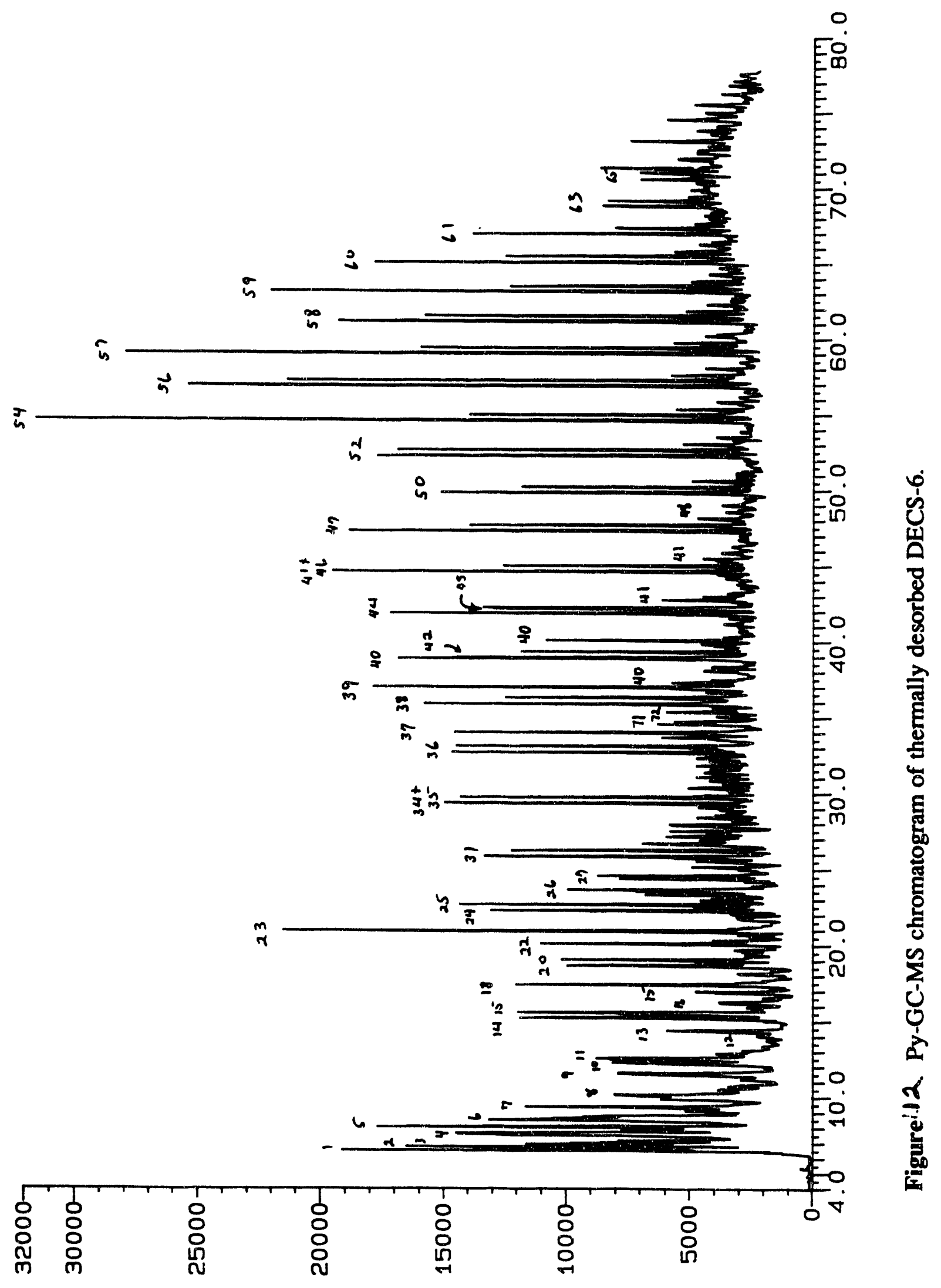




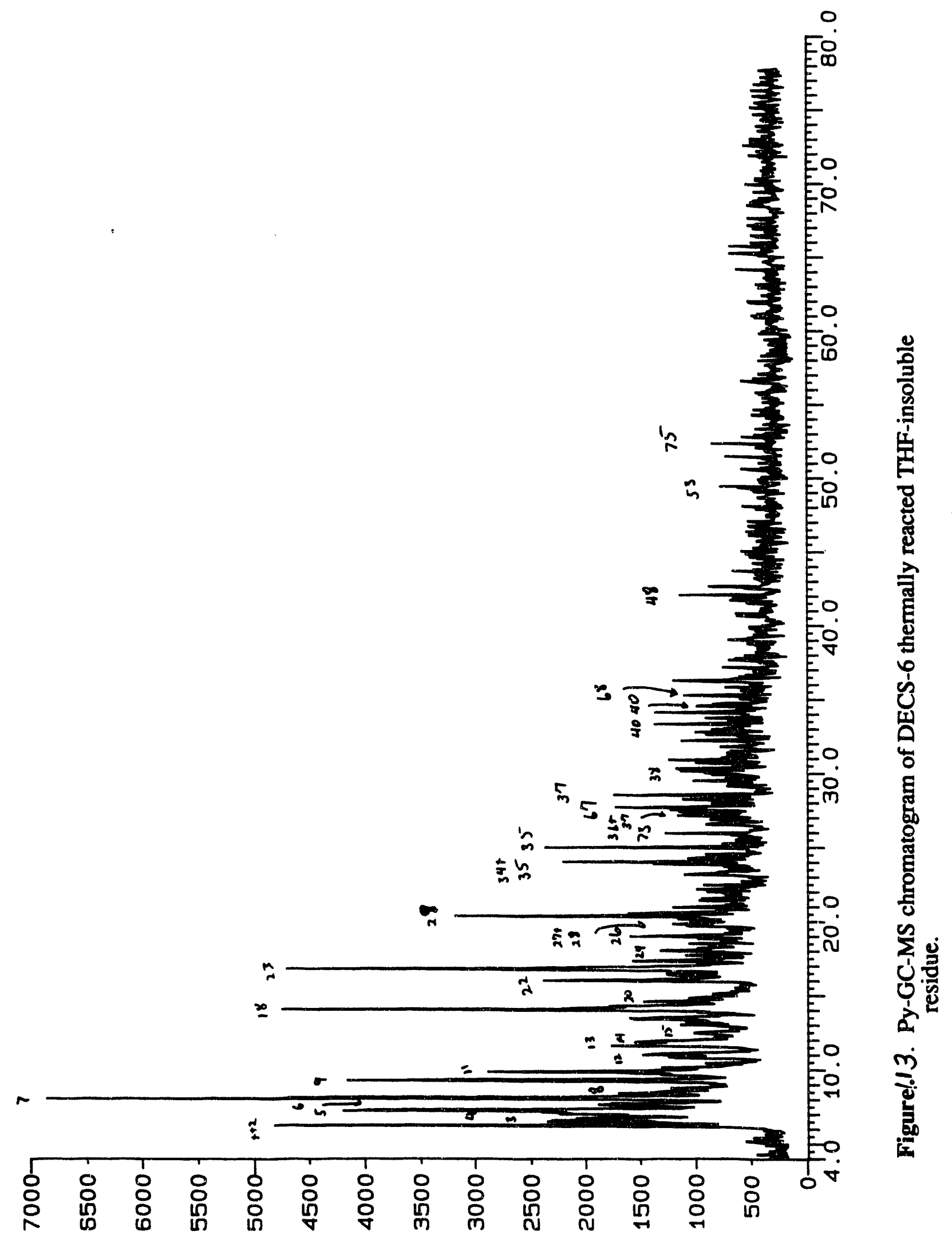




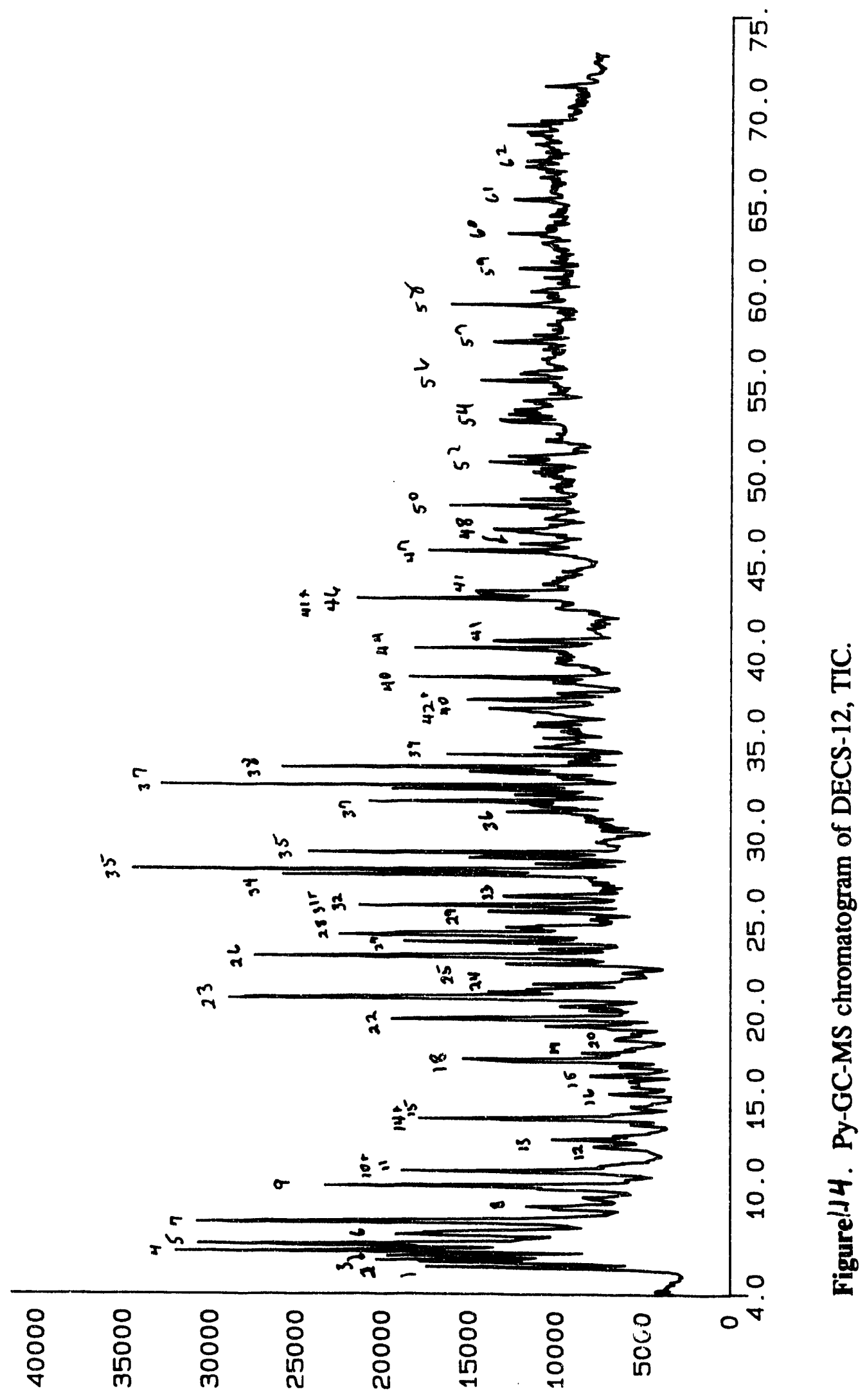




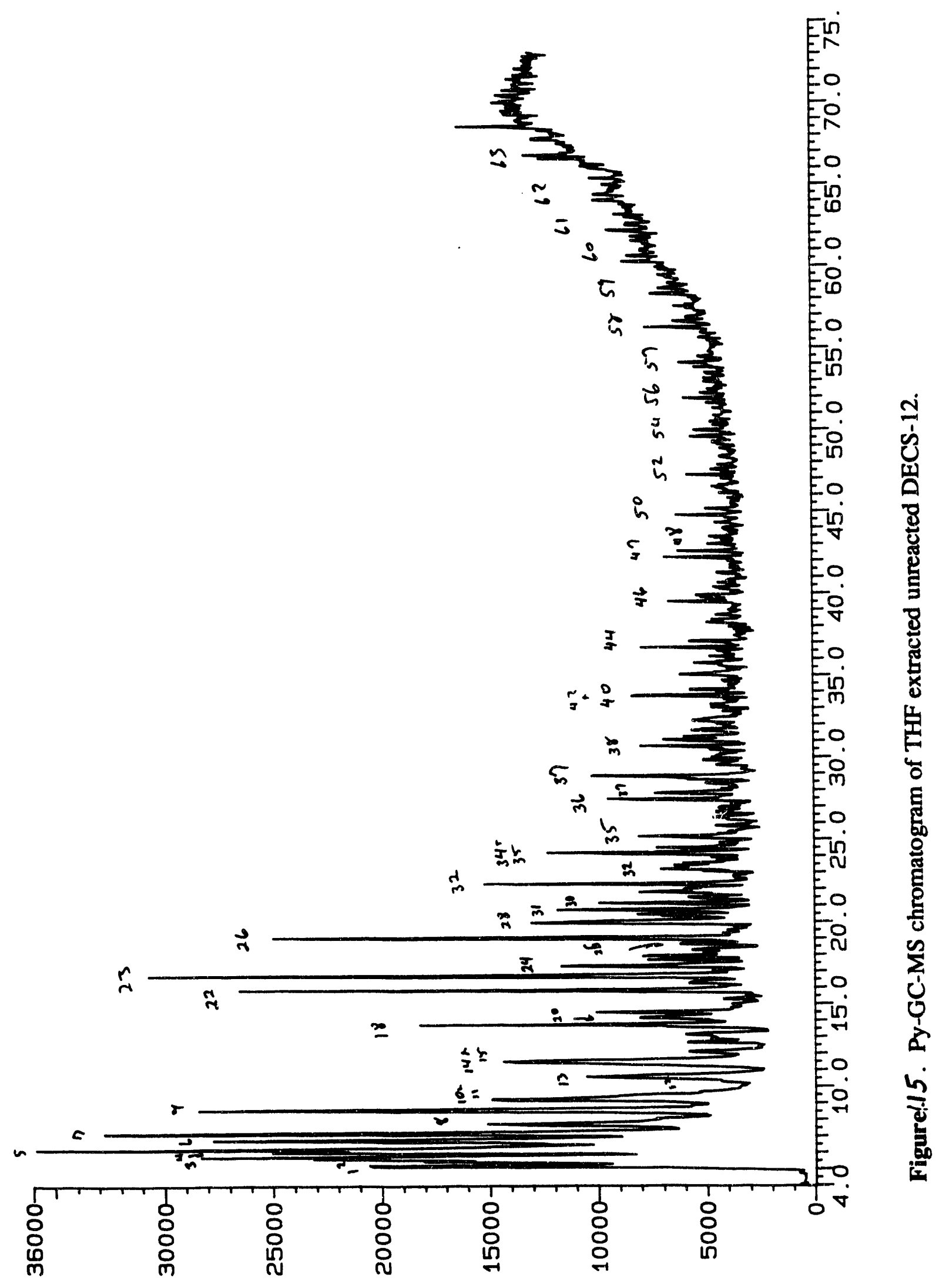




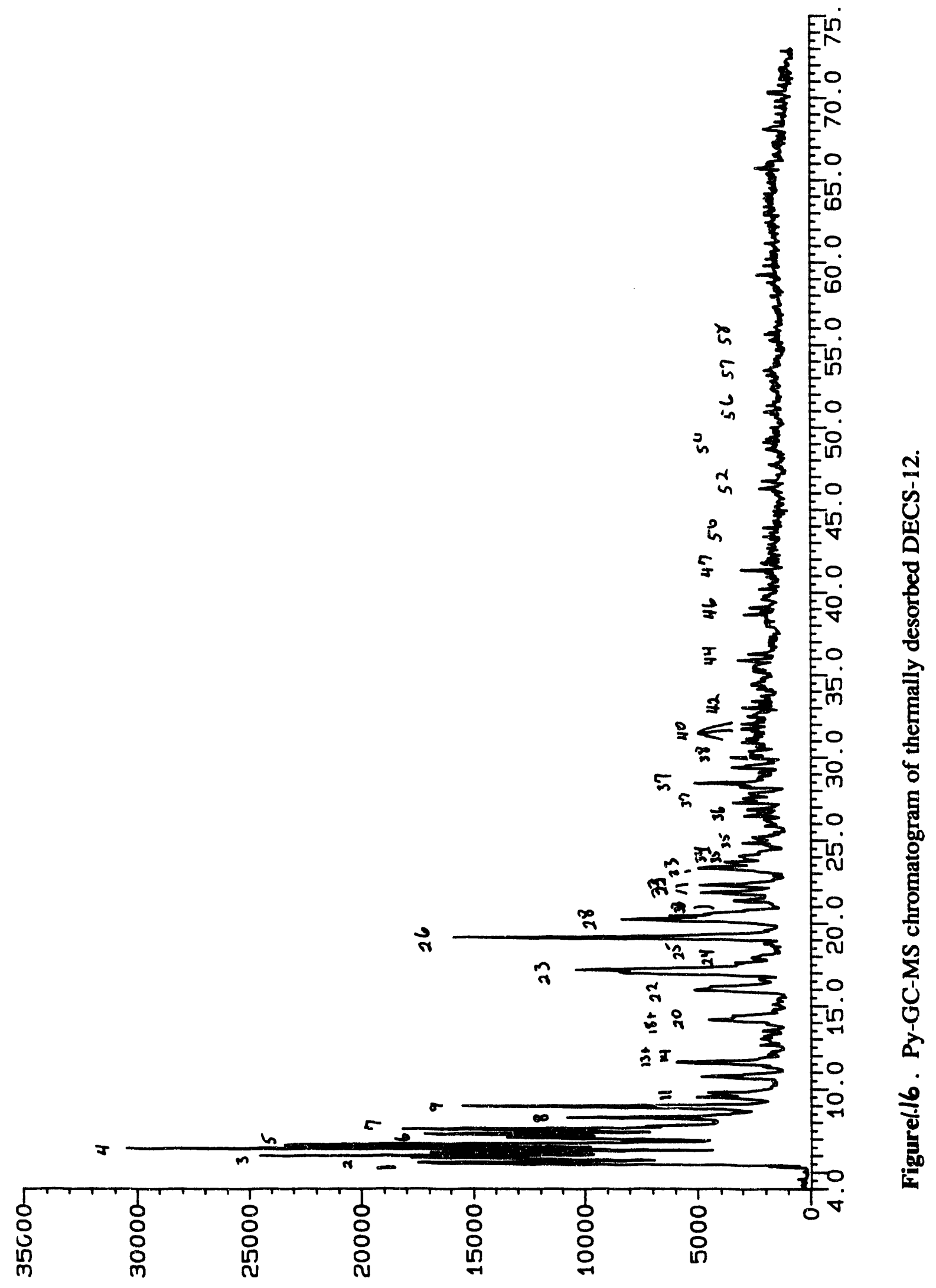




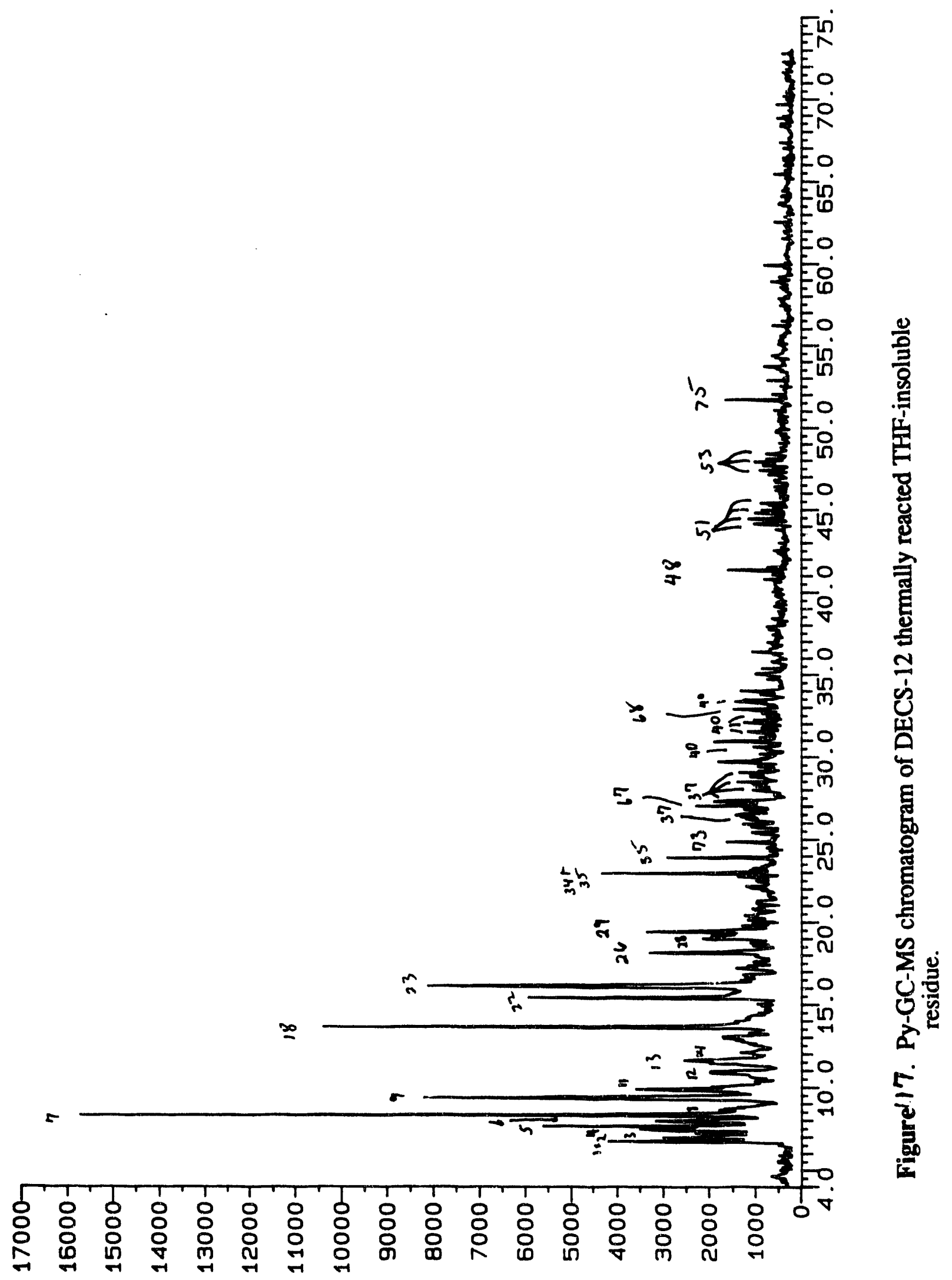


TIC

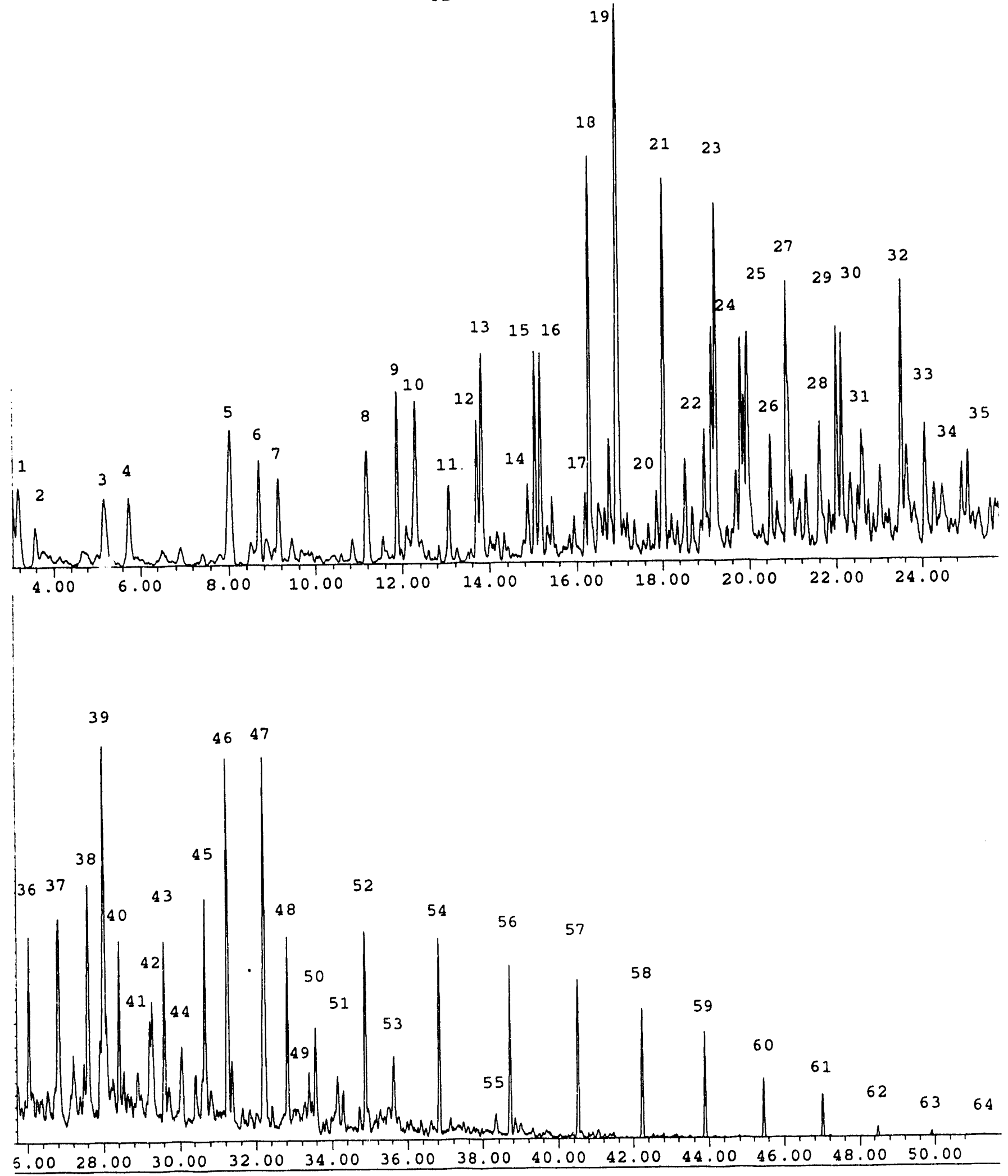

Figuref18. GC/MS chromatogram of the oil fraction of the reacted residue, DECS-7 


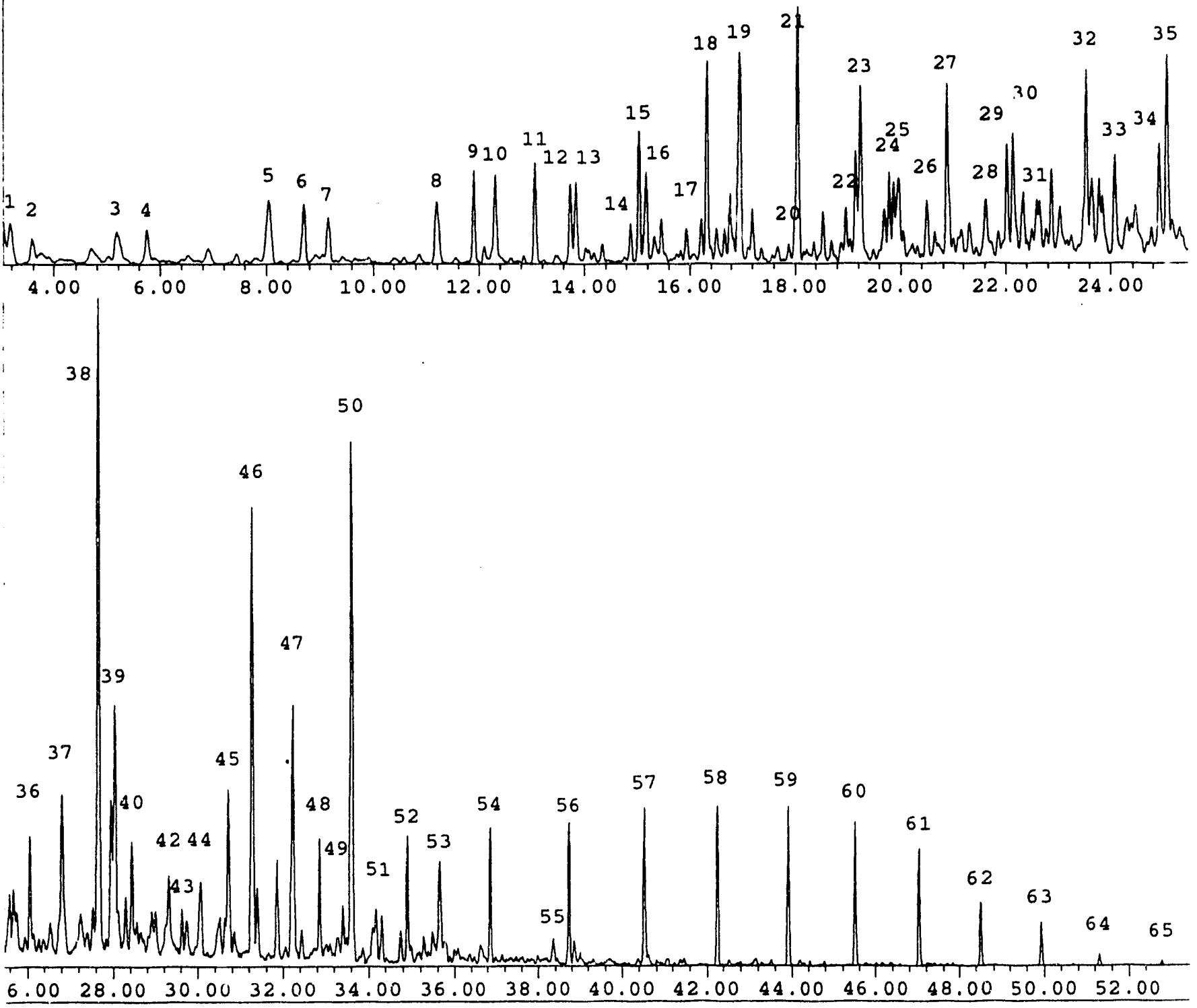

Figure.19. GC/MS chromatogram of the oil fraction of the reacted residue, DECS-6 
TIC:

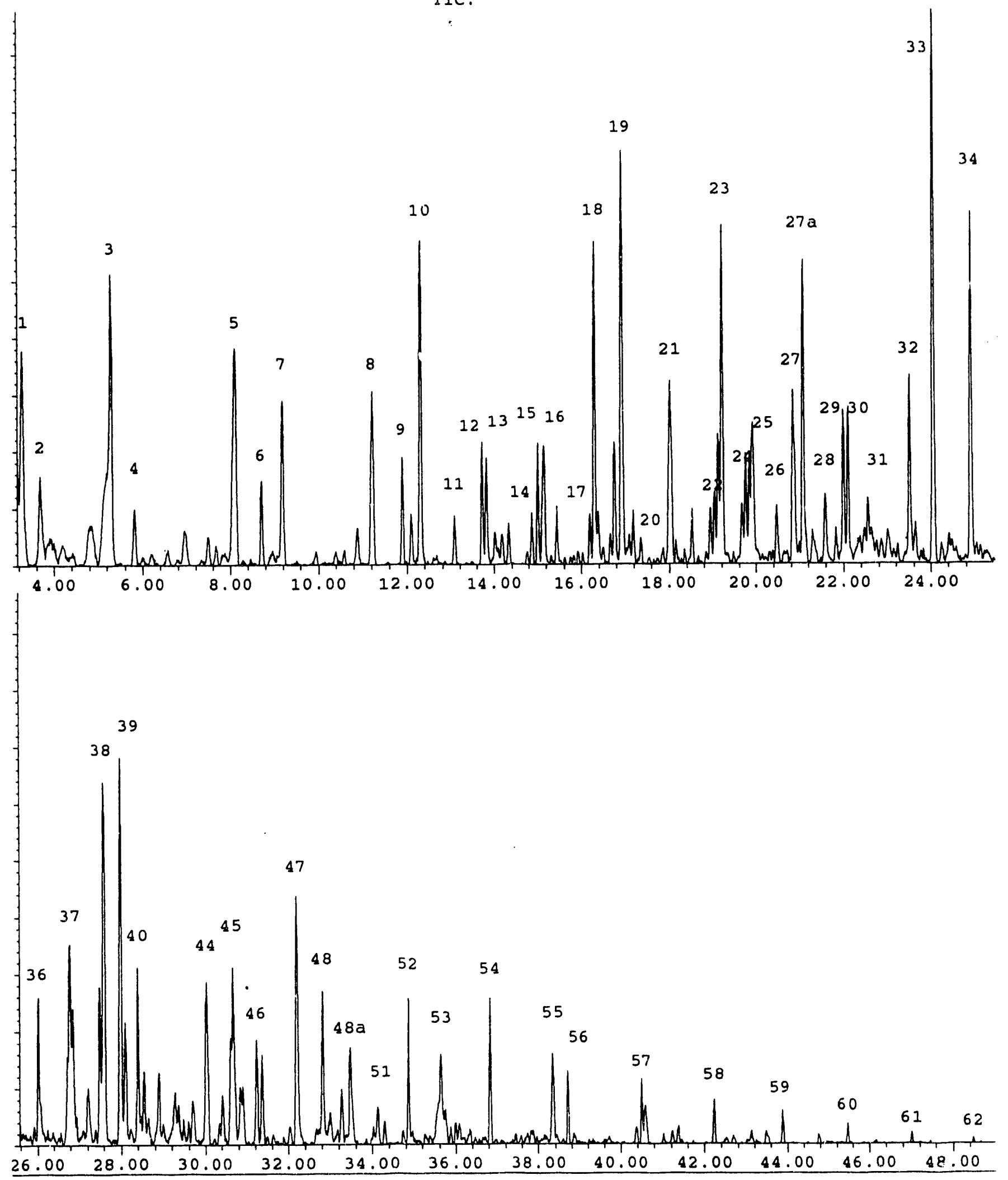

Figure20. $\begin{gathered}1.20 \\ \text { GC/MS chromatogram of the oil fraction of the reacted residue, DECS-12 }\end{gathered}$ 


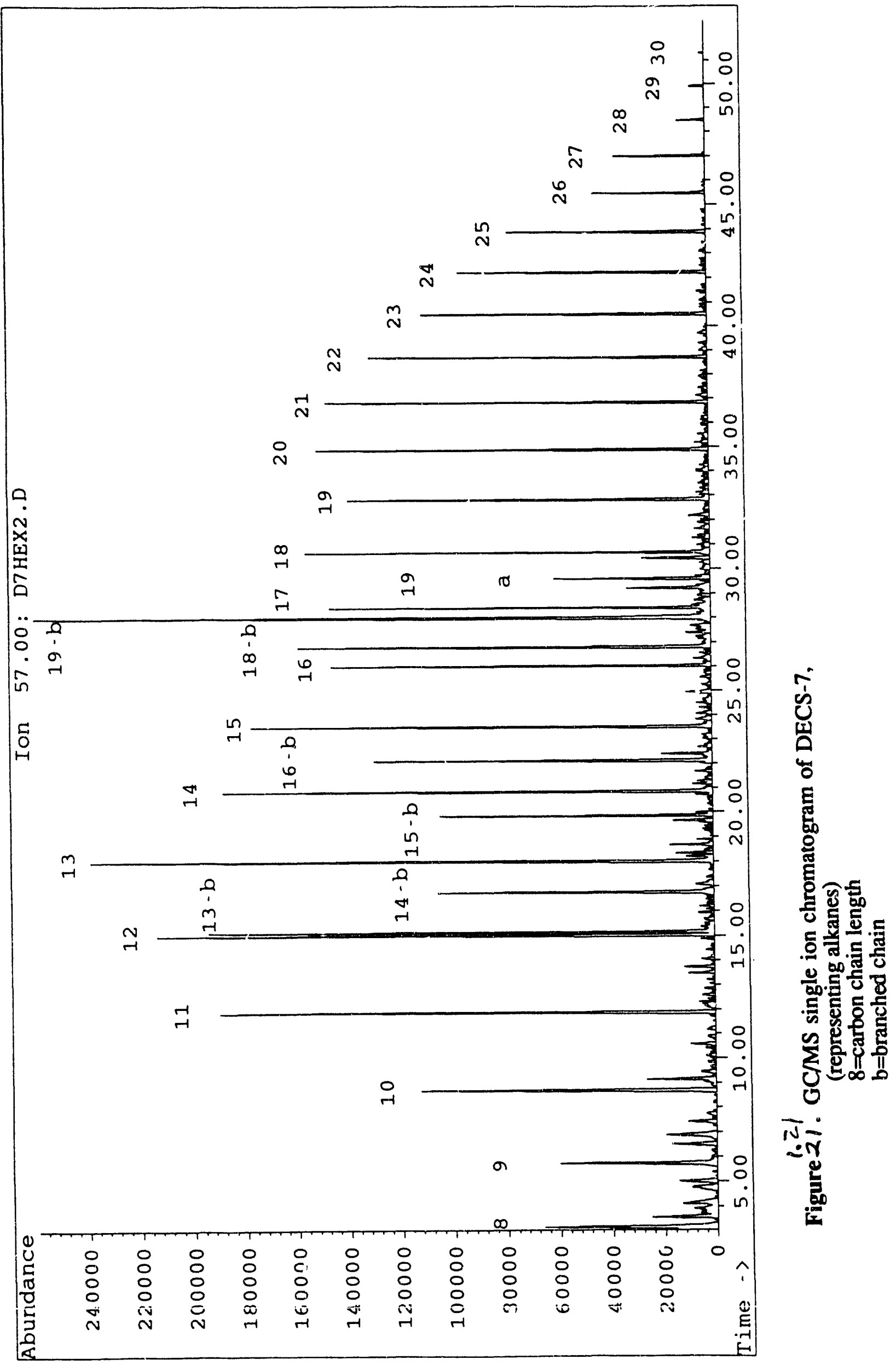




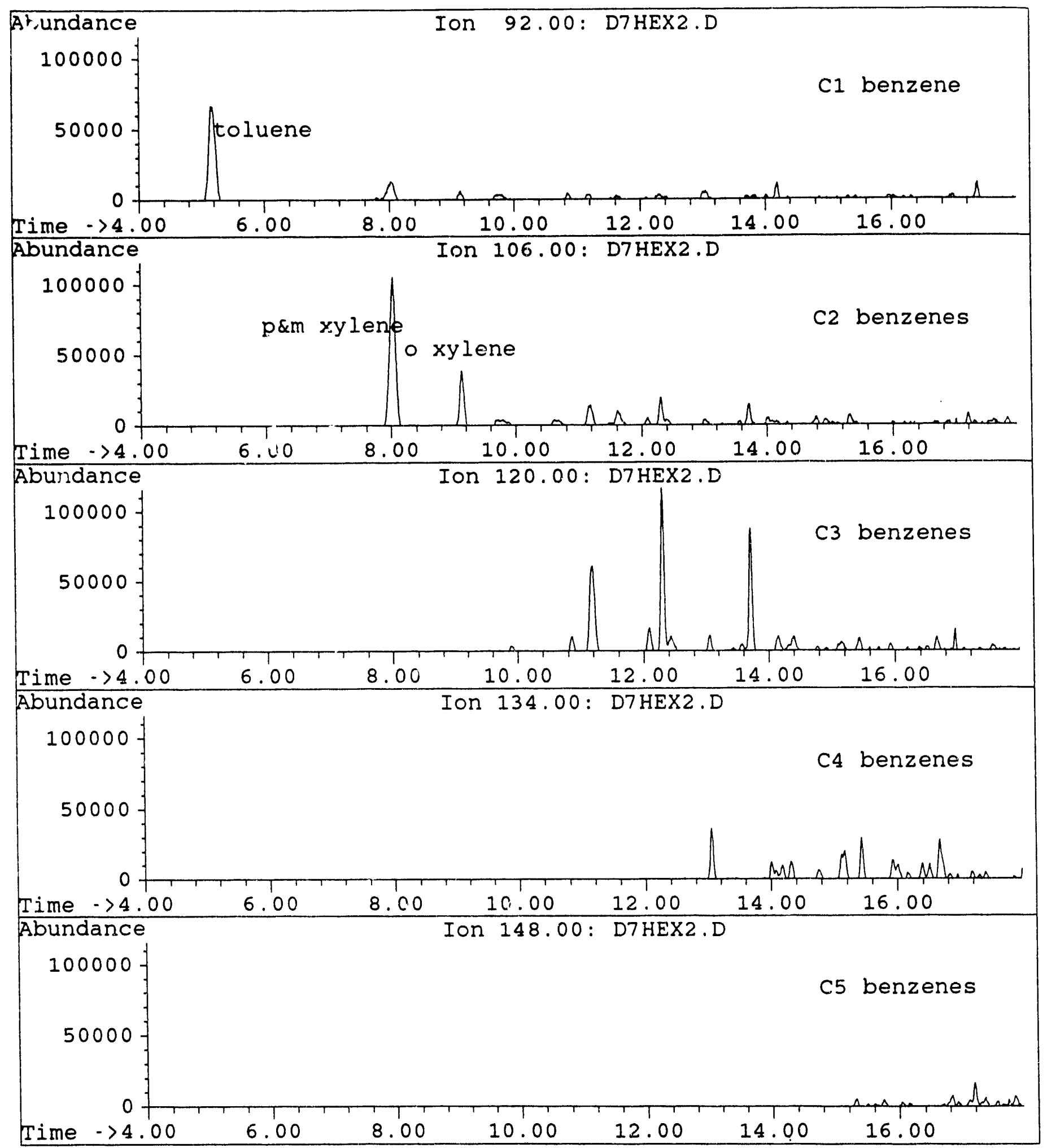

1.22

Figure 22 GC/MS single ion chromatogram of DECS-7, (representing benzene and alkyl benzenes) 


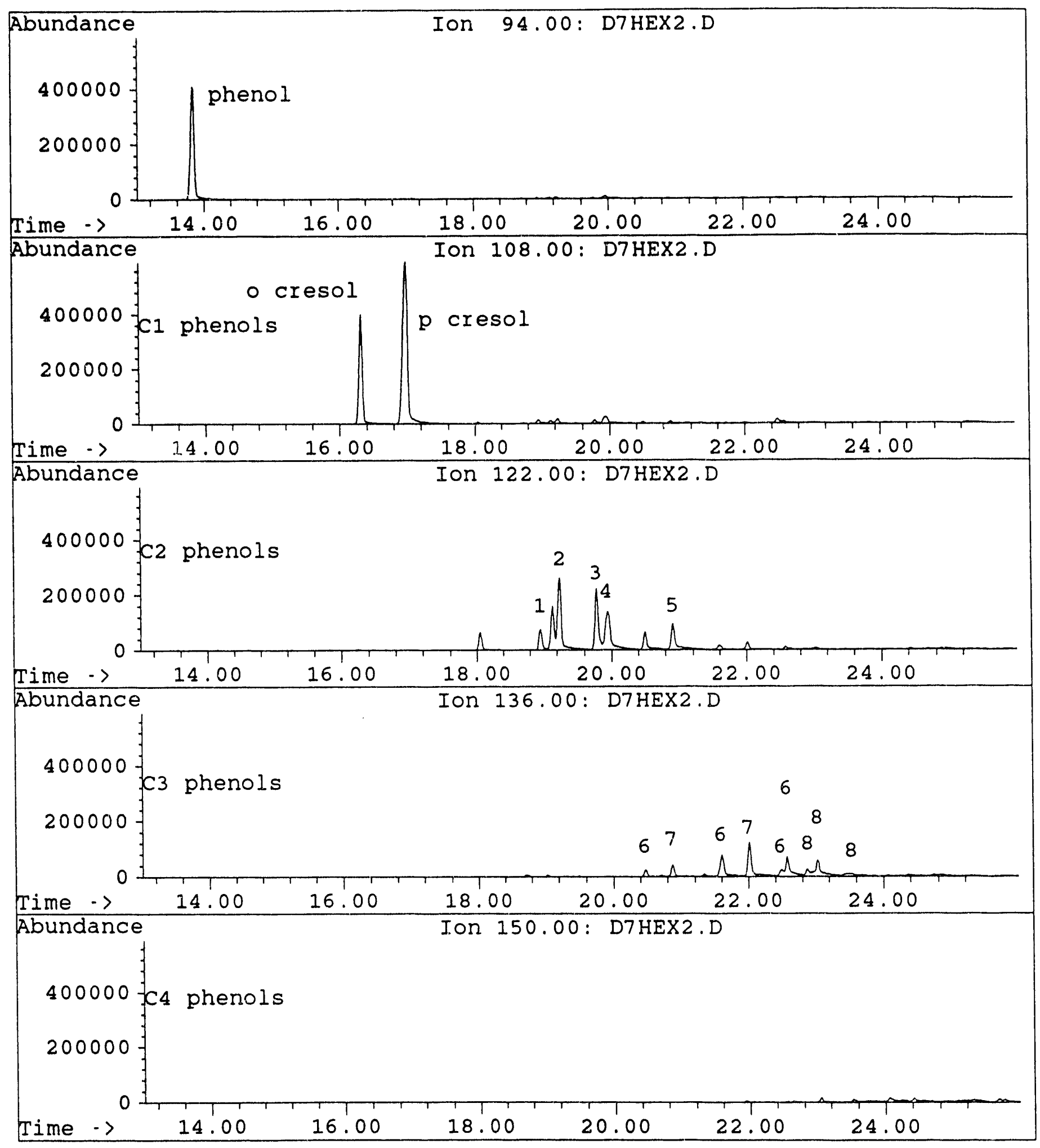

Figure'23. GC/MS single ion chromatogram of DECS-7, (representing phenol and alkyl phenols) 


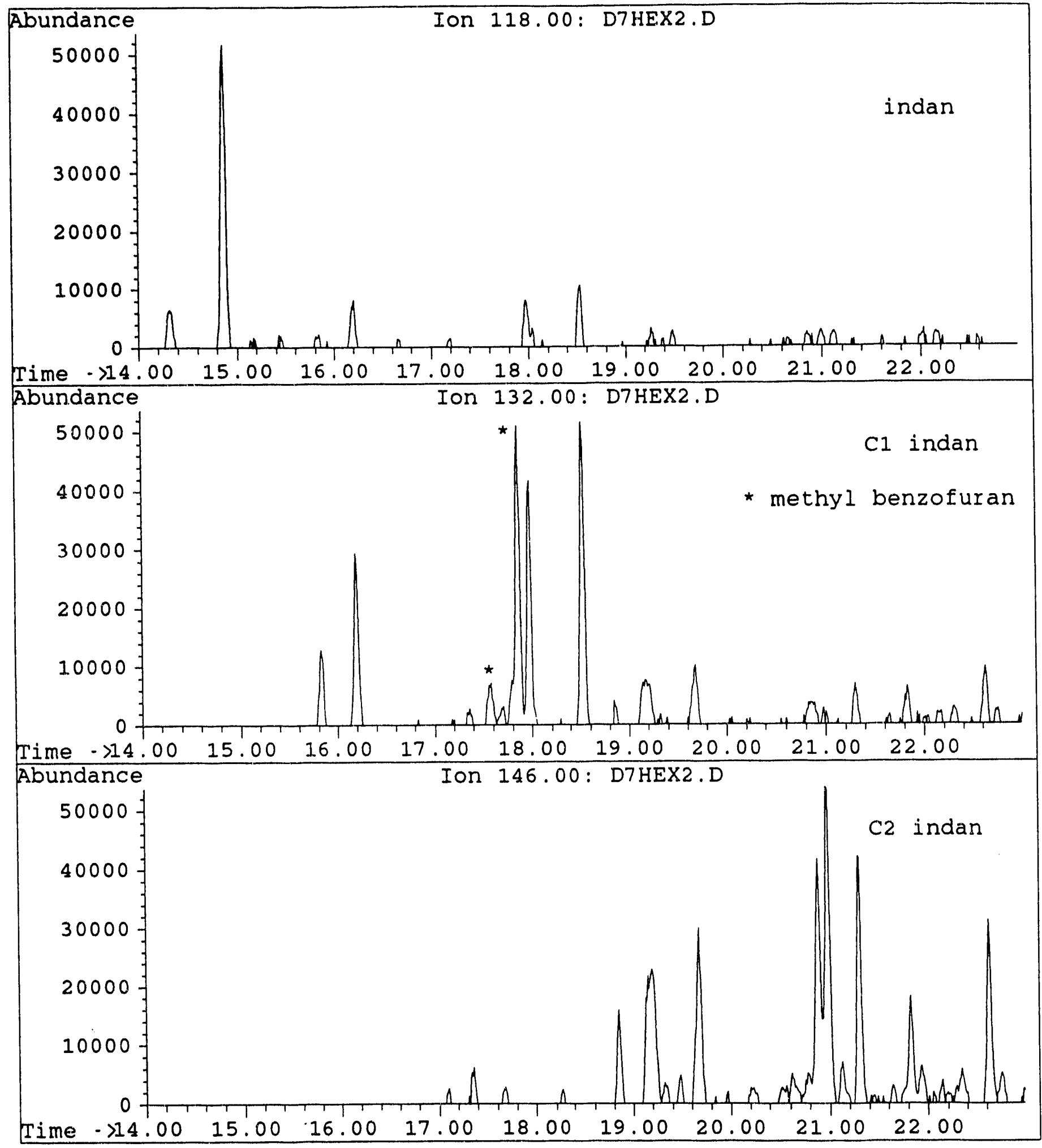

Figure 2 4. GC/MS single ion chromatogram of DECS-i (representing indan and alkyl indan) 


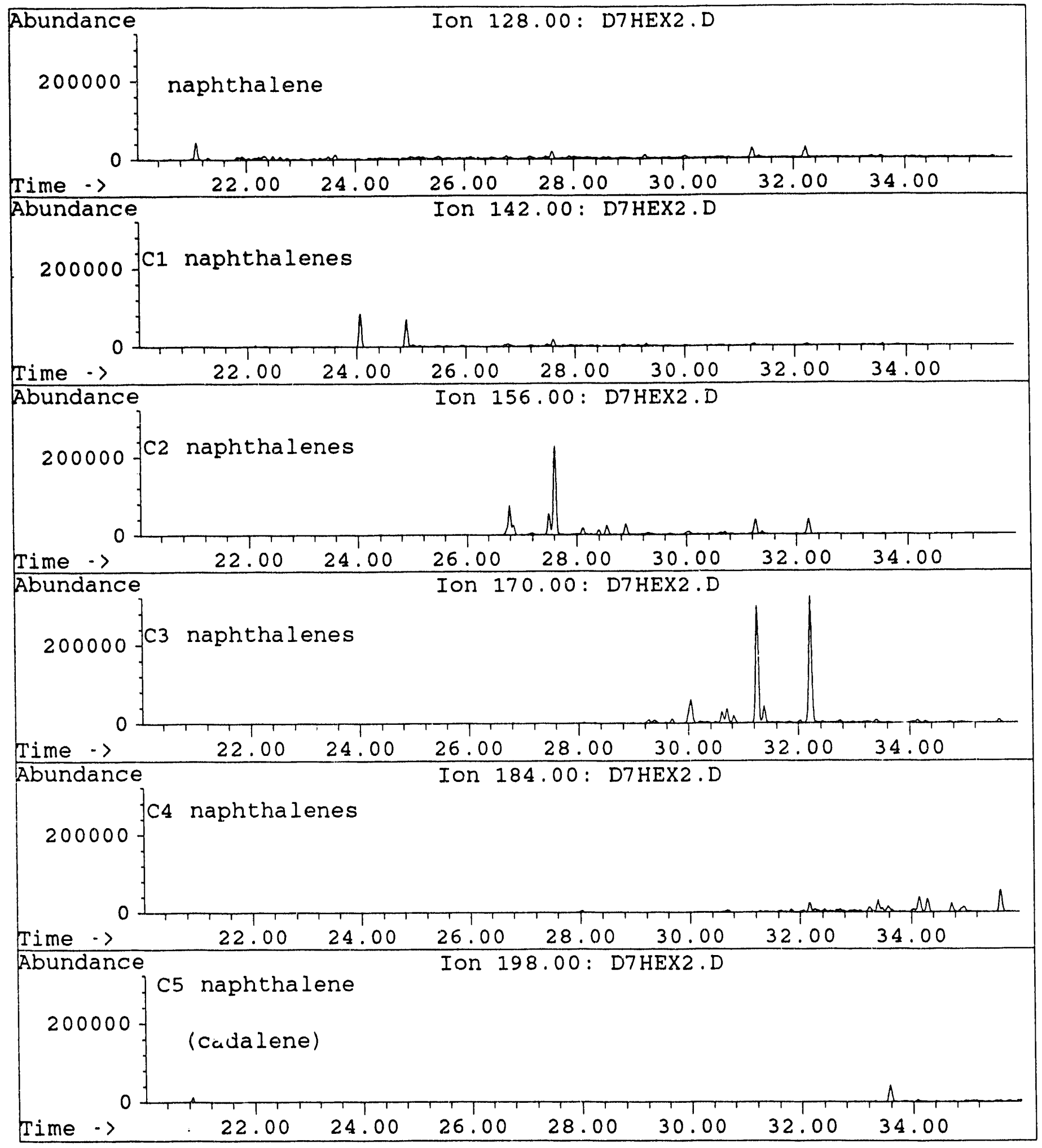

Figure'25. GC/MS single ion chromatogram of DECS-7, (representing naphthalene and alkyl naphthalene) 


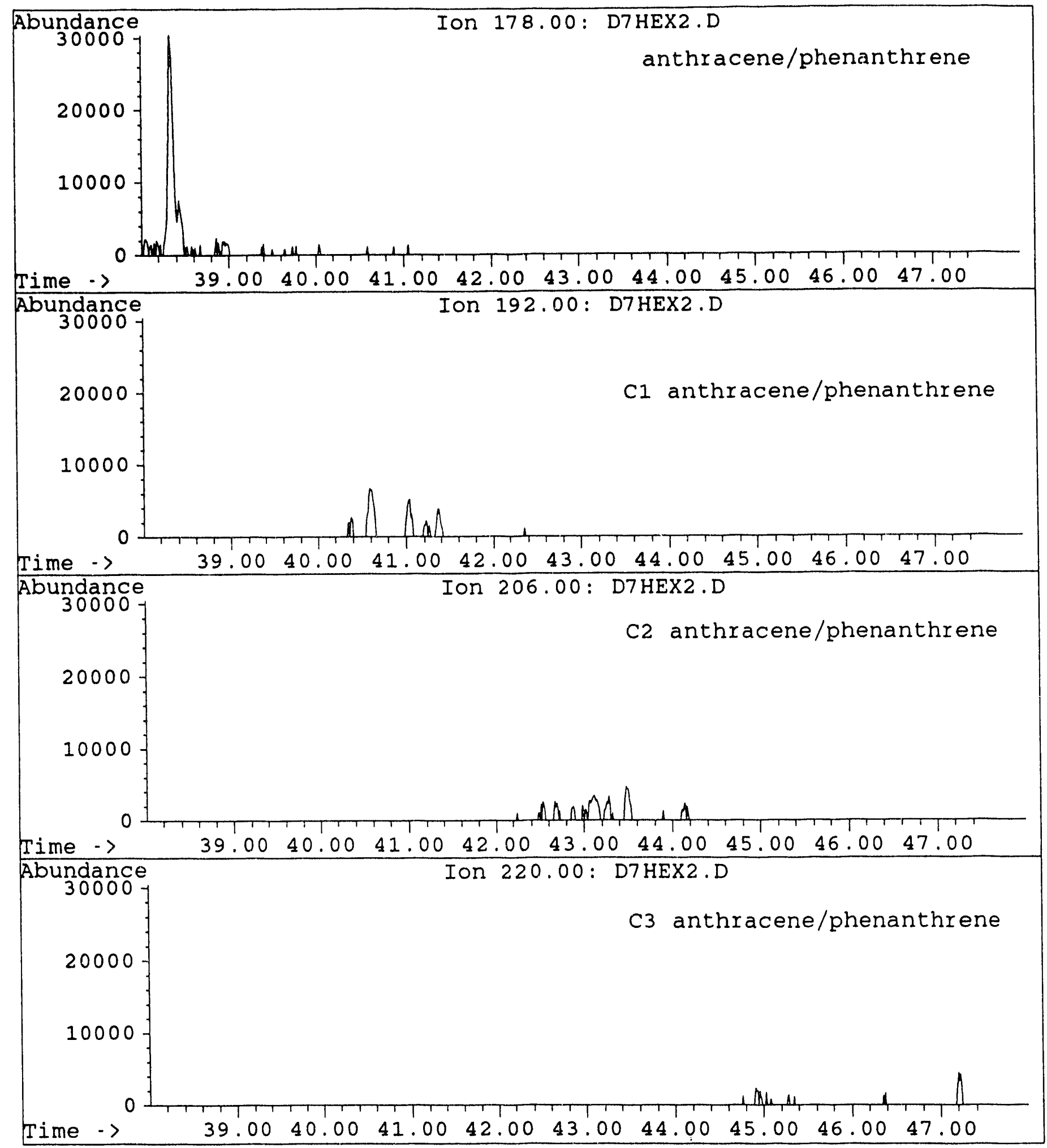

Figure' 26 6. GC/MS single ion chromatogram of DECS-7, (representing phenanthrene/anthracene and alkyl phen/anth) 


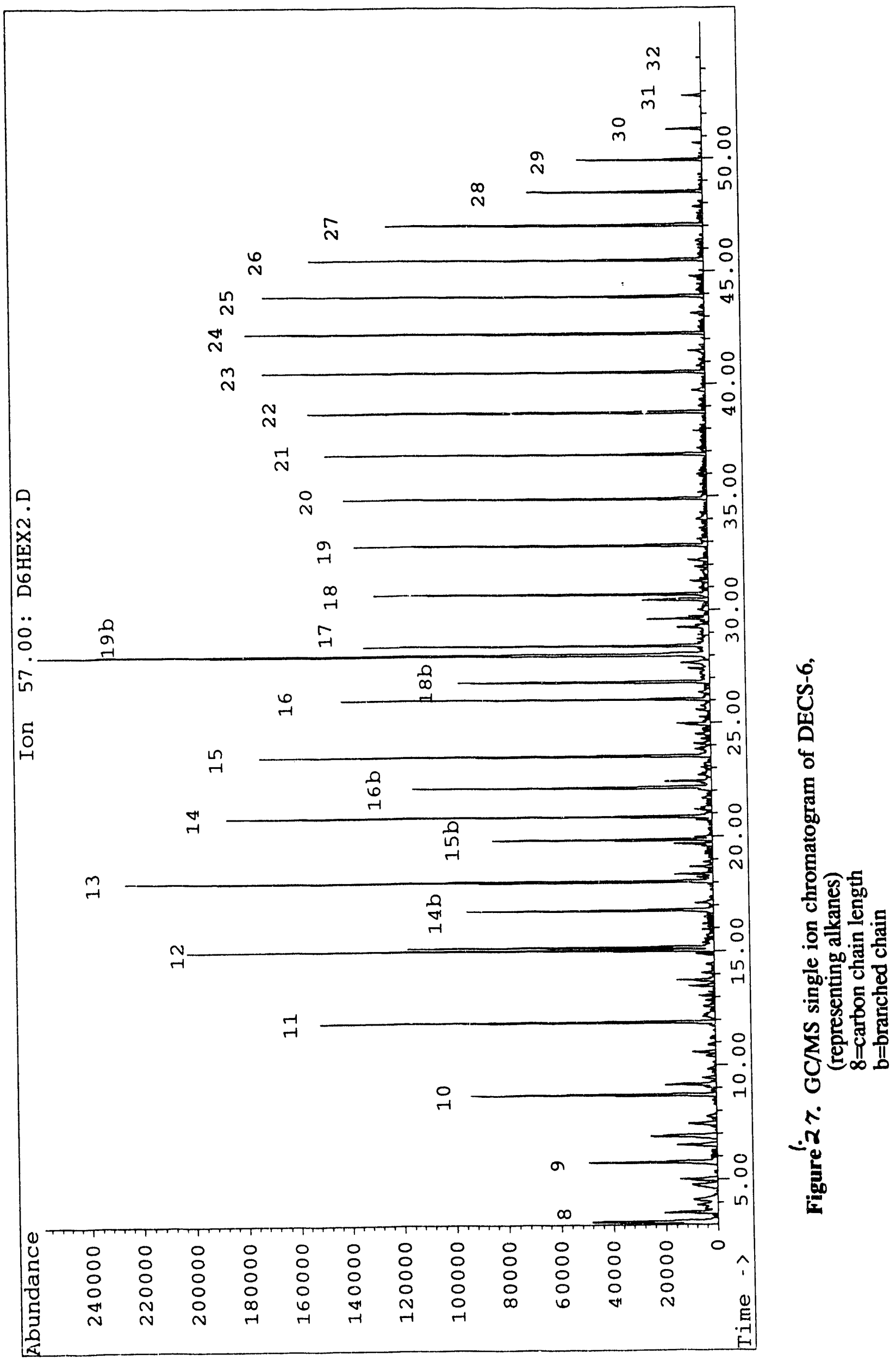




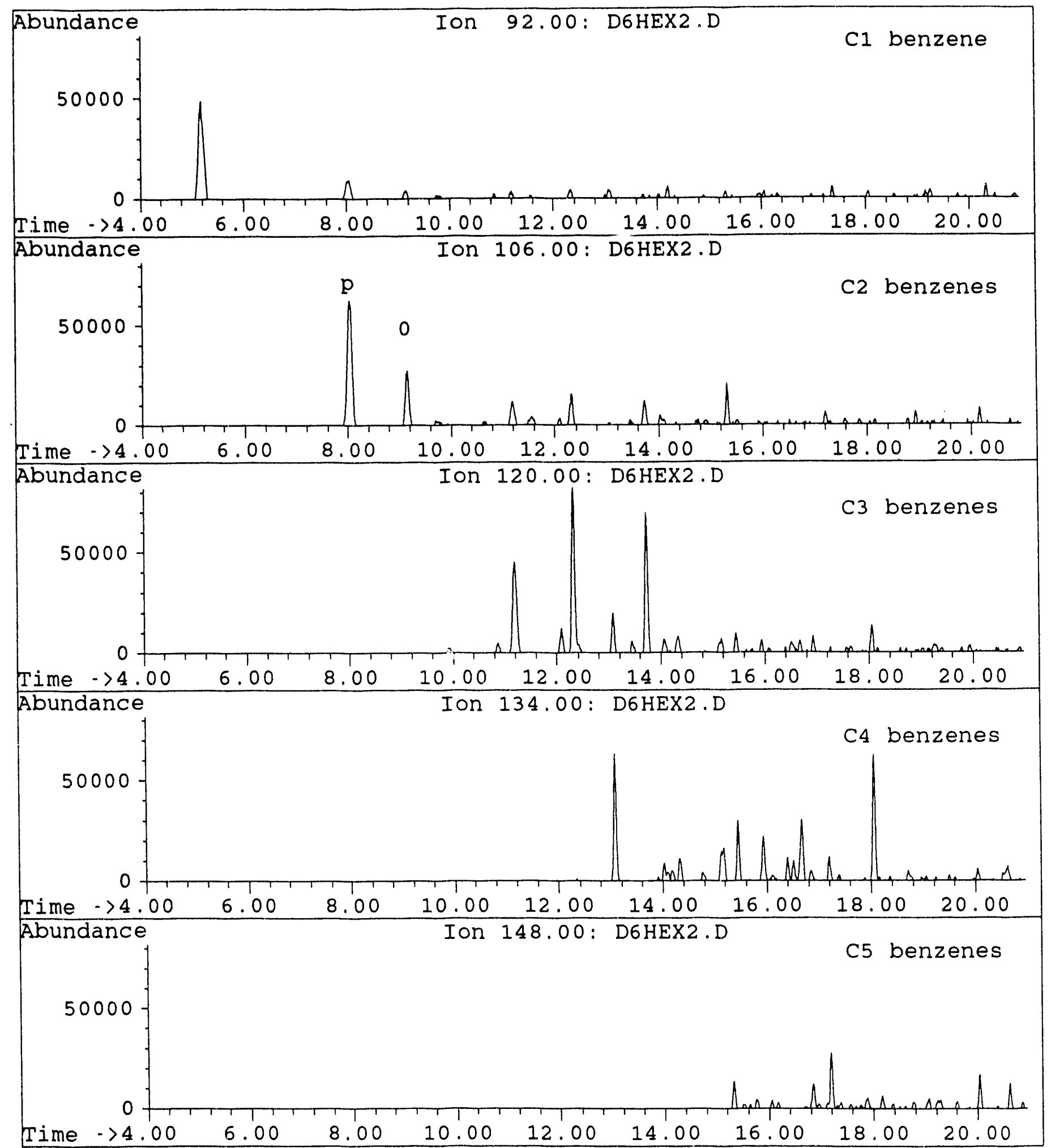

Figure'28. GC/MS single ion chromatogram of DECS-6, (representing benzene and alkyl benzenes) 


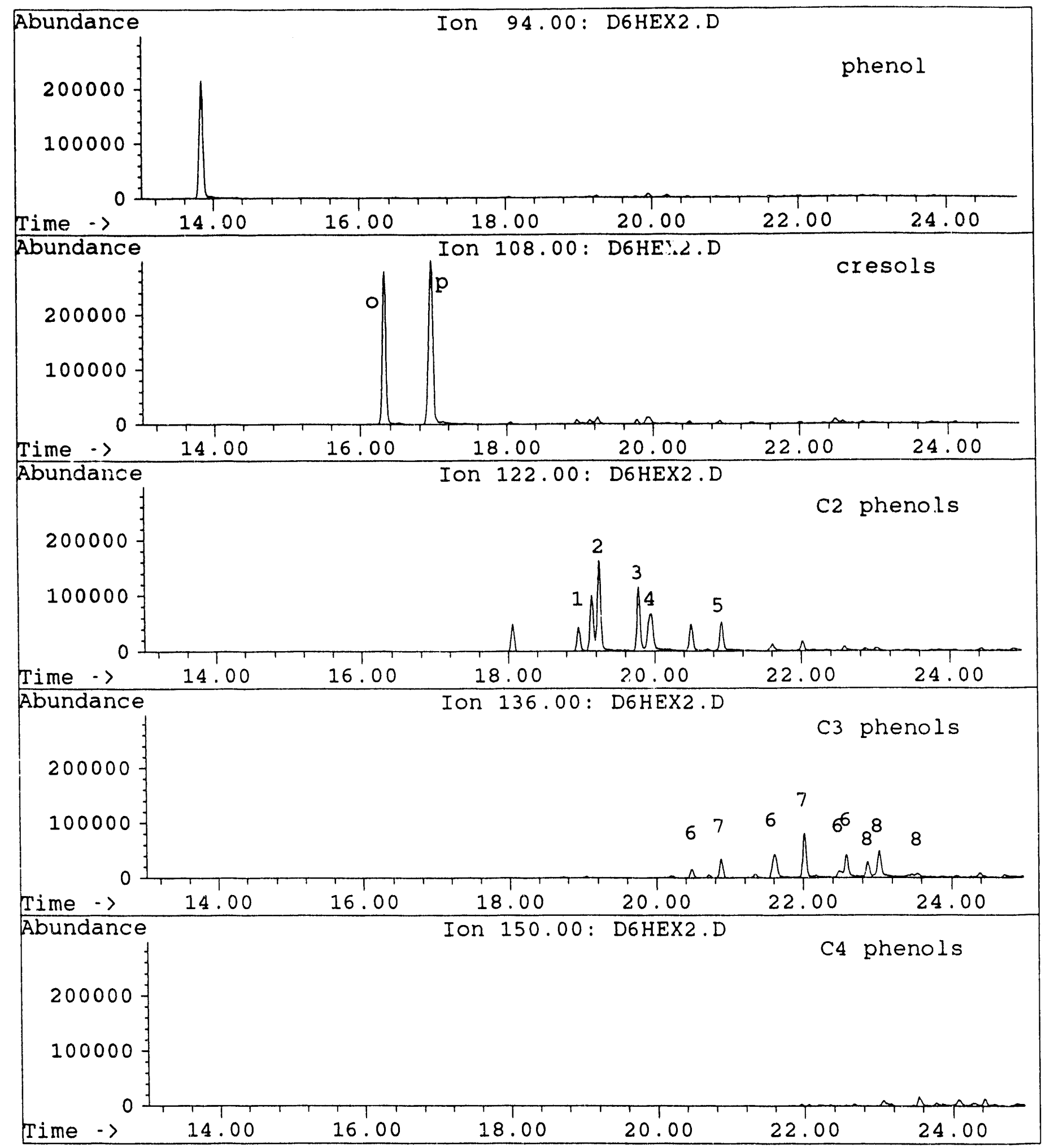

Figure'29. GC/MS single ion chromatogram of DECS-6, (representing phenol and alkyl phenols) 


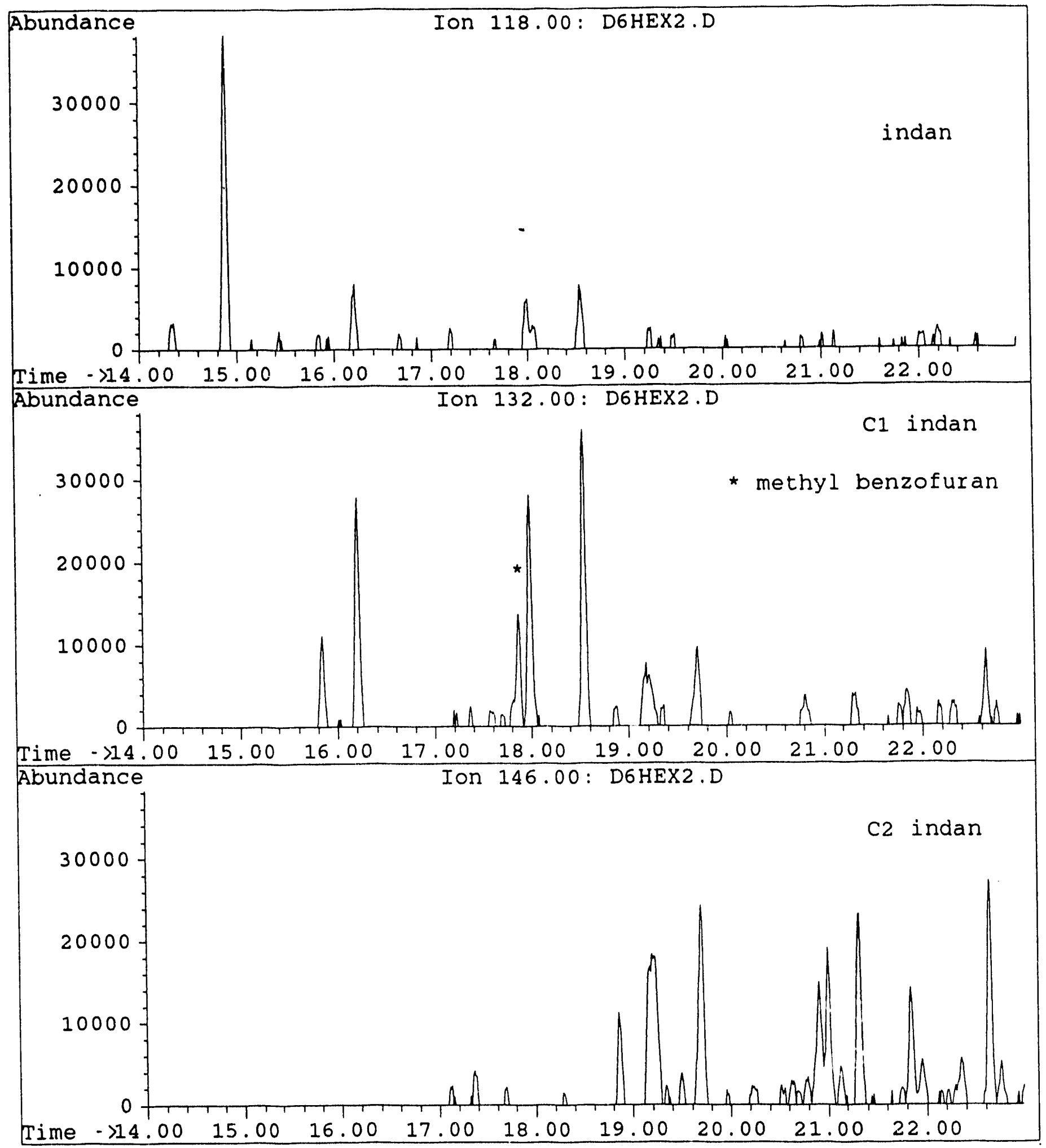

Figure ${ }^{1}$ 30. GC/MS single ion chromatogram of DECS-6, (representing indan and alkyl indan) 


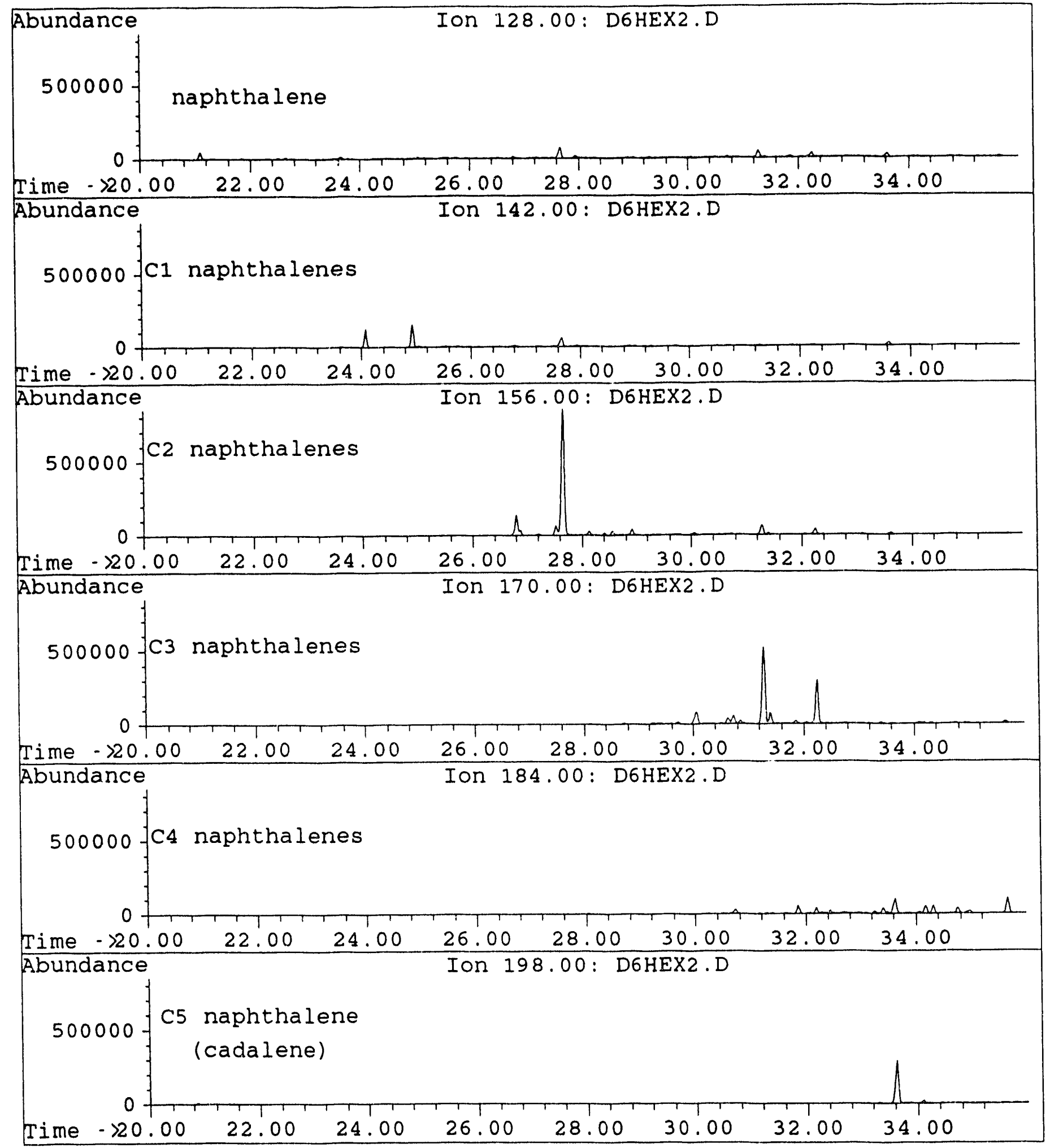

Figure $^{\prime} 31$. GC/MS single ion chromatogram of DECS-6 (representing naphthalene and alkyl naphthalene) 


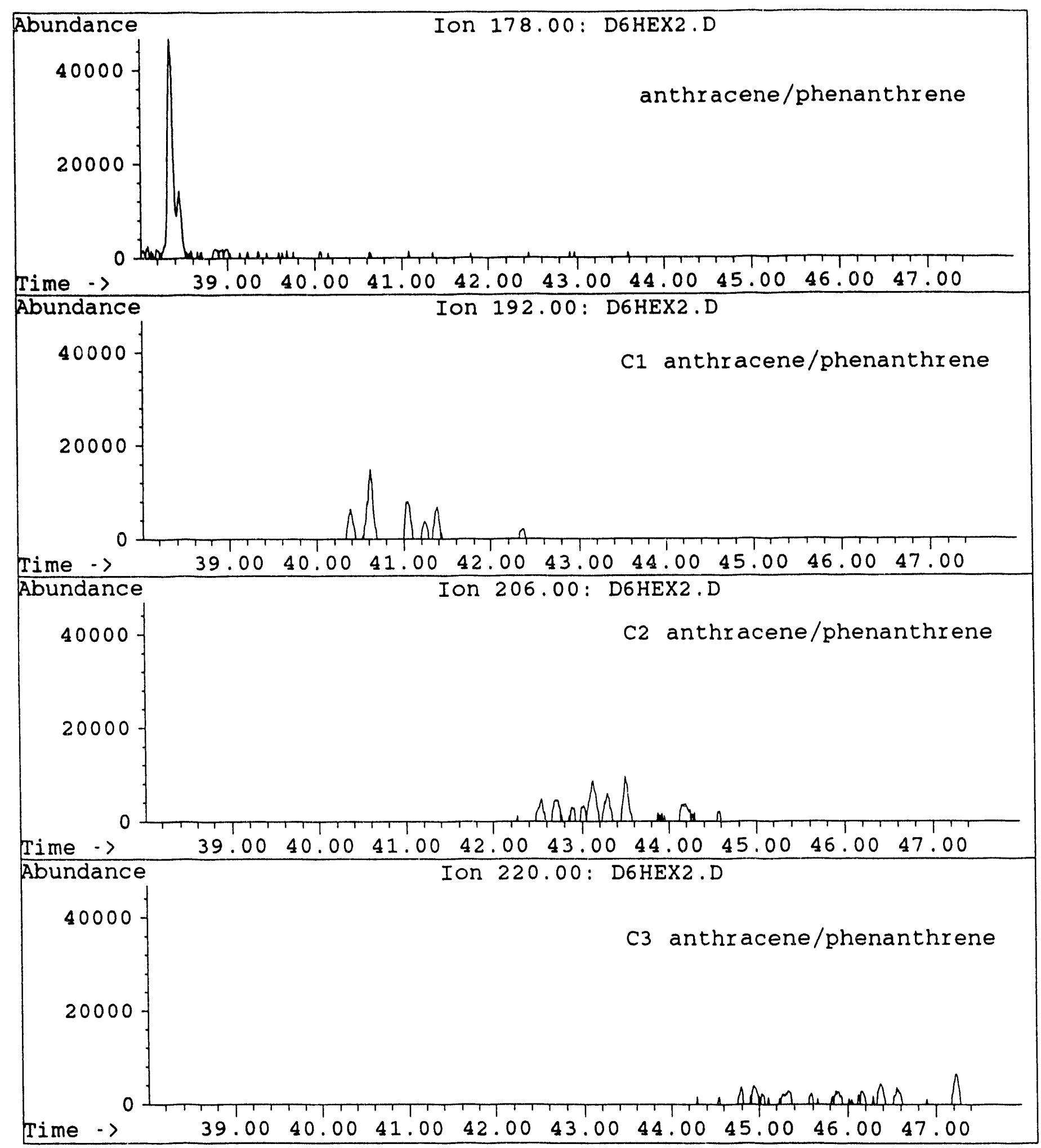

Figure $\mathfrak{1}^{\mathbf{3}} 2$. GC/MS single ion chromatogram of DECS-6, (representing phenanthrene/anthracene and alkyl phen/anth) 


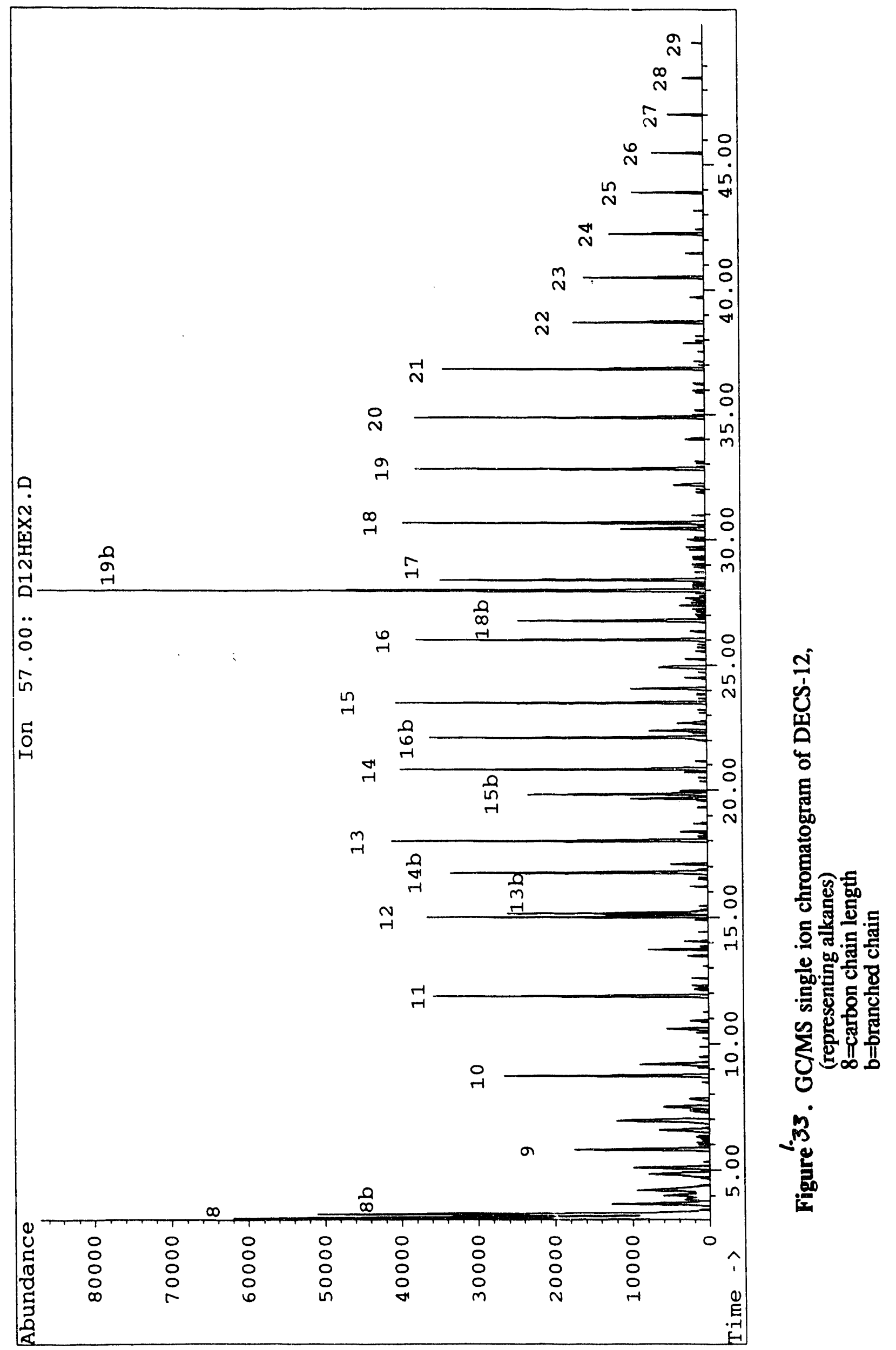




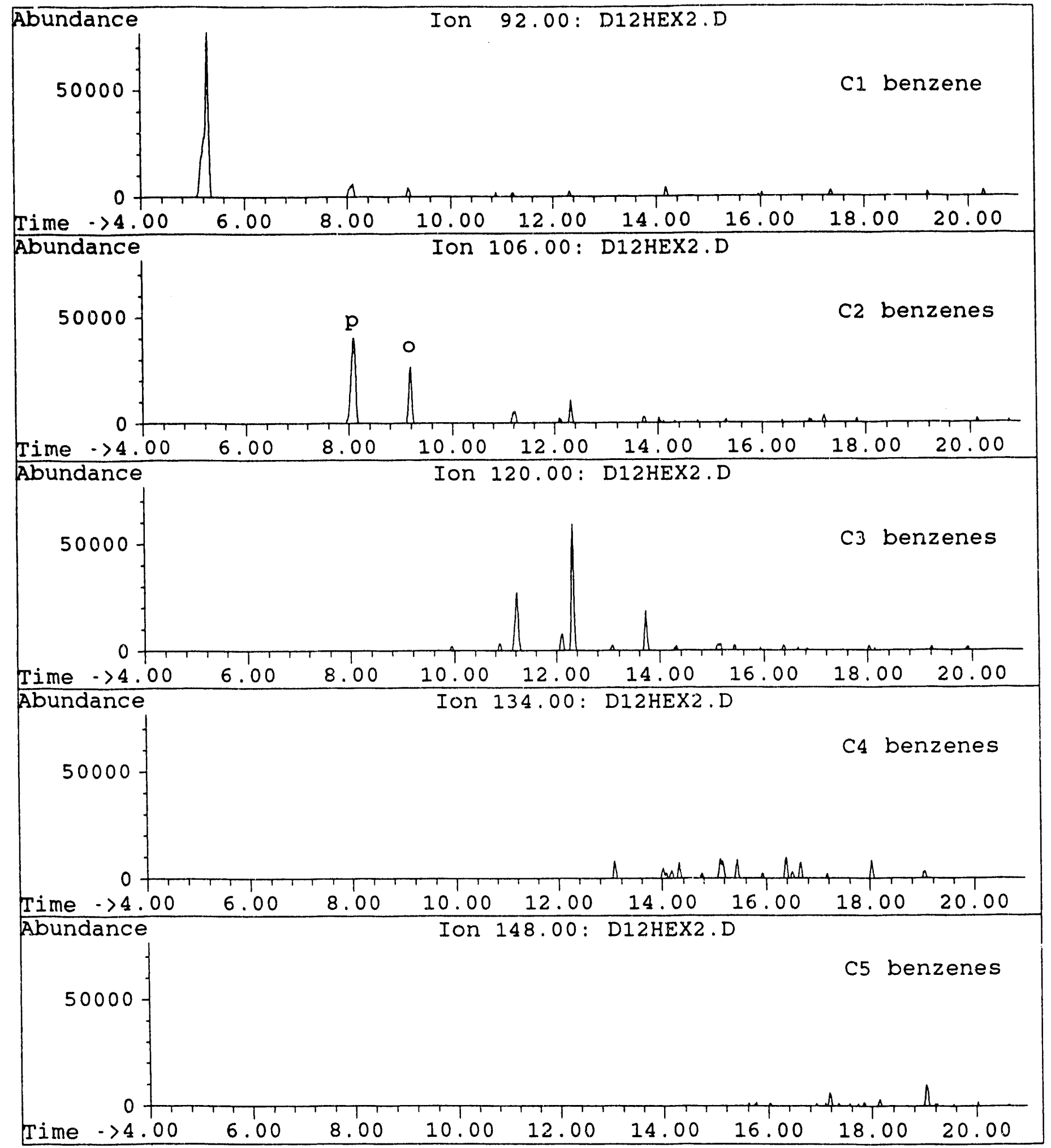

Figure 34 . GC/MS single ion chromatogram of DECS-12, (representing benzene and alkyl benzenes) 


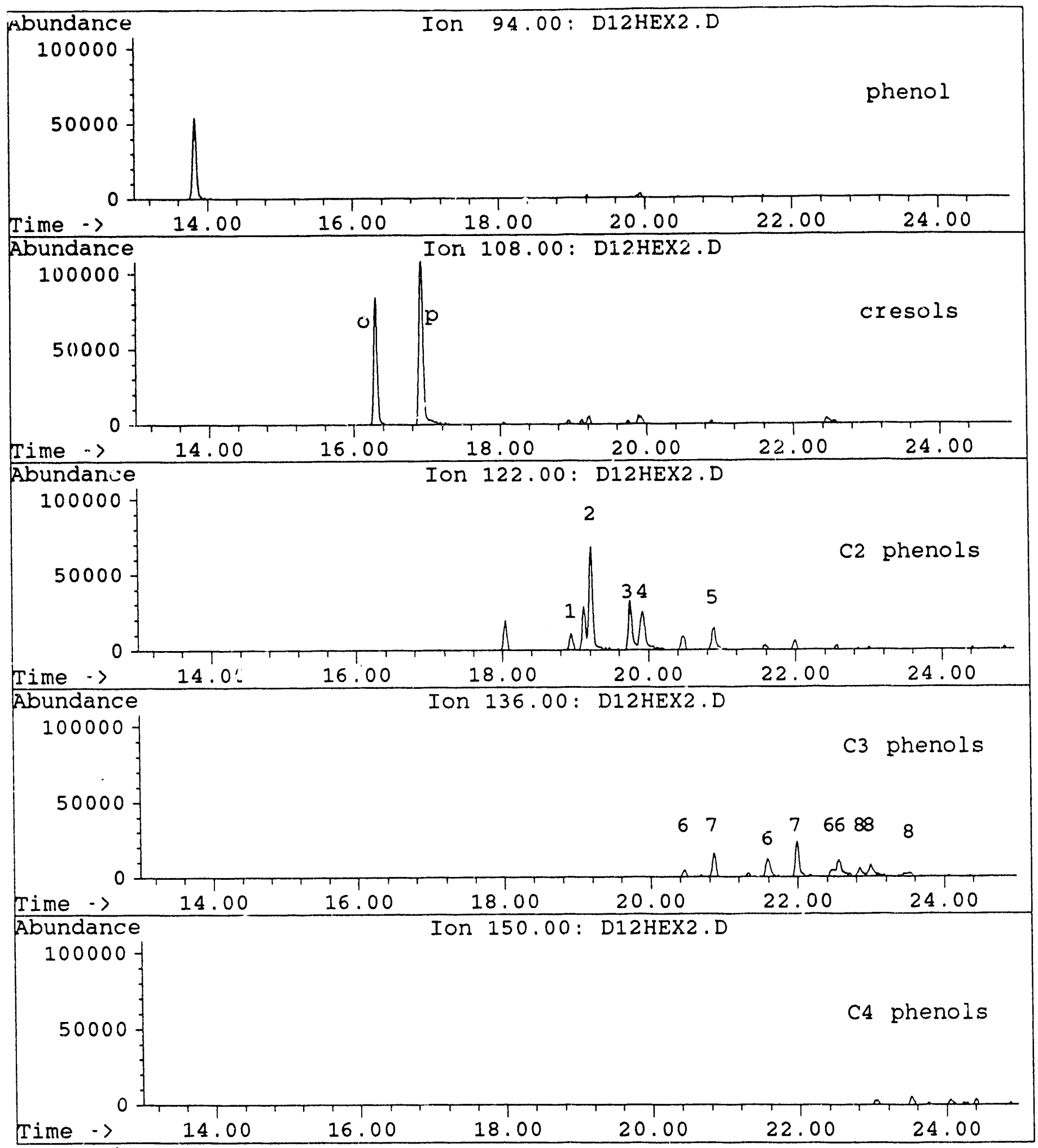

Figure ${ }^{\text {' }}$ 5. GC/MS single ion chromatogram of DECS-12, (representing phenol and alkyl phenols) 


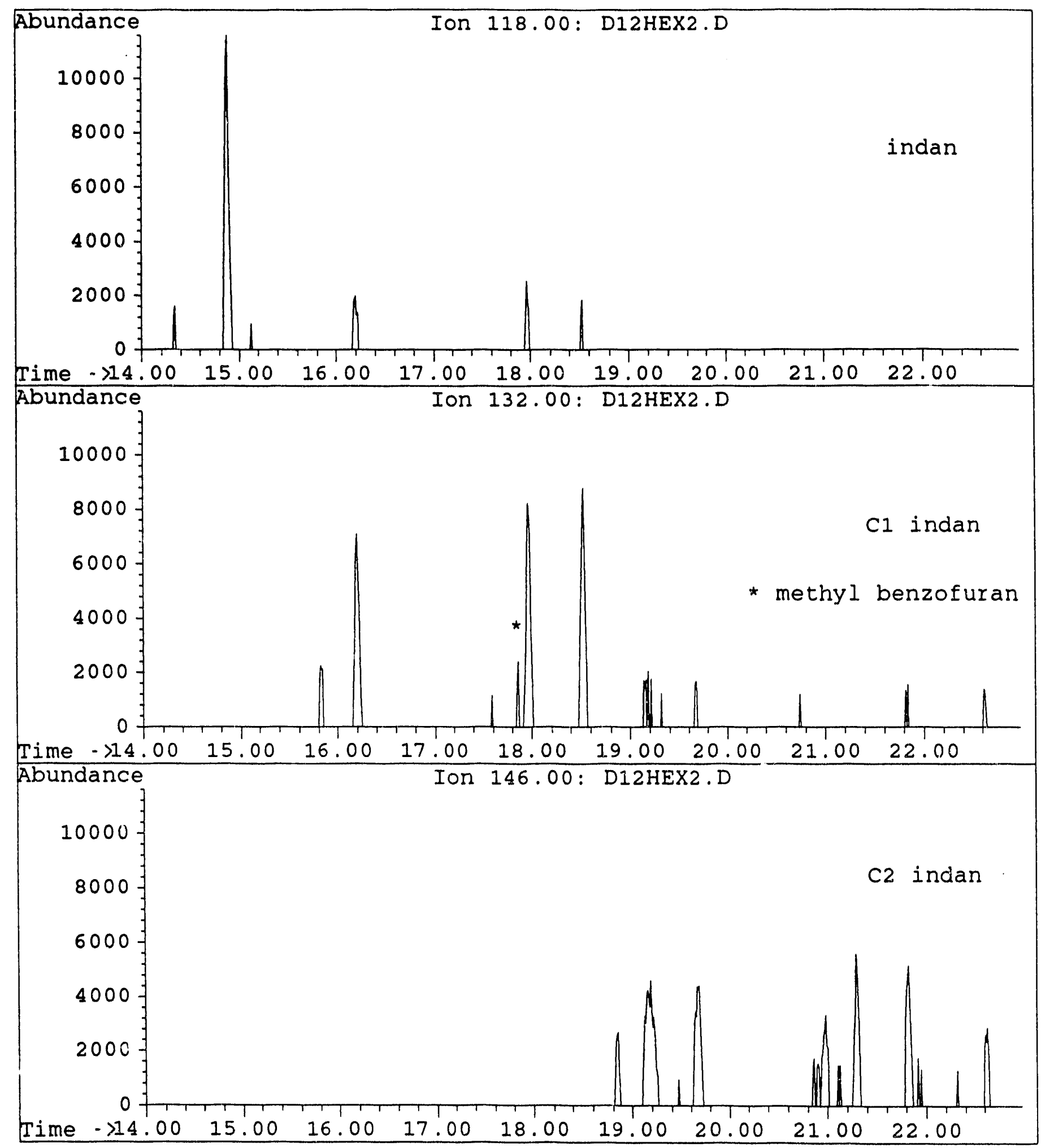

Figure'36. GC/MS single ion chromatogram of DECS-12, (representing indan and alkyl indan) 


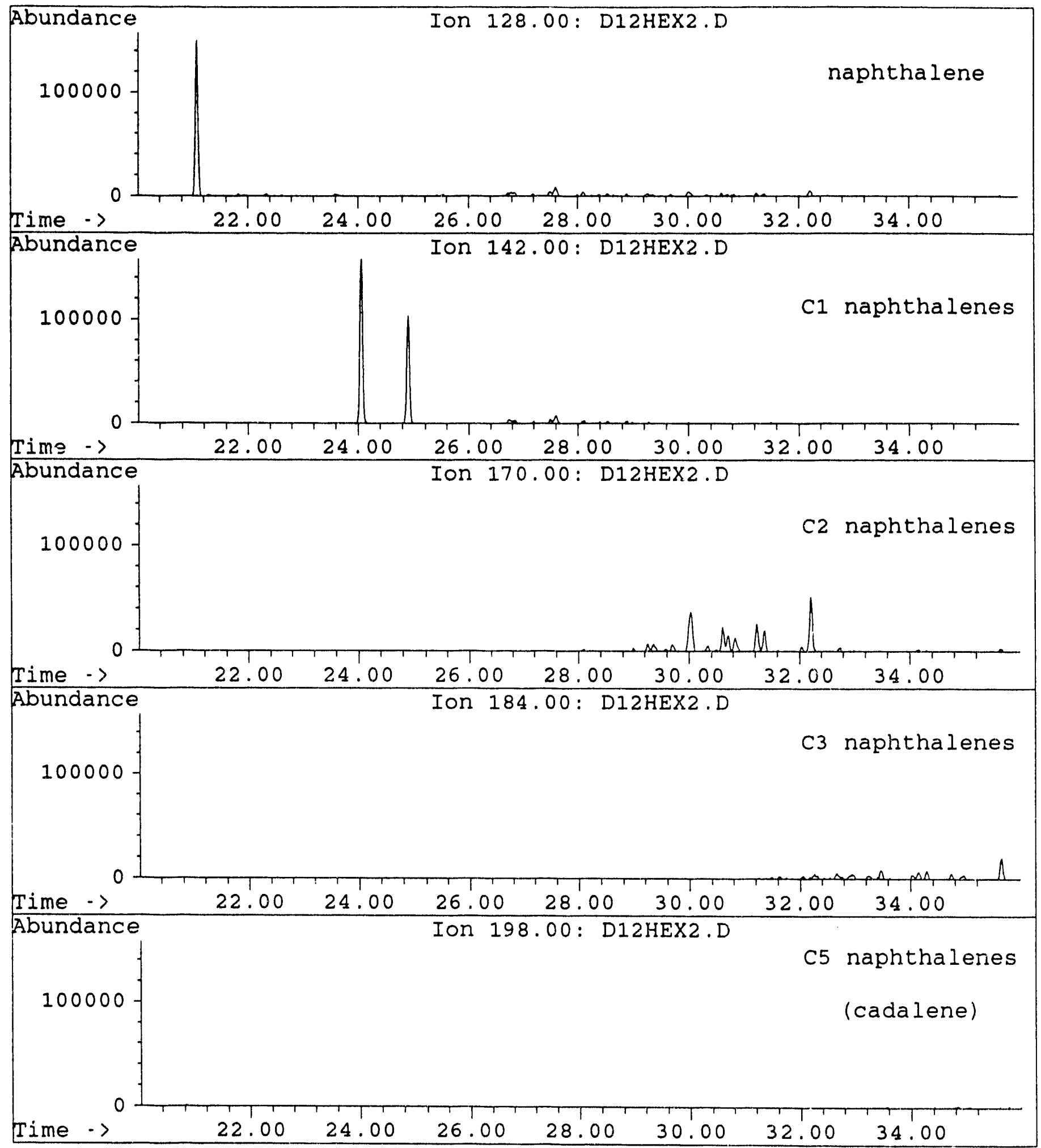

Figure 37 . GC/MS single ion chromatogram of DECS-12, (representing naphthalene and alkyl naphthalene) 


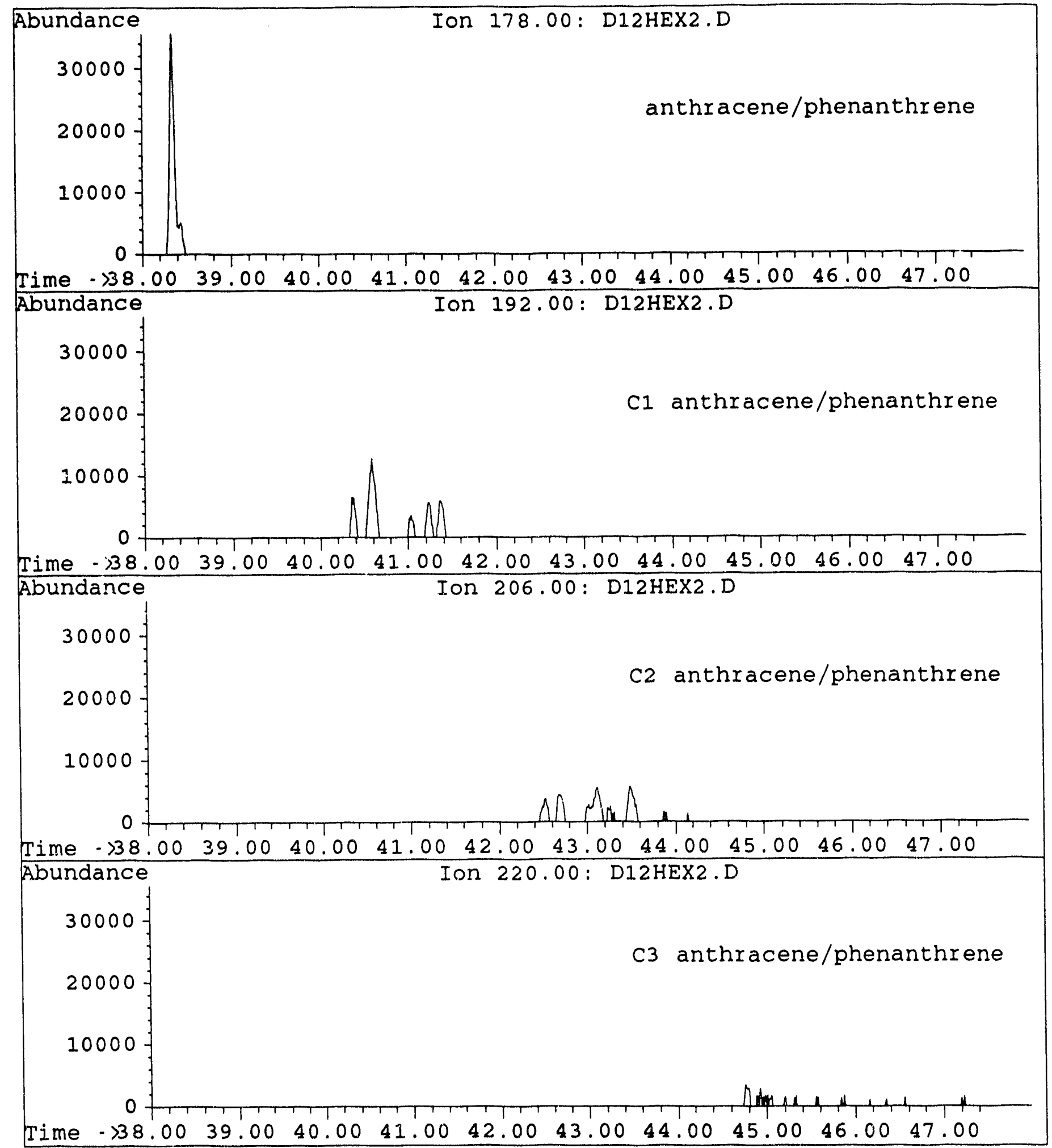

Figure 38 . GC/MS single ion chromatogram of DECS-12,

(representing phenanthrene/anthracene and alkyl phen/anth) 


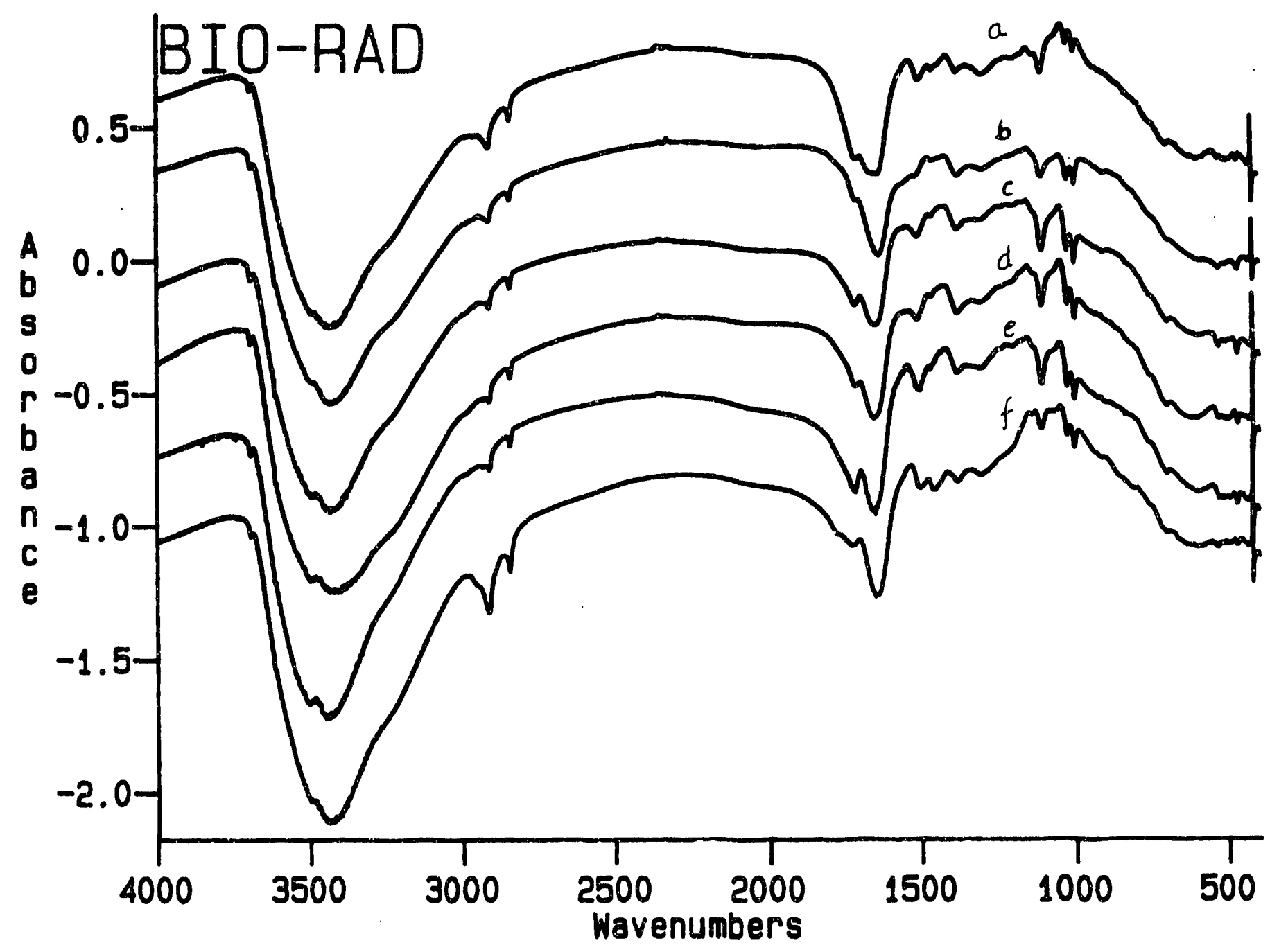

Figure 2.1 FTIR difference spectra after subtracting the spectrum of the raw coal 'as-received' from the spectra of the residues from the solvent-free thermal liquefactions for a) raw-undried; b) vacuum dried coal; and the coal dried in air at $100{ }^{\circ} \mathrm{C}$ for c) $2 \mathrm{~h}$; d) $20 \mathrm{~h}$; e) $100 \mathrm{~h}$ and f) at $150^{\circ} \mathrm{C}$ for $20 \mathrm{~h}$. 


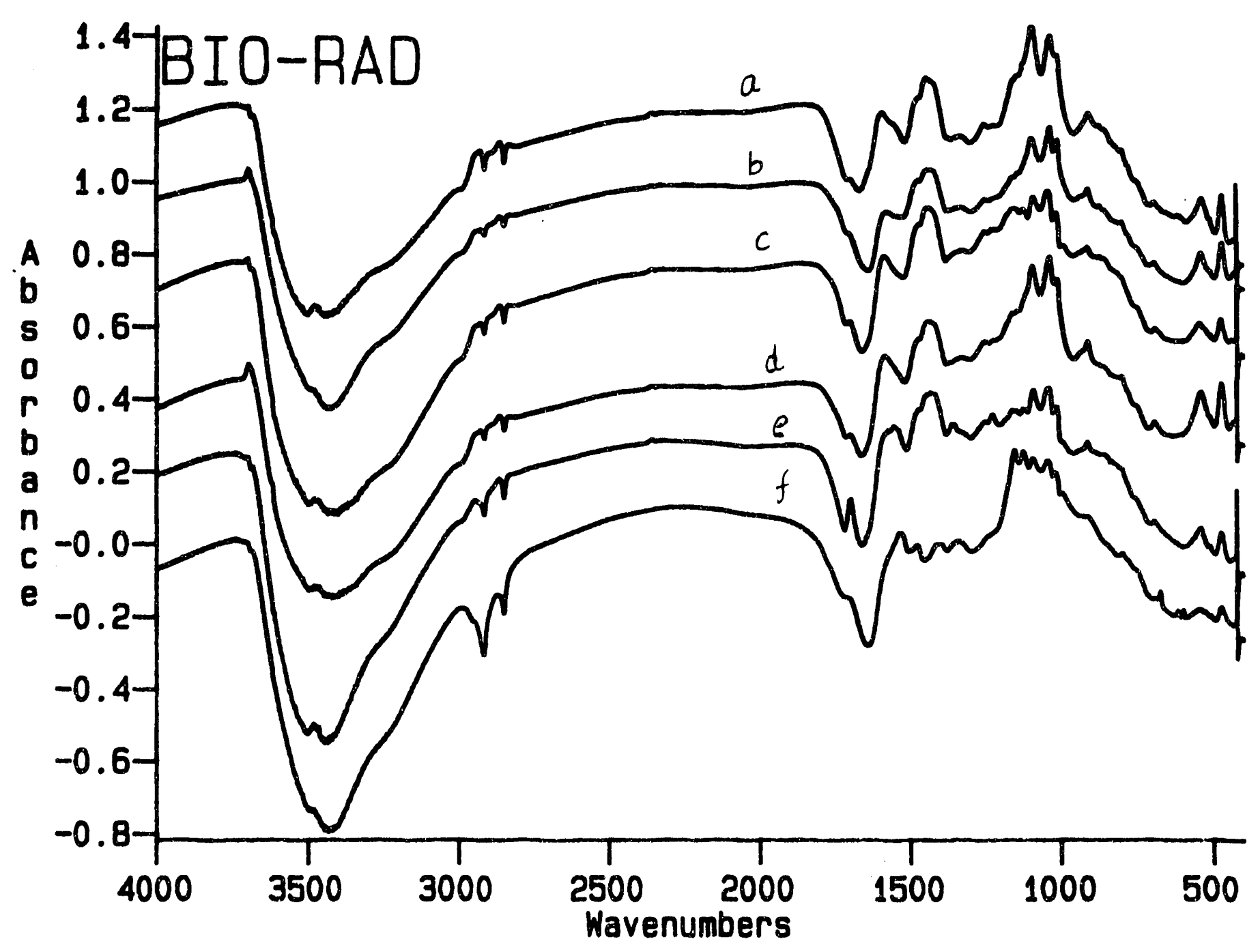

Figure 2.2 FTIR difference spectra after subtracting the spectrum of the raw coal 'as-received' from the spectra of the residues from the solvent-free catalytic liquefactions for a) raw-undried; b) vacuum dried coal; and the coal dried in air at $100{ }^{\circ} \mathrm{C}$ for $\left.\mathrm{c}\right) 2 \mathrm{~h}$; d) $20 \mathrm{~h}$; e) $100 \mathrm{~h}$ and f) at $150^{\circ} \mathrm{C}$ for $20 \mathrm{~h}$. 


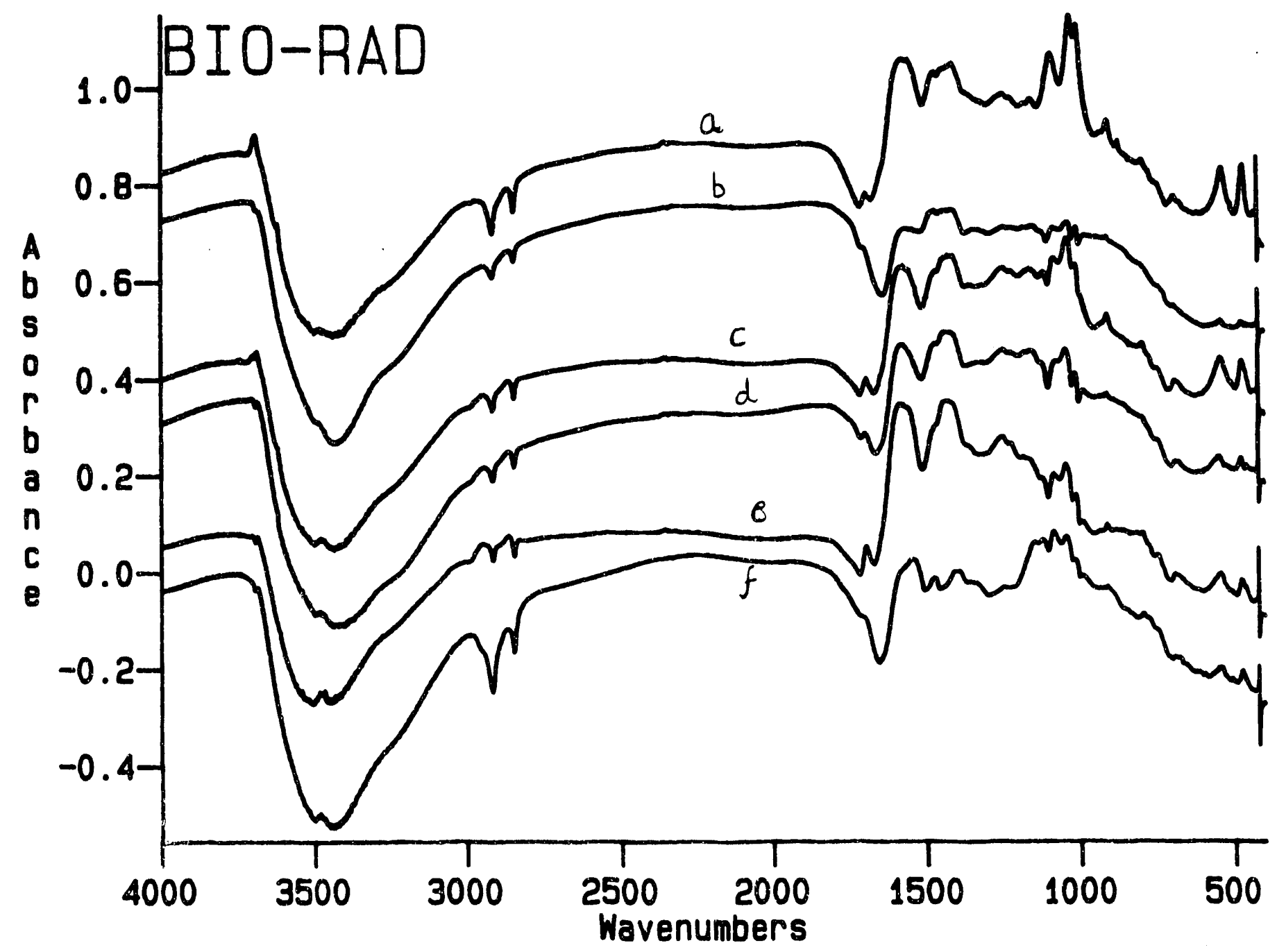

Figure 2.3 FTIR difference spectra after subtracting the spectrum of the raw coal 'as-received' from the spectra of the residues from the thermal liquefactions in presence of tetralin for a) rawundried; b) vacuum dried coal; and the coal dried in air at $100{ }^{\circ} \mathrm{C}$ for c) $2 \mathrm{~h}$; d) $20 \mathrm{~h}$; e) $100 \mathrm{~h}$ and f) at $150^{\circ} \mathrm{C}$ for $20 \mathrm{~h}$. 


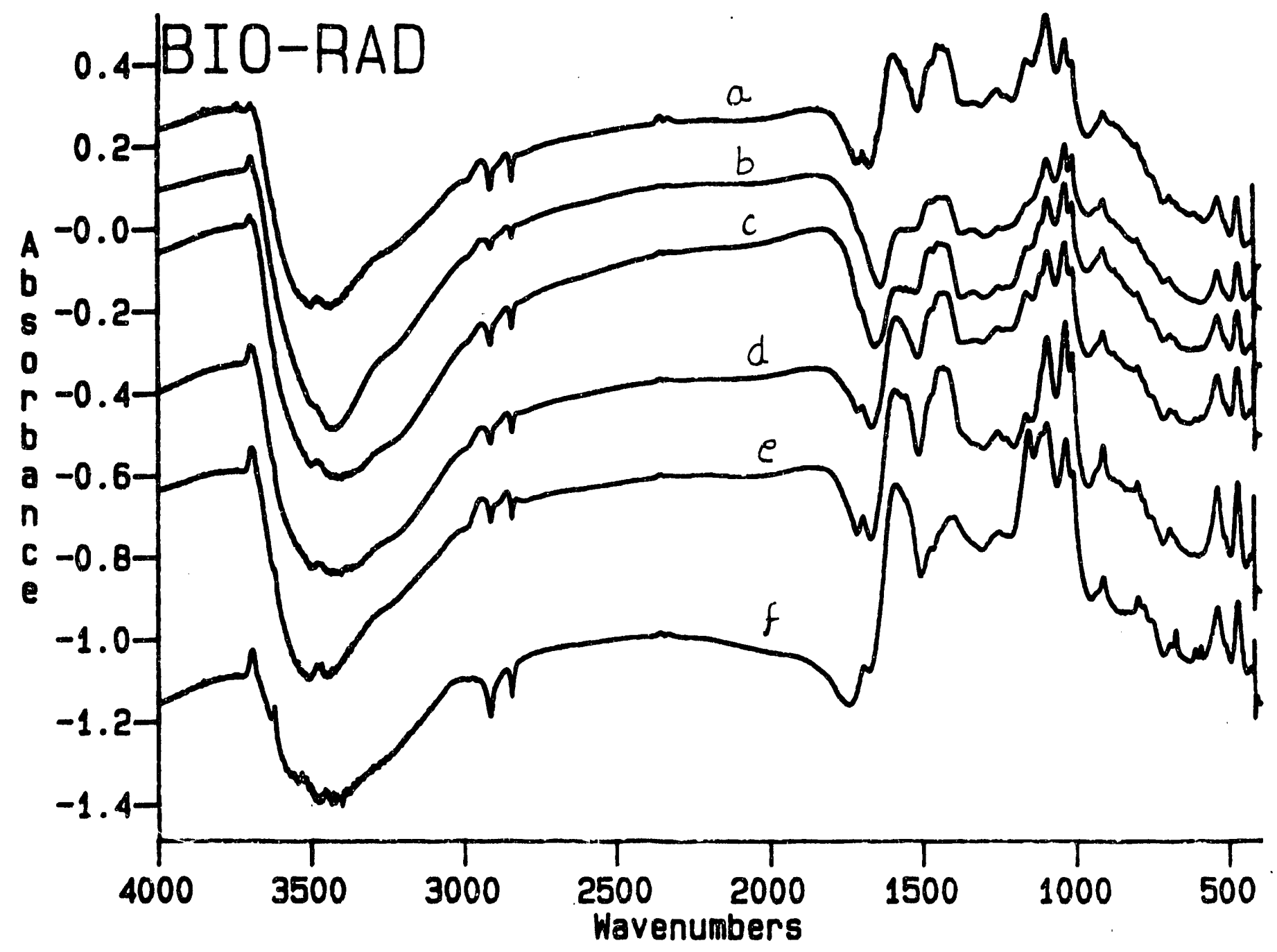

Figure 24 FTIR difference spectra after subtracting the spectrum of the raw coal 'as-received' from the spectra of the residues from the catalytic liquefactions in presence of tetralin for a) rawundried; b) vacuum dried coal; and the coal dried in air at $100{ }^{\circ} \mathrm{C}$ for c) $2 \mathrm{~h}$; d) $20 \mathrm{~h}$; e) $100 \mathrm{~h}$ and f) at $150^{\circ} \mathrm{C}$ for $20 \mathrm{~h}$. 


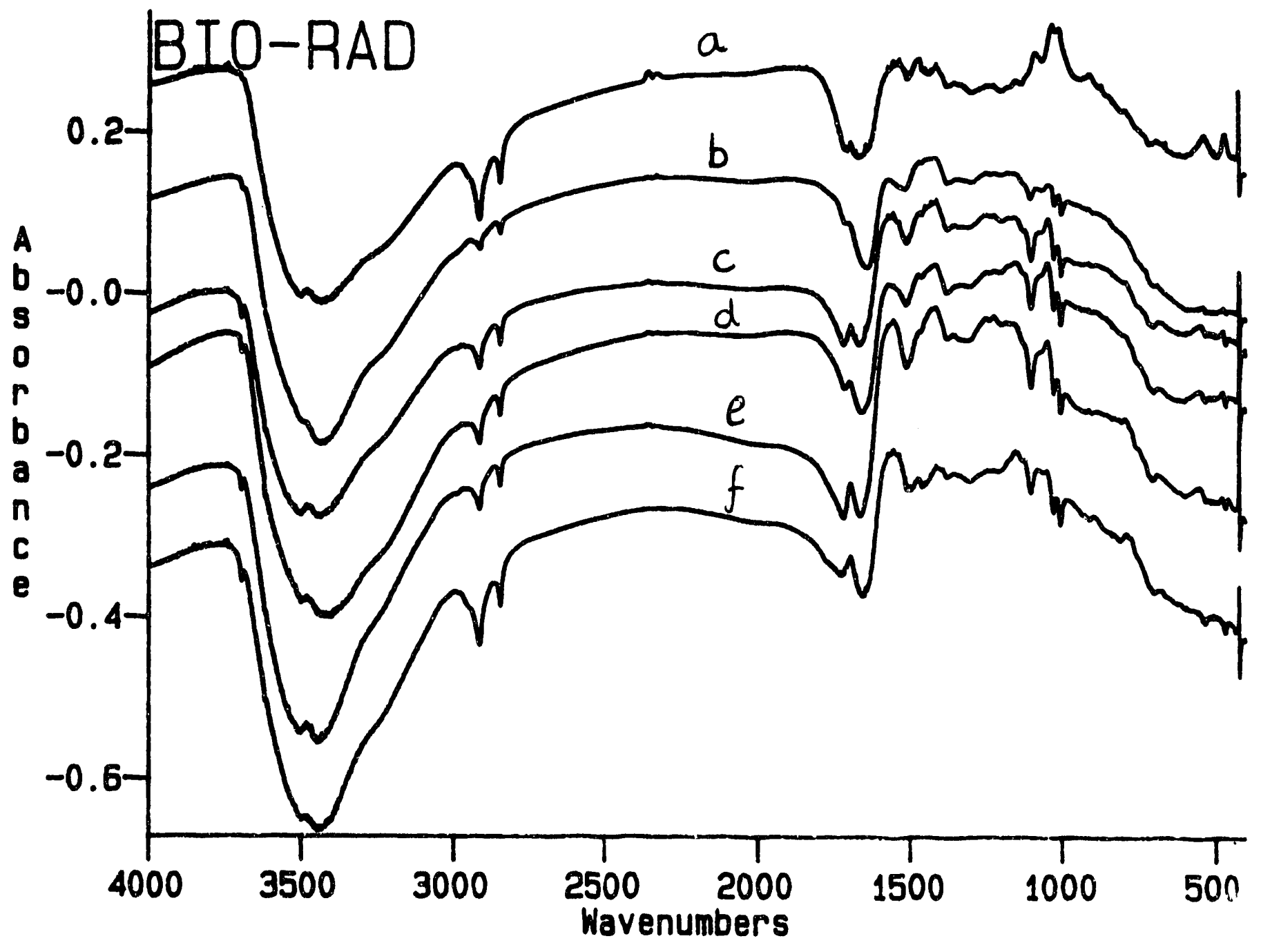

Figure 2.5 FTIR difference spectra after subtracting the spectrum of the raw coal 'as-received' from the spectra of the residues from the thermal liquefactions in presence of 1-methylnaphthalene for a) raw-undried; b) vacuum dried coal; and the coal dried in air at $100{ }^{\circ} \mathrm{C}$ for c) $2 \mathrm{~h}$; d) $20 \mathrm{~h}$; e) $100 \mathrm{~h}$ and f) at $150{ }^{\circ} \mathrm{C}$ for $20 \mathrm{~h}$. 


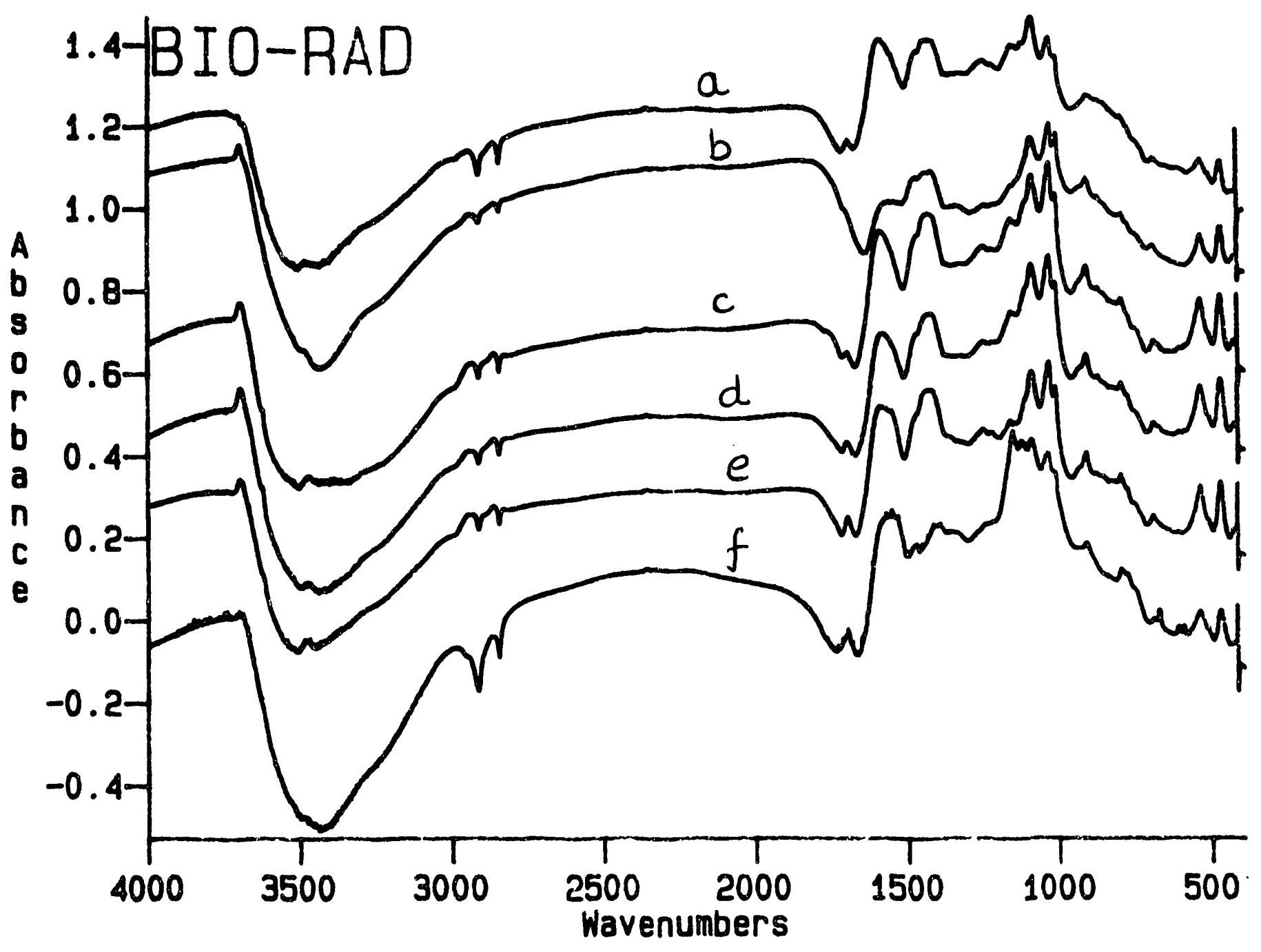

Figure 2.6 FTIR difference spectra after subtracting the spectrum of the raw coal 'as-received' from the spectra of the residues from the catalytic liquefactions in presence of 1 -methylnaphthalene for a) raw-undried; b) vacuum dried coal; and the coal dried in air at $100^{\circ} \mathrm{C}$ for c) $2 \mathrm{~h}$; d) $20 \mathrm{~h}$; e) $100 \mathrm{~h}$ and f) at $150^{\circ} \mathrm{C}$ for $20 \mathrm{~h}$. 

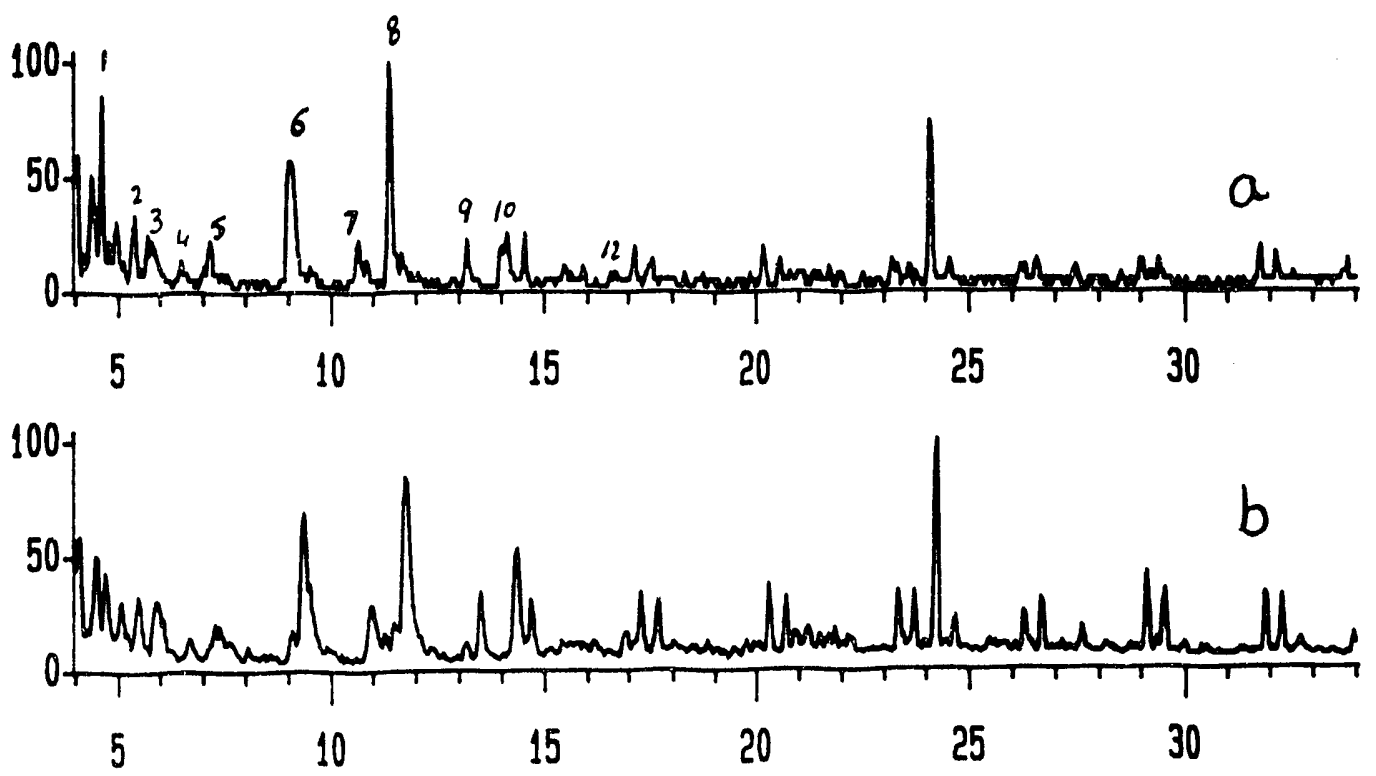

Figure 2.7 Py-GC-MS profiles of the a) raw coal; b) coal dried under vacuum at $100{ }^{\circ} \mathrm{C}$ for $2 \mathrm{~h}$. 

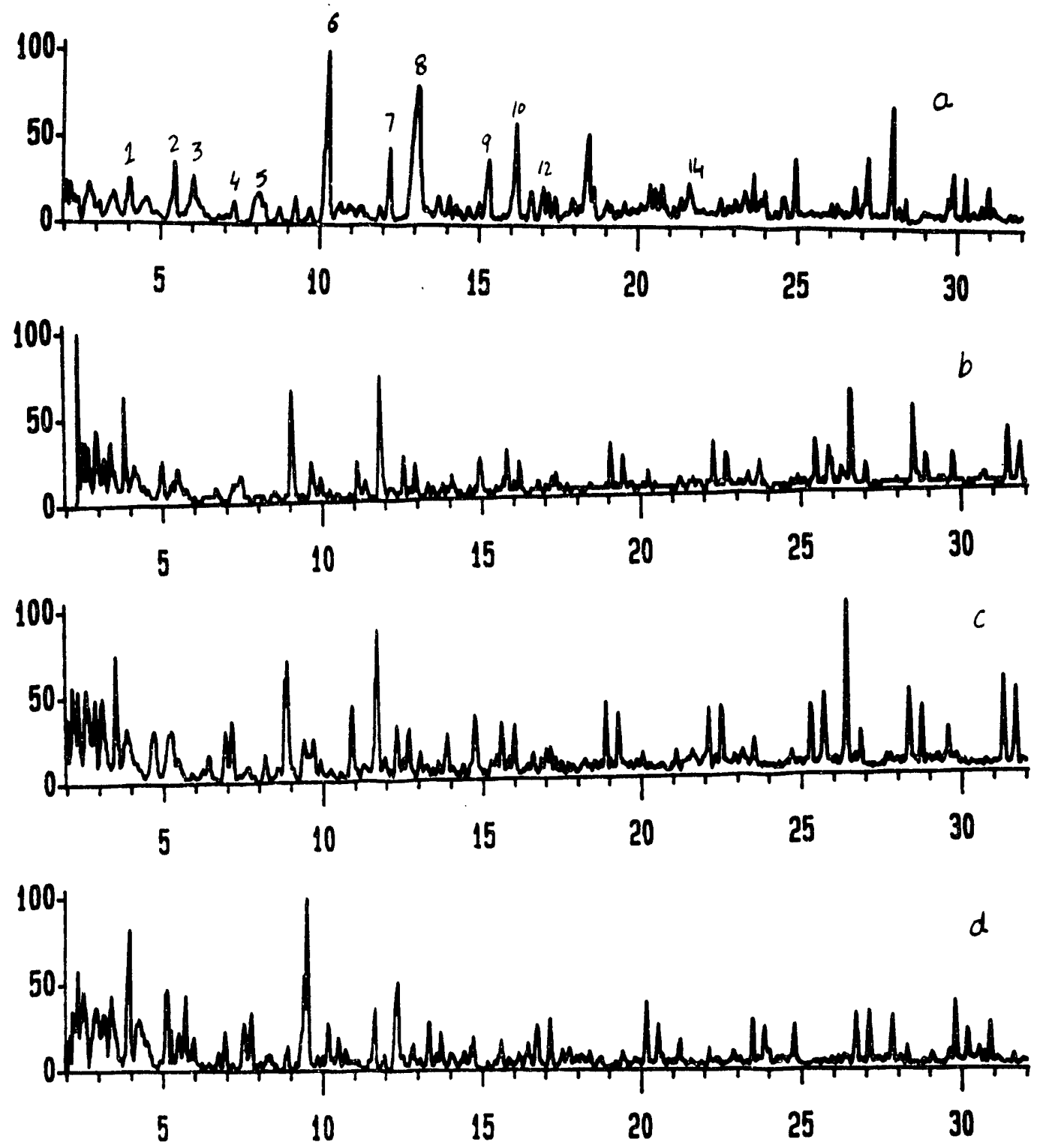

Figure 2.8 Py-GC-MS profiles of the coal dried in air at $100^{\circ} \mathrm{C}$ for a) $2 \mathrm{~h}$; b) $20 \mathrm{~h}$; c) $100 \mathrm{~h}$; and d) at $150{ }^{\circ} \mathrm{C}$ for $20 \mathrm{~h}$. 

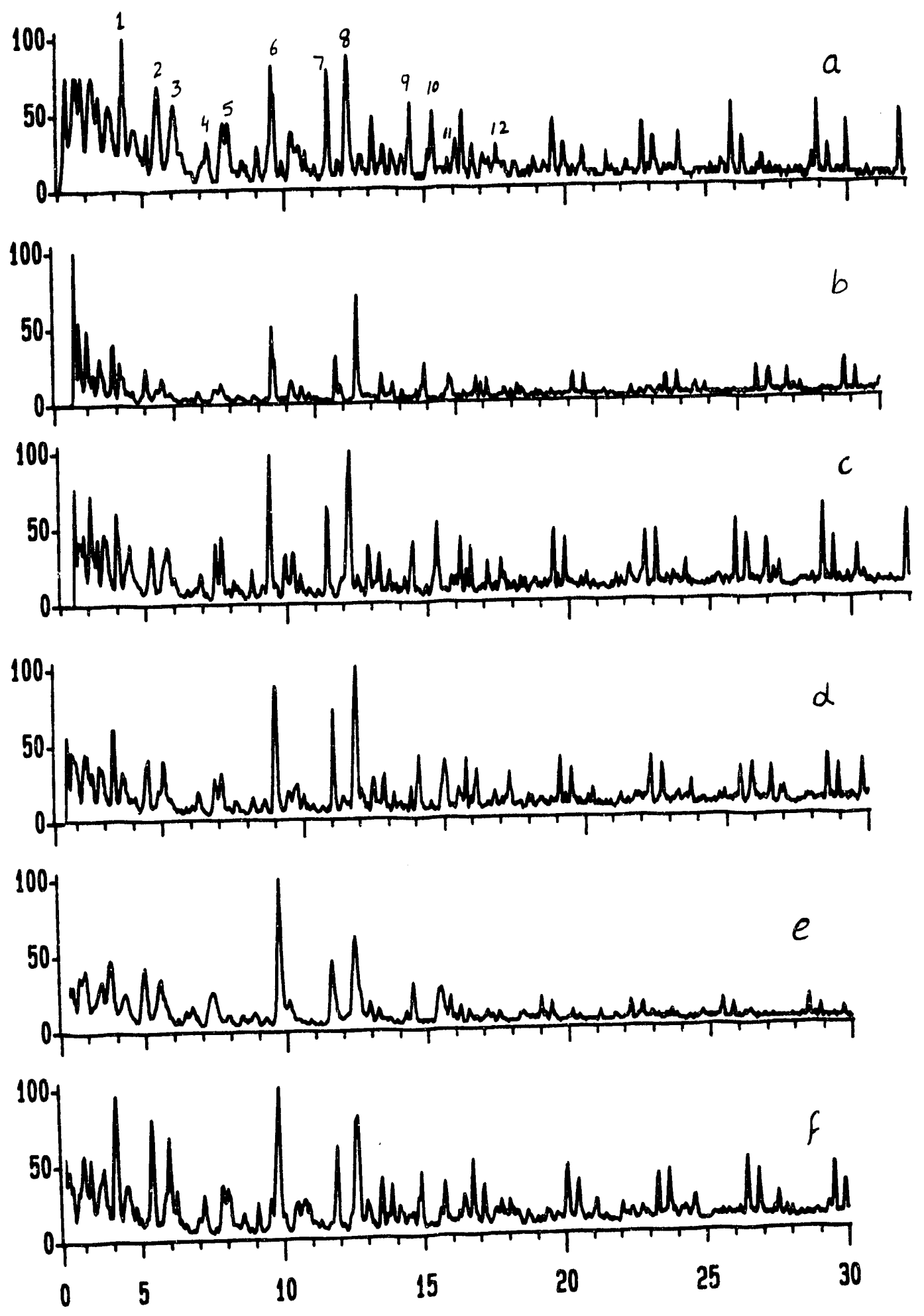

Figure 2.9 Py-GC-MS profiles of the residues from the solvent-free thermal liquefactions of a) raw-undried coal; b) coal dried under vacuum and the coal dried in air at $100{ }^{\circ} \mathrm{C}$ for $\left.\mathrm{c}\right) 2 \mathrm{~h}$; d) $20 \mathrm{~h}$; e) $100 \mathrm{~h}$; and f) at $150{ }^{\circ} \mathrm{C}$ for $20 \mathrm{~h}$. 

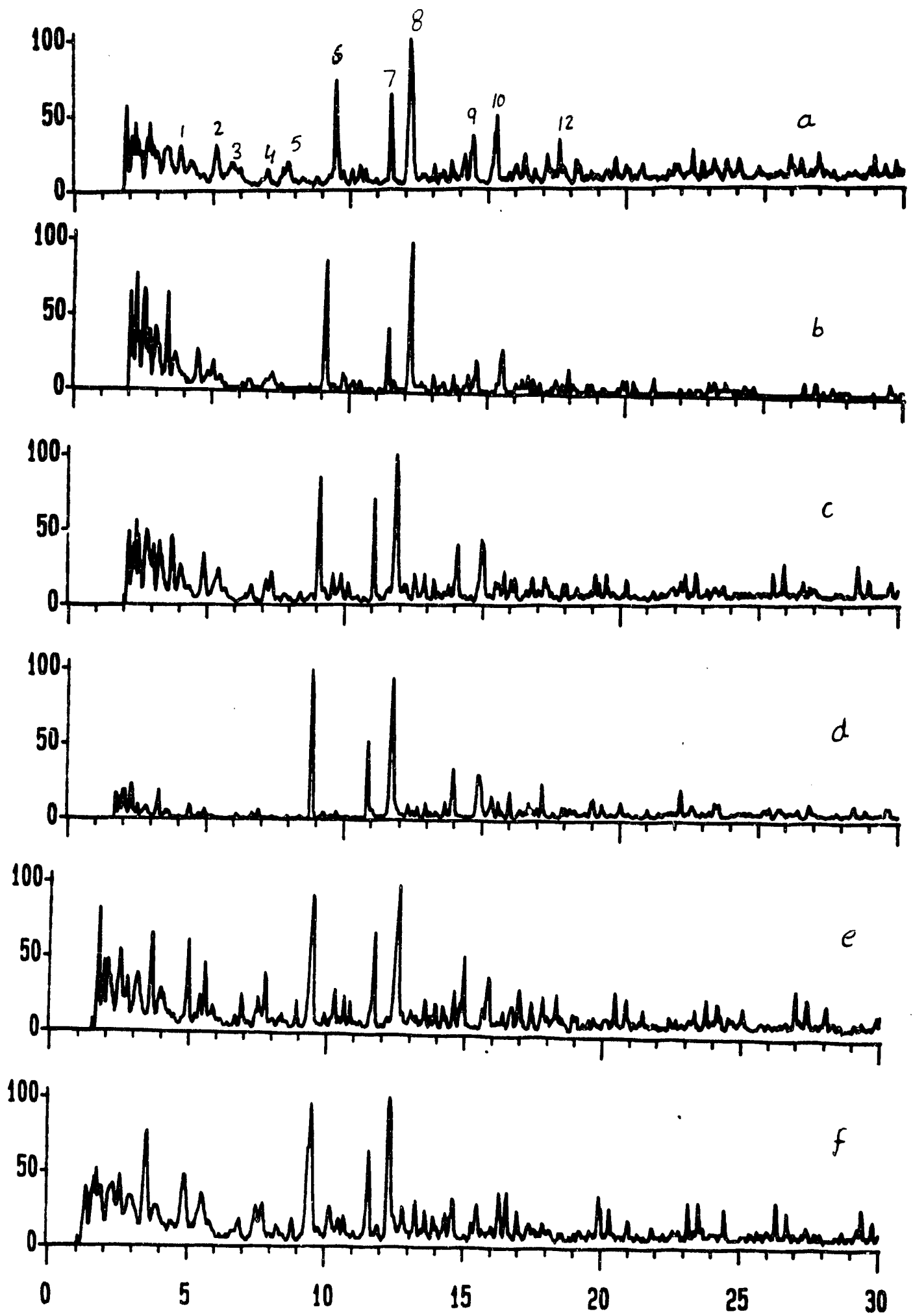

Figure 210. Py-GC-MS profiles of the residues from the solvent-free catalytic liquefactions of a) raw-undried coal; b) coal dried under vacuum and the coal dried in air at $100^{\circ} \mathrm{C}$ for c) $2 \mathrm{~h}$; d) $20 \mathrm{~h}$; e) $100 \mathrm{~h}$; and f) at $150^{\circ} \mathrm{C}$ for $20 \mathrm{~h}$. 

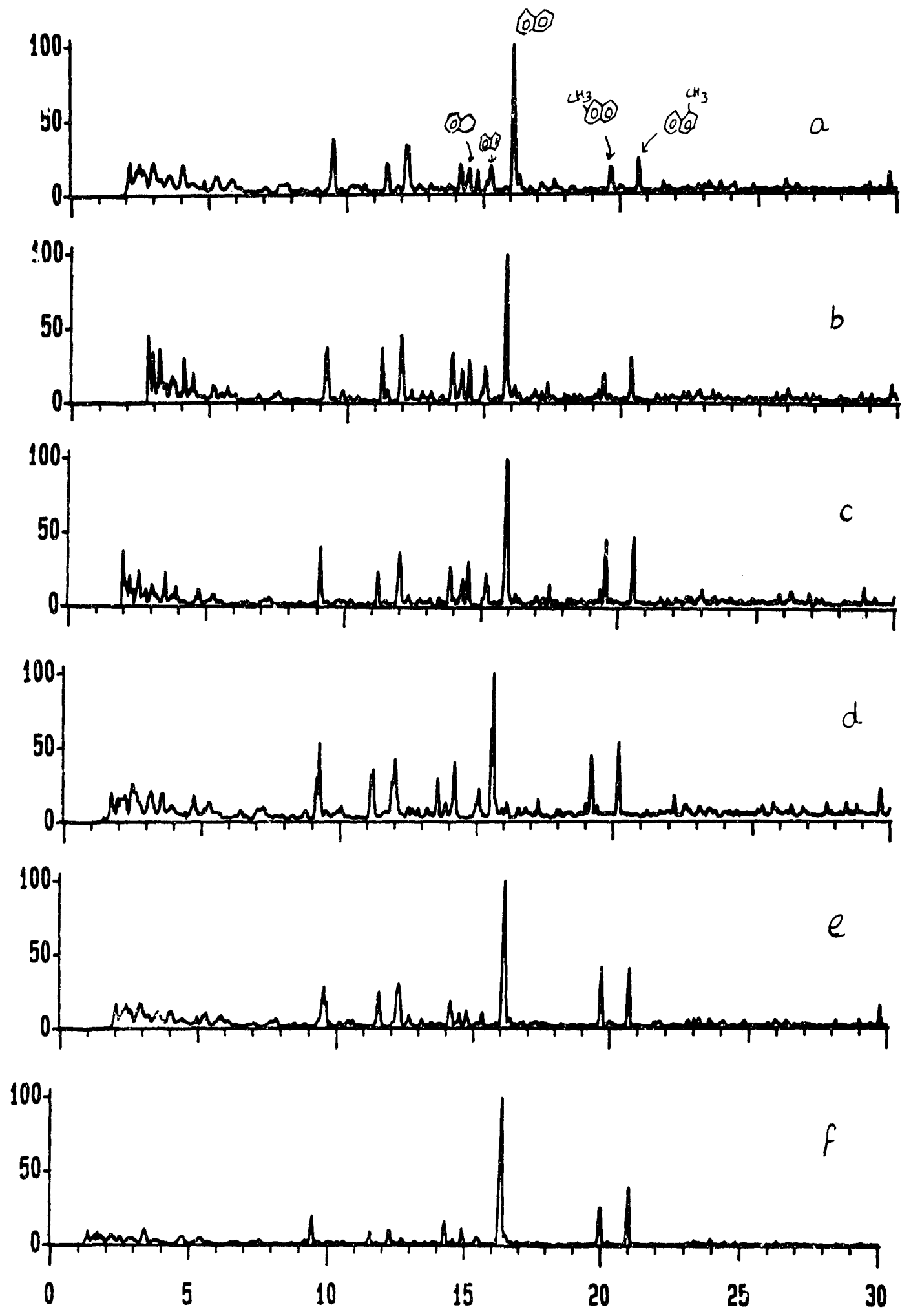

Figure 2.11. Py-GC-MS profiles of the residues from the thermal liquefactions in presence of tetralin of a) raw-undried coal; b) coal dried under vacuum and the coal dried in air at $100^{\circ} \mathrm{C}$ for c) $2 \mathrm{~h}$; d) $20 \mathrm{~h}$; e) $100 \mathrm{~h}$; and f) at $150{ }^{\circ} \mathrm{C}$ for $20 \mathrm{~h}$. 

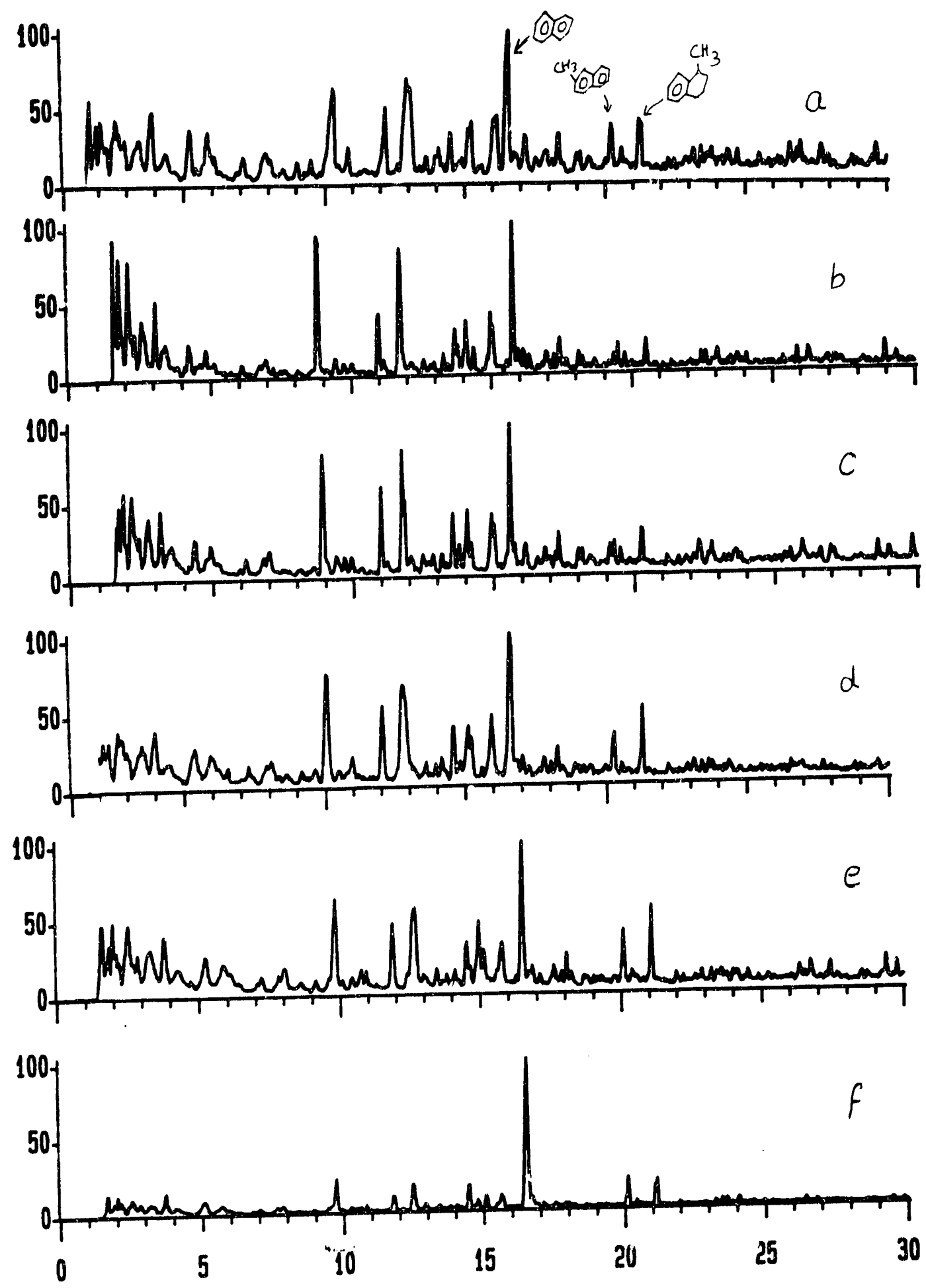

Figure212. Py-GC-MS profiles of the residues from the catalytic liquefactions in presence of tetralin of a) raw-undried coal; b) coal dried under vacuum and the coal dried in air at $100{ }^{\circ} \mathrm{C}$ for c) $2 \mathrm{~h}$; d) $20 \mathrm{~h}$; e) $100 \mathrm{~h}$; and f) at $150{ }^{\circ} \mathrm{C}$ for $20 \mathrm{~h}$. 

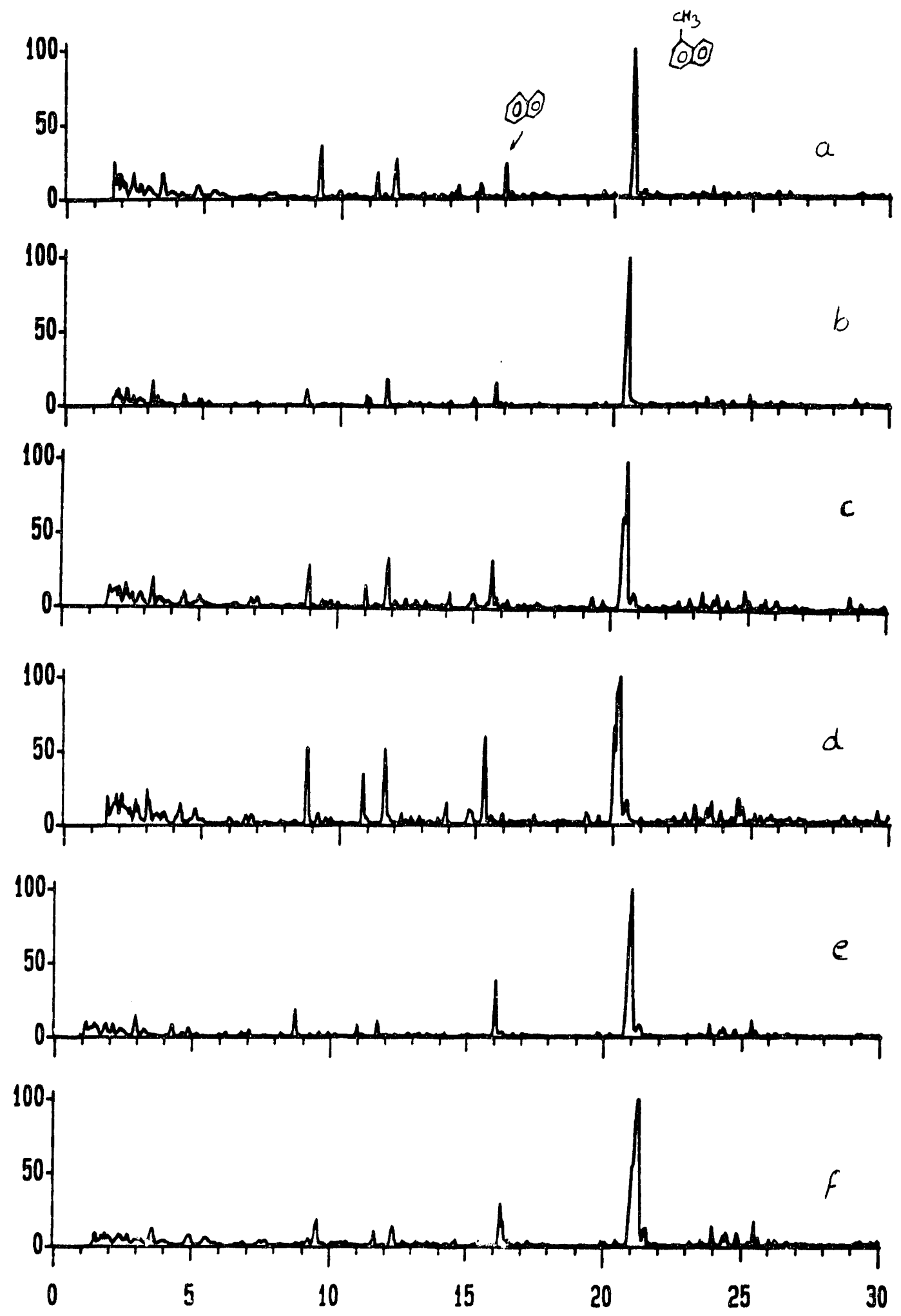

Figure2.13. Py-GC-MS profiles of the residues from the thermal liquefactions in presence of 1-methyinaphthalene of a) rawundried coal; b) coal dried under vacuum and the coal dried in air at $100{ }^{\circ} \mathrm{C}$ for c) $2 \mathrm{~h}$; d) $20 \mathrm{~h}$; e) $100 \mathrm{~h}$; and f) at $150{ }^{\circ} \mathrm{C}$ for $20 \mathrm{~h}$. 

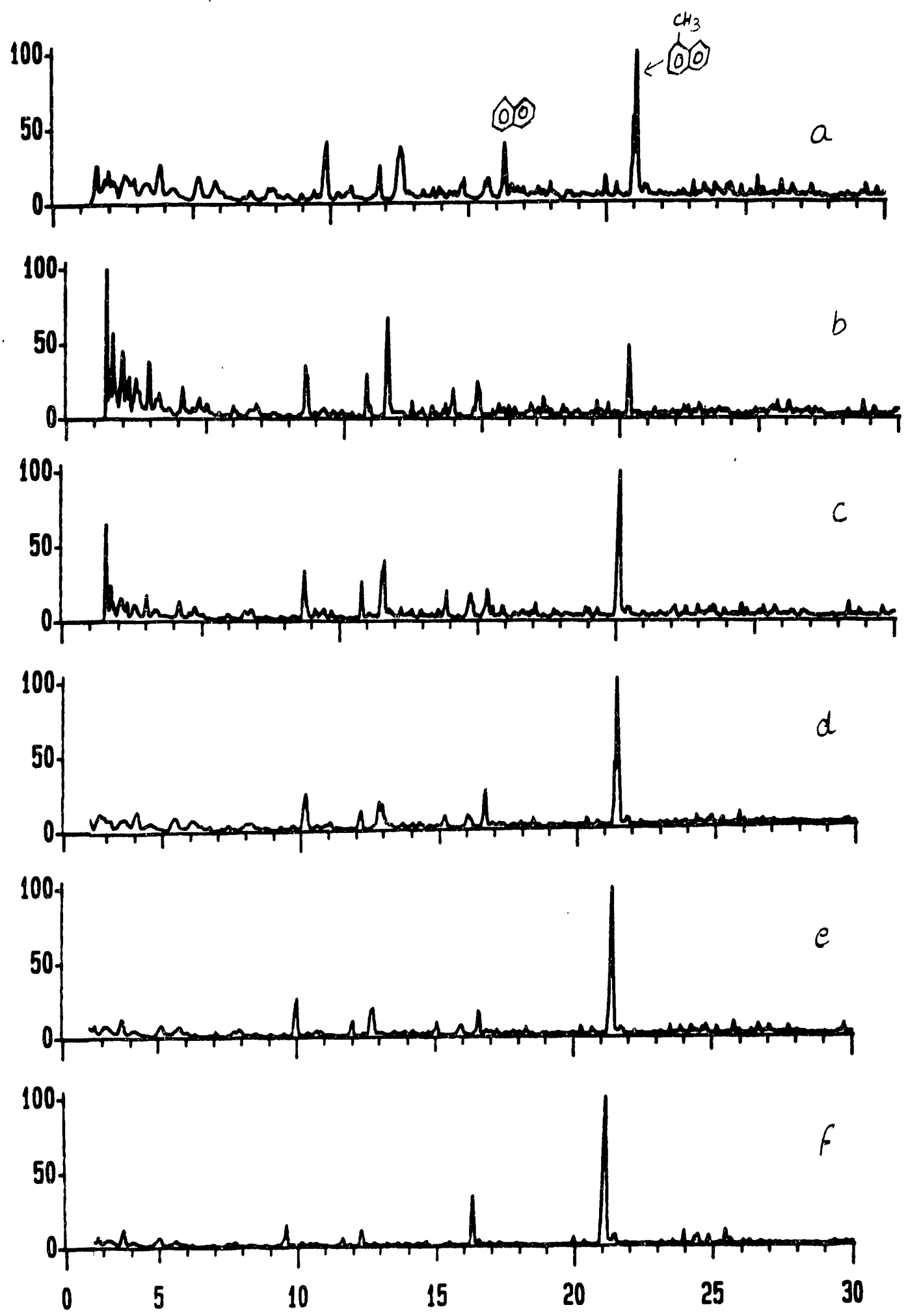

Figure2.14. Py-GC-MS profiles of the residues from the catalytic liquefactions in presence of 1-methylnaphthalene of a) rawundried coal; b) coal dried under vacuum and the coal dried in air at $100^{\circ} \mathrm{C}$ for c) $2 \mathrm{~h}$; d) $20 \mathrm{~h}$; e) $100 \mathrm{~h}$; and f) at $150^{\circ} \mathrm{C}$ for $20 \mathrm{~h}$. 

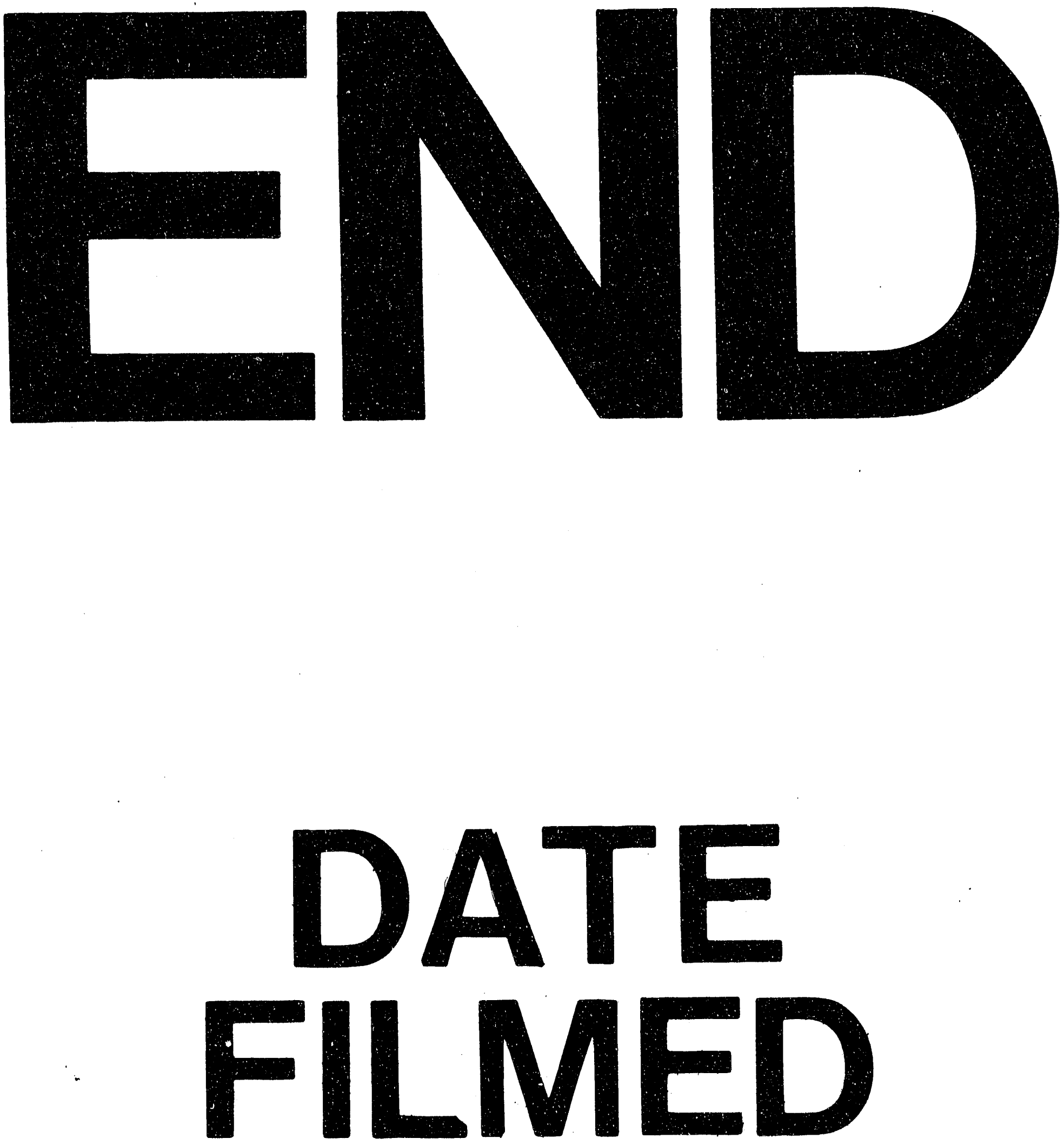

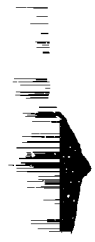

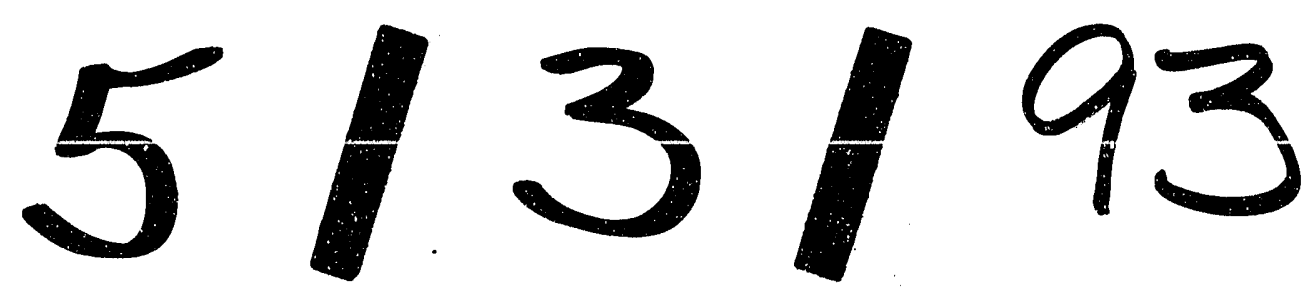


